\title{
Determinação de ParÂmetros Atmosféricos de ESTRELAS EM NGC 6528 E NGC 6553 - Aglomerados Globulares de ReferênCIA para O Estudo de Populações Ricas em Metais
}

por

Paula R. T. Coelho

Orientadora: Beatriz Barbuy

Dissertação de Mestrado

Universidade de São Paulo

Instituto Astronômico e Geofísico

São Paulo - Brasil Julho de 2000 
"You can fight without ever winning but never ever win without a fight"

Neil Peart 


\section{Agradecimentos}

À Dra. Beatriz Barbuy, pela orientação.

Ao Bruno, Jorge, Marcos, Ricardo, Roberto e Thaís pelas importantes discussões e ajudas inestimáveis.

Aos funcionários do IAG e às "meninas" da biblioteca e da secretaria, por manterem a estrutura funcionando.

A FAPESP, pelo apoio financeiro, sem o qual este trabalho teria sido realizado por outra pessoa.

Aos "companheiros de luta” Anderson, Eduardo, Flávio, Gustavo, Hektor, Lucimara, Mauro, Ronaldo e Roseli pela descontração e companherismo.

À Luciana, por literalmente "estar ao meu lado" quando eu desanimava.

Ao Marcelo por tantas vezes ter posto as coisas pra funcionar.

Ao meu pai, Adalberto, por tudo.

Aos meus tios, Guilherme, João, Keila, Nicolau, Olaia, Paulo, Regina, Zaia e à vó Bárbara pelo apoio tão crítico no início deste mestrado e pelo carinho recebido por toda a minha vida.

À Profa. Mineco, in memoriam, pelo primeiro incentivo, tão cedo, e que foi tão importante.

À Dra. Maria do Carmo, por ter me reerguido num momento tão crítico e ter garantido as condições mais primordiais para que eu realizasse qualquer trabalho.

Aos amigos, que durante esses anos tem estado sempre ao meu lado:

- Andréa e Bianca, já fazem quantos anos mesmo?

- Cleide, só você pra destrinchar minhas maluquices.

- Irineu e Nicolai, culpados disso tudo ter começado. Obrigada pelo incentivo e por terem acreditado em mim.

- Karen, minha sempre "prima-amiga", obrigada por tudo.

- Mário Sérgio, meu "irmão do coração" (e à Helô, "minha irmã por tabela").

- Priscila, minha "mãe do coração", obrigada por ter preenchido com tanto carinho um espaço vazio aqui dentro.

- Sartorelli, você é o culpado de ter dado o empurrão final!

Ao Wilton, meu amor, meu "Moço", por tudo. 


\section{Resumo}

Os aglomerados globulares ricos em metais do bojo são uma peça chave na compreensão da história evolutiva da nossa Galáxia e o estudo dessas populações estelares simples pode fornecer vínculos importantes aos modelos de formação do bojo galáctico.

Neste trabalho apresentamos o estudo feito com 22 estrelas dos aglomerados globulares NGC 6528 e NGC 6553, aglomerados representativos da população estelar do bojo.

Através do uso de dados fotométricos e espectroscópicos determinamos a velocidade radial, temperatura efetiva, gravidade superficial e metalicidade das estrelas.

Encontramos parâmetros que cobrem os intervalos $3200 \leq \mathrm{T}_{\text {ef }} \leq 5000 \mathrm{~K}$ e -0.5 $\leq \log \mathrm{g} \leq 2.4$, representando portanto uma faixa de estágios evolutivos do aglomerado. O valor médio de $[\mathrm{Fe} / \mathrm{H}]$ para os dois aglomerados foi estimado em -0.5dex, tanto pelo uso de índices de metalicidade de Lick, de calibrações de larguras equivalentes de TiO W(TiO) em função de parâmetros atmosféricos e principalmente através de espectros sintéticos. Foram encontrados também indícios de sobreabundância de elementos $\alpha$.

Essas estrelas estudadas são estrelas de referência para o estudo de populações estelares velhas e ricas em metais, de modo que testar e calibrar os espectros sintéticos com esses espectros estelares é um importante passo para garantir a qualidade dos espectros sintéticos na síntese de populações estelares. 


\begin{abstract}
The metal-rich bulge globular clusters are a keystone for the understanding of the evolutionary history of our Galaxy and the study of the bulge stellar populations provides constraints to models of bulge formation.
\end{abstract}

In this work we present the study of 22 stars in the globular clusters NGC 6528 and NGC 6553, templates of the metal-rich populations of the bulge.

With the use of photometric and spectroscopic data, we have found the radial velocities, effective temperatures, gravities and metallicities of these stars.

The parameters found are in the range $3200 \leq T_{\text {ef }} \leq 5000 \mathrm{~K}$ and $-0.5 \leq \log g \leq 2.4$, covering from the Horizontal Branch to the tip of the Red Giant Branch evolutionary stages. The mean metallicity determined was $[\mathrm{Fe} / \mathrm{H}]=-0.5 \mathrm{dex}$, from the Lick indices, calibrations of equivalent widths of $\mathrm{TiO}$ as a function of stellar parameters and comparisons to the synthetic spectra. A trend is found for an overabundance of $\alpha$ elements.

These stars are templates for the study of old metal-rich stellar populations and the fitting of the synthetic spectra to the observed stellar spectra is an important check of the quality of the synthetic spectra for stellar population synthesis. 


\section{Índice}

1 Introdução

8

2 Os aglomerados globulares NGC 6528 e NGC 6553

3 Os dados

3.1 Dados fotométricos 24

3.2 Dados espectroscópicos 27

3.3 Redução dos espectros 28

3.4 Espectros finais obtidos 31

4 Determinação dos parâmetros astrofísicos 33

4.1 Velocidades radiais 33

4.2 Temperaturas 40

4.2.1 Temperaturas fotométricas 40

4.2.2 Temperatura através da calibração $\mathrm{TiO} \times \mathrm{T}_{\text {ef }}$ 48

4.3 Gravidades superficiais 57

4.4 Índices de metalicidade 60

5 Determinação de metalicidades através de síntese espectral 66

6 Conclusões 79

7 Perspectivas 83

Apêndice I: Calibrações dos índices de TiO em função de parâmetros atmosféricos 90

8 Bibliografia 93 


\section{Índice de figuras}

Figura 1: Imagem da galáxia obtida com o detetor infravermelho DIRBE a bordo do satélite COBE. A imagem combina as exposições obtidas em 1.2, 2.2 e $3.4 \mu \mathrm{m}$ (http:// space.gsfc.nasa.gov/astro/cobe).

Figura 2: Histograma da distribuição de metalicidades dos aglomerados globulares da nossa Galáxia. As curvas sobrepostas aos histogramas representam as gaussianas que ajustam as componentes pobre e rica em metais. Os picos ocorrem em $[\mathrm{Fe} / \mathrm{H}]=-1.59 \mathrm{e}$ $[\mathrm{Fe} / \mathrm{H}]=-0.51$ com desvios padrões de 0.34 e 0.23 respectivamente. Esses resultados foram obtidos por McLachlan \& Basford (1988) e Ashman et al. (1994). Figura obtida de Ashman \& Zepf (1998).

Figura 3: Diagramas cor-magnitude do aglomerado NGC 6553 confeccionados com os dados de Ortolani et al. (1995). Pode-se perceber que para diagramas que envolvem cores no visível há um comportamento anômalo do ramo das gigantes, onde estrelas mais frias podem ser menos luminosas do que as correspondentes mais quentes de mesma luminosidade. Esse efeito diminui e tende a desaparecer conforme observamos o diagrama em cores mais vermelhas.

16

Figura 4: O locus médio dos dois aglomerados comparados ao locus médio do aglomerado 47 Tuc. O locus do NGC 6528 foi deslocado $\Delta \mathrm{V}=-0.85$ para coincidir com o do NGC 6553, de modo a obter-se ao mesmo tempo o menor avermelhamento e distância (NGC 6528 e NGC 6553 respectivamente). O módulo de distância do NGC 6553 é quase 1 mag menor do que o de NGC 6528. Diagrama retirado de Ortolani et al. (1995).

Figura 5: Funções de luminosidade da seqüência principal (MS) e gigantes (RGB+HB) das estrelas do NGC 6528 (linhas tracejadas) e de estrelas na Janela de Baade (linhas sólidas). A função de luminosidade do NGC 6528 foi deslocada $\Delta V=+0.15$ para que os picos correspondentes ao HB coincidissem e foi também multiplicada por 2 para normalizar as contagens em $V=20.45$. Abaixo de $V=21$ a função de luminosidade do bojo é progressivamente mais incompleta. Figura retirada de Ortolani et al. (1995).

Figura 6: Diagramas cor-magnitude do aglomerado globular NGC 6528. No painel superior são mostradas todas as estrelas observadas pelo HST. O quadrado indica a região ampliada no painel inferior, onde podemos ver a indentificação das estrelas para as quais dispomos de espectros. A identificação das estrelas é a mesma utilizada em van den Bergh \& Younger (1979). 25

Figura 7: Diagramas cor-magnitude para o NGC 6553. À semelhança da figura anterior, o pai- 
nel inferior corresponde a uma ampliação da região marcada no painel superior. A identificação usada para as estrelas é a de Hartwick (1975).

Figura 8: Os diagramas acima mostram o locus médio traçado para os aglomerados NGC 6528 e NGC 6553

Figura 9: Fluxograma da redução dos dados espectroscópicos. Os nomes em parênteses identificam as tarefas do IRAF utilizadas.

Figura 10: Ilustração do efeito das bandas telúricas nos espectros observados. Acima pode-se ver o espectro da estrela III3 do NGC 6553 normalizado, antes da correção pelo espectro telúrico. Ao meio tem-se o espectro observado e normalizado da estrela quente HD7950, já editado para apresentar apenas as linhas telúricas. Embaixo temse o espectro da estrela de programa já dividido pelo espectro telúrico, e pronto para a comparação com os espectros sintéticos.

Figura 11: Os histogramas acima mostram as velocidades radiais heliocêntricas observadas no campo dos aglomerados NGC 6553 (à esquerda) e NGC 6528 (à direita). Para cada um dos aglomerados o diagrama superior refere-se à velocidade determinada pelo método clássico e o diagrama inferior refere-se à velocidade determinada pelo método de correlação cruzada. Os valores obtidos com os ajustes gaussianos podem ser observados nos próprios diagramas.

Figura 12: No alto à esquerda: imagem digitalizada do aglomerado NGC 6528 obtida no STSCl. Alto à direita: mapa original de van den Bergh \& Younger (1979) que define as nomenclaturas usadas neste trabalho. Inferior: mapa criado com os dados do HST com o objetivo de realizar a identificação cruzada entre as diferentes nomenclaturas.

Figura 13: No alto à esquerda: imagem digitalizada do aglomerado NGC 6553 obtida no STSCl. Alto à direita: mapa original de Hartwick (1975) que define as nomenclaturas usadas neste trabalho. Inferior: mapa criado com os dados do HST com o objetivo de realizar a identificação cruzada entre as diferentes nomenclaturas.

Figura 14: Ajustes utilizados na determinação das temperaturas fotométricas. Os dados usados foram os de Bessell et al. (1998). Para cada ajuste são apresentados os coeficientes ajustados e os respectivos erros. 44

Figura 15: Ilustração do método usado para avaliação do erro das calibrações $T_{\text {ef }} \times$ cor. _ 45

Figura 16: Comparação do espectro observado da estrela II-51 do NGC 6553 (temperatura fotométrica de $3900 \mathrm{~K}$ ) ao espectro sintético de parâmetros similares. É visível que a temperatura fotométrica estimada para esta estrela está muito distante do valor da temperatura efetiva real. Essa estrela é o caso mais extremo dentre um total de 9 estrelas cujas temperaturas fotométricas diferem significativamente da temperatura 
efetiva.

Figura 17: Representação da medida dos índices Fe5270 e Mg2 para a estrela NGC 6528 I 27. Os círculos brancos indicam os limites dos contínuos, os círculos pretos representam os pontos médios de cada contínuo e a reta pontilhada define o contínuo local. Os diamantes indicam os limites da banda passante. No painel superior, a linha mais grossa sobre o espectro indica a região para a qual será calculada a largura equivalente. No painel inferior, as linhas tracejadas e pontilhadas definem então a região para o cálculo em magnitudes da banda.

Figura 18: Temperaturas efetivas em função dos índices de TiO para $\Delta \lambda \sim 8 \AA$ e $[\mathrm{Fe} / \mathrm{H}]=-0.3$. A dispersão é devida à gravidade superficial que compreende o intervalo $-0.5 \leq \log$ $\mathrm{g} \leq 2.5$.

Figura 19: Ajuste do índice de TiO4 em função da temperatura. Foram realizados dois ajustes distintos cujos coeficientes podem ser vistos no próprio gráfico.

Figura 20: Comparação entre espectros de estrelas de temperaturas diferentes. O formato de arco apresentado pelo RGB desses aglomerados foi explicado como sendo devido a grande absorção devida às bandas de $\mathrm{TiO}$ nas estrelas mais frias desses aglomerados ricos em metais. A evolução dessa absorção com a temperatura é visível na figura acima.

Figura 21: CB em função da cor V-I segundo dados de Bessell et al. (1998). Os valores do ajuste podem ser vistos no próprio diagrama.

Figura 22: Divisão entre espectros sintéticos de mesma temperatura e gravidade superficial mas diferentes metalicidades. São claramente visíveis as regiões mais sensíveis à metalicidade (maiores contagens). 70

Figura 23: Histogramas dos valores de $[\mathrm{Fe} / \mathrm{H}]$ obtidos para cada estrela estudada, conforme tabela 16. Os valores de $[\mathrm{Fe} / \mathrm{H}]$ para cada aglomerado foram estimados pela média dos valores obtidos para cada estrela, exceto aquelas cujos valores são mais discrepantes.

Figura 24: Comparação entre espectros observados e sintéticos para as regiões sensíveis às abundâncias não-solares adotadas.

Figura 25: Espectro observado da estrela NGC 6528 I 1 (em preto, $\mathrm{T}_{\text {ef }}=4300 \mathrm{~K}, \log \mathrm{g}=1.7$ ) e espectros sintéticos de $[\mathrm{Fe} / \mathrm{H}]=-0.6$ (em vermelho) e $[\mathrm{Fe} / \mathrm{H}]=-0.3$ (em verde), ambos com $\mathrm{T}_{\mathrm{ef}}=4250 \mathrm{~K}$ e log $\mathrm{g}=1.5 . \Delta \lambda \sim 8 \AA$.

Figura 26: Espectro observado da estrela NGC 6528 I 25 (em preto, $\mathrm{T}_{\mathrm{ef}}=4100 \mathrm{~K}, \log \mathrm{g}=1.5$ ) e espectros sintéticos de $[\mathrm{Fe} / \mathrm{H}]=-0.6$ (em vermelho) e $[\mathrm{Fe} / \mathrm{H}]=-0.3$ (em verde), ambos com $\mathrm{T}_{\mathrm{ef}}=4000 \mathrm{~K}$ e log $\mathrm{g}=1.5 . \Delta \lambda \sim 4 \AA$. 75 
Figura 27: No topo: espectro observado da estrela NGC $6553 \mathrm{III} 17$ (em preto, Tef $=3700 \mathrm{~K}$, $\log \mathrm{g}=0.3)$ e espectros sintéticos de $[\mathrm{Fe} / \mathrm{H}]=-0.6(\mathrm{em}$ vermelho) e $[\mathrm{Fe} / \mathrm{H}]=-0.3(\mathrm{em}$ verde), ambos com $\mathrm{T}_{\mathrm{ef}}=3700 \mathrm{~K}, \log \mathrm{g}=0.5$. Embaixo: espectro observado da estrela NGC 6553 II 51 (em preto, $\mathrm{T}_{\mathrm{ef}}=3200 \mathrm{~K}, \log \mathrm{g}=-0.5$ ) e espectros sintéticos de [Fe/ $\mathrm{H}]=-0.6$ (em vermelho) e $[\mathrm{Fe} / \mathrm{H}]=-0.3$ (em verde), ambos com $\mathrm{T}_{\mathrm{ef}}=3200 \mathrm{~K}$ e log g $=0 . \Delta \lambda \sim 4 \AA$.

Figura 28: No topo: espectro observado da estrela NGC 6528 I 6 (em preto, $\mathrm{T}_{\text {ef }}=3600 \mathrm{~K}, \log$ $\mathrm{g}=0.4)$ e espectros sintéticos de $[\mathrm{Fe} / \mathrm{H}]=-0.6$ (em vermelho) e $[\mathrm{Fe} / \mathrm{H}]=-0.3$ (em verde), ambos com $\mathrm{T}_{\mathrm{ef}}=3600 \mathrm{~K}, \log \mathrm{g}=0.5$. Embaixo: espectro observado da estrela NGC 6528 I 27 (em preto, $\mathrm{T}_{\mathrm{ef}}=3400 \mathrm{~K}, \log \mathrm{g}=0.3$ ) e espectros sintéticos de $[\mathrm{Fe} / \mathrm{H}]$ $=-0.6$ (em vermelho) e $[\mathrm{Fe} / \mathrm{H}]=-0.3$ (em verde), ambos com $\mathrm{T}_{\mathrm{ef}}=3400 \mathrm{~K}, \log \mathrm{g}=$ 0.5. $\Delta \lambda \sim 4 \AA$.

Figura 29: Espectro observado da estrela NGC 6553 III 3 (em preto, $T_{\text {ef }}=3900 \mathrm{~K}, \log g=1.0$ ) e espectros sintéticos de $[\mathrm{Fe} / \mathrm{H}]=-0.6$ (em vermelho) e $[\mathrm{Fe} / \mathrm{H}]=-0.3$ (em verde), ambos com $\mathrm{T}_{\text {ef }}=3900 \mathrm{~K}$ e log $\mathrm{g}=1.0 . \Delta \lambda \sim 8 \AA$.

Figura 30: Índices de TiO4 medidos $(\Delta \lambda \sim 4 \AA)$ em função da temperatura. Os quadrados brancos indicam os índices medidos nos espectros sintéticos e os círculos pretos indicam o ajuste obtido. 


\section{Índice de tabelas}

Tabela 1: Dados gerais dos aglomerados globulares estudados, conforme Barbuy et al. (1998).

Tabela 2: Valores de metalicidade dos aglomerados encontrados na literatura. 15

Tabela 3: Abundâncias determinadas por Barbuy et al. (1999) para o NGC 6553, Barbuy (2000) para o NGC 6528 e McWilliam \& Rich (1994) para estrelas de campo do bojo. 22

Tabela 4: Dados dos espectros utilizados. 32

Tabela 5: Velocidades heliocêntricas determinadas. 36

Tabela 6: Comparação das velocidades radiais determinadas para os aglomerados com dados da literatura. 39

Tabela 7: Valores de avermelhamento e excesso de cor utilizados. 46

Tabela 8: Temperaturas efetivas determinadas a partir dos dados fotométricos. 47

Tabela 9: Definições utilizadas para os índices de TiO. 50

Tabela 10:Temperaturas obtidas através dos índices de TiO. As temperaturas em branco correspondem a índices que estavam fora dos limites dos ajustes.

Tabela 11:Temperaturas finais determinadas para as estrelas. Os desvios típicos estão estimados em $150 \mathrm{~K}$ para $\mathrm{T}_{\text {ef }}>3750$ e $200 \mathrm{~K}$ para $\mathrm{T}_{\text {ef }}<3750 \mathrm{~K}$. 55

Tabela 12:Valores de log g determinados 59

Tabela 13:Definições dos índices de metalicidade medidos. As diferenças entre as duas definições foram tipicamente de 0.01 mag para o Mg2, e $0.4 \AA$ para os índices do ferro.

Tabela 14:Valores de $[\mathrm{Fe} / \mathrm{H}]$ determinados para algumas estrelas através dos ajustes polinomiais de Worthey et al. (1994) 62 
Tabela 15:Índices espectrais medidos.

Tabela 16:Metalicidades estimadas para as estrelas estudadas.

Tabela 17:Parâmetros atmosféricos finais determinados para as estrelas estudadas. 82

Tabela 18: Coeficientes das funções dos ajustes $\mathrm{W}(\mathrm{TiO})=\mathrm{f}\left(\mathrm{T}_{\mathrm{ef}}, \log \mathrm{g},[\mathrm{Fe} / \mathrm{H}]\right)$. 91 


\section{Introdução}

O conceito de populações estelares introduzido por Baade (1944) tornou-se um tema unificador que relaciona diversos campos de pesquisa distintos. O conceito original de Baade cresceu e foi generalizado para muito além do problema a que ele se propôs resolver (Sandage 1986 e referências nele contidas), que era o de separar as estrelas entre duas populações distintas:

- estrelas que populavam o disco das galáxias espirais, caracterizadas pelos diagramas cor-magnitude (daqui por diante DCM) de aglomerados abertos e que ele chamou de População I, e;

- estrelas que populavam o halo das galáxias espirais e as galáxias elípticas, caracterizadas pelo DCM de aglomerados globulares e que ele chamou de População II.

Atualmente o principal objetivo do estudo de populações estelares é a compreensão da formação e da evolução das galáxias. Os estudos de populações estelares pretendem distinguir os diversos componentes de uma galáxia e relacionar esses componentes com populações de diferentes idades, composições químicas, propriedades cinemáticas e posições.

O conceito de população estelar também fez surgir noções de como a Galáxia pode ter sido formada, por colapso dissipativo a partir de um grande volume de gás como deduzido a partir de correlações entre composição química e cinemática de estrelas individuais (Eggen et al. 1962), ou a partir de acresção de nuvens de massas equivalentes a galáxias anãs (Searle \& Zinn 1978). 
Além disso, a compreensão das diferenças entre as populações é de importância central para vários problemas de calibração de magnitudes absolutas como indicadores de distância (como variáveis RR Lyrae em aglomerados globulares e Cefeidas em aglomerados abertos).

Na década de 50, o trabalho de Baade concluía que as estrelas de População II eram caracterizadas pelos DCM dos aglomerados globulares e pelas estrelas de campo sub-anãs e RR Lyrae. Mais importante, essas pareciam ser o tipo de estrelas que formavam a maior parte da população próxima ao bojo galáctico, de galáxias elípticas próximas como NGC 147, NCG 185, Sculptor, Fornax, M32 e NGC 205, e do bojo de M31. No entanto Morgan \& Osterbrock (1969) mostraram que o espectro integrado de algumas galáxias elípticas e do bojo de M31 apresentavam linhas espectrais muito mais intensas do que os espectros obtidos de estrelas de População II até então conhecidas. De fato, a separação tão distinta entre as duas Populações e a homogeneidade química da População II como era defendida por Baade, já estava sendo posta em dúvida por outros trabalhos, entre os quais podemos citar:

- Keenan \& Keller (1953) encontram populações com DCM intermediários entre os aglomerados abertos e os aglomerados do halo;

- Morgan (1956, 1959) e Mayall (1946) mostraram haver uma progressão contínua das intensidades das linhas espectrais dos aglomerados de População II;

- Kinman (1959a,b) obteve velocidades radiais e espectros de aglomerados globulares e mostrou que a propriedade cinemática dos aglomerados com fortes linhas espectrais era diferente dos aglomerados de linhas fracas, e;

- Baum et al. (1959) também notou que as galáxias elípticas são muito mais vermelhas que os aglomerados do halo, não podendo, portanto, serem constituídas da mesma população estelar.

A conferência do Vaticano de 1965 trouxe essas descobertas para discussão (Blaauw 
1965) e substituiu a separação original de Baade de apenas duas populações discretas por uma série de subtipos que possuíam características contínuas.

De fato, a crença inicial de que o bojo de nossa galáxia era composto da mesma população estelar do halo, velha e pobre em metais, estava errada. A região mais central da Via Láctea apresenta uma população estelar claramente distinta, como definido pelas características clássicas de uma população: idade, abundância, cinemática e estrutura.

Os 1000 pc centrais da nossa Galáxia são caracterizados por uma população velha, metálica e de alta densidade espacial (Rich 1988 e McWilliam \& Rich 1994). Sua massa é de $2 \times 10^{10} \mathrm{M}_{\text {, }}$, cerca de $1 / 3$ da massa do disco. A imagem do bojo obtida pelo satélite Cosmic Background Explorer (COBE, figura 1) assim como seus espectros, ilustram a natureza distinta do bojo e realçam sua similaridade às galáxias elípticas.

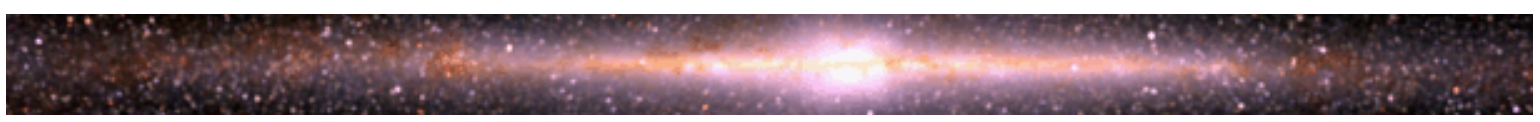

Figura 1: Imagem da galáxia obtida com o detetor infravermelho DIRBE a bordo do satélite COBE. A imagem combina as exposições obtidas em 1.2, 2.2 e $3.4 \mu \mathrm{m}$ (http://space.gsfc.nasa.gov/astro/cobe).

Dessa semelhança com as galáxias elípticas e com os bojos de outras espirais, Whitford (1978) sugeriu que as estrelas gigantes do bojo galáctico poderiam servir como valiosas padrões na síntese de populações de elípticas. De fato, estudos como os de Ortolani et al. (1990, 1995), Rich (1988) e Terndrup (1988) confirmam que o bojo contém predominantemente estrelas velhas e ricas em metais.

Valiosos para o estudo de populações estelares devido à sua homogeneidade química, os aglomerados globulares provaram ser objetos insubstituíveis em muitas áreas da astrofísica: eles fornecem vínculos observacionais para os estudos de cosmologia, formação de galáxias, evolução de estrelas de baixa massa, dinâmica estelar, propriedades de estrelas variáveis e binárias, estrutura e dinâmica Galáctica, entre outras áreas. Os aglomerados globulares são 
particularmente úteis nos estudos de evolução estelar (ver Renzini \& Pecci 1988 e referências nele contidas) uma vez que todas as suas estrelas possuem virtualmente a mesma idade e, na maioria dos casos, são quimicamente homogêneos.

Em outras palavras, aglomerados globulares representam a mais pura e simples população estelar que podemos encontrar, em oposição à população de campo, resultados de uma mistura de idades e composições químicas. Eles também representam um padrão de população estelar para testes e calibração de sínteses de populações evolucionárias (Renzini 1986, Buzzoni 1988, Bruzual et al. 1997).

Neste trabalho apresentamos o estudo realizado com 15 estrelas do aglomerado globular NGC 6528 e 8 estrelas do aglomerado globular NGC 6553. Através de dados fotométricos obtidos no European Southern Observatory (ESO) e com o Hubble Space Telescope (HST), espectros do ESO e síntese de espectros determinamos: a temperatura efetiva, gravidade superficial, metalicidade e velocidade radial dessas estrelas. São apresentados também os valores dos índices Mg2, Fe5270 e Fe5335 (Burstein et al. 1984 e Worthey et al. 1994) e de três índices de TiO segundo Schiavon \& Barbuy (2000, comunicação privada).

No capítulo 2 apresentamos um histórico dos estudos já realizados sobre esses aglomerados e os dados disponíveis na literatura. No capítulo 3 apresentamos a descrição dos dados de que dispomos e o método usado na redução de dados. No capítulo 4 descrevemos os métodos utilizados na determinação dos parâmetros astrofísicos e os resultados encontrados. A determinação da metalicidade das estrelas através da síntese espectral está descrita no capítulo 5. As conclusões obtidas são apresentadas no capítulo 6 e as perspectivas deste trabalho são discutidas no capítulo 7. 


\section{Os aglomerados globulares NGC 6528 e NGC 6553}

Atualmente são conhecidos cerca de 150 aglomerados globulares na nossa galáxia. Nem todos os aglomerados devem ter sido detectados, principalmente devido ao obscurecimento causado pelo bojo galáctico, e a estimativa é de que existam cerca de 200 aglomerados no total. Esse sistema de aglomerados globulares é bem concentrado sendo que quase metade dos aglomerados se situam dentro de um raio de $5 \mathrm{kpc}$ do centro galáctico.

$\mathrm{Na}$ figura 2 é apresentado um histograma da distribuição de metalicidades dos aglomerados globulares da nossa galáxia. A primeira característica a ser notada é a presença de dois picos distintos que sugerem duas populações distintas de aglomerados globulares. Os aglomerados ricos em metais se estendem por um sistema achatado e giram em torno do centro

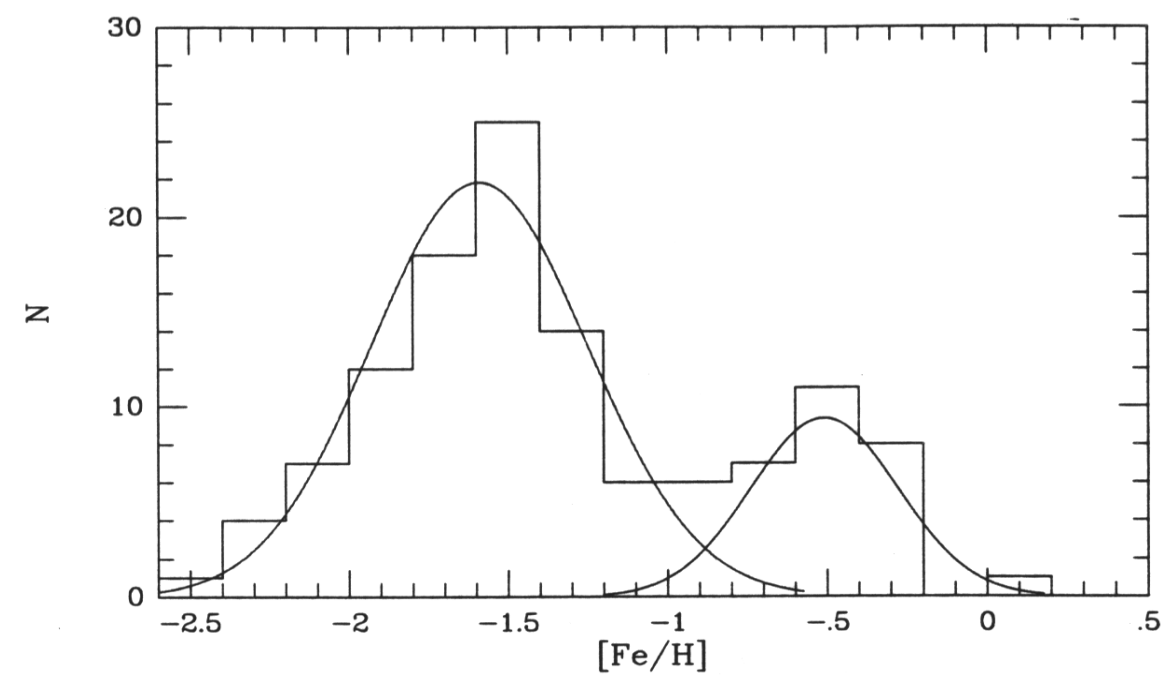

Figura 2: Histograma da distribuição de metalicidades dos aglomerados globulares da nossa Galáxia. As curvas sobrepostas aos histogramas representam as gaussianas que ajustam as componentes pobre e rica em metais. Os picos ocorrem em $[\mathrm{Fe} / \mathrm{H}]=-1.59$ e $[\mathrm{Fe} / \mathrm{H}]=-0.51 \mathrm{com}$ desvios padrões de 0.34 e 0.23 respectivamente. Esses resultados foram obtidos por McLachlan \& Basford (1988) e Ashman et al. (1994). Figura obtida de Ashman \& Zepf (1998). 
galáctico, ao contrário dos aglomerados pobres em metais que possuem rotação quase nula e apresentam uma distribuição espacial esférica. A distribuição espacial de metalicidades é um importante vínculo para os modelos de evolução química porque são representativos do enriquecimento químico específico da componente da Galáxia ao qual o estudo se refere.

A questão de qual componente da Galáxia está associada aos aglomerados globulares ricos em metais foi discutida por diversos autores. Entre eles, Zinn (1985) encontrou que as propriedades espaciais e cinemáticas desses aglomerados eram as esperadas de um disco espesso, enquanto que van den Bergh (1993) defendia que eles estavam associados à população do bojo. Com o objetivo específico de estudar essa questão, Minniti (1995) concluiu que os aglomerados globulares ricos em metais que estão a um raio galáctico $\mathrm{R}_{\mathrm{G}}>3 \mathrm{kpc}$ pertencem ao disco espesso, mas que os aglomerados com $\mathrm{R}_{\mathrm{G}}<3 \mathrm{kpc}$ são cinematicamente associados ao bojo.

Um avanço nessa discussão foi o survey de DCMs feito por Barbuy, Bica \& Ortolani (1998) com o objetivo de determinar distâncias e avermelhamento de aglomerados globulares. Nesse trabalho foram observados 17 aglomerados com alturas galácticas $|\mathrm{z}|<500 \mathrm{pc}$ e as metalicidades e distribuições espaciais obtidas são muito próximas às de estrela de campo do bojo.

Dentre esses aglomerados estavam NGC 6528 e NGC 6553 (ver tabela 1) que foram inicialmente indicados por Morgan (1959) como sendo dois dos aglomerados globulares mais ricos em metais conhecidos. O NGC 6553 se situa relativamente próximo ao Sol enquanto que NGC 6528 localiza-se muito próximo ao centro galáctico, na Janela de Baade ${ }^{1}$. Bica \& Alloin (1986) observaram espectros integrados de 63 aglomerados com o intuito de estabelecer uma

1. A janela de Baade é uma região de extinção relativamente baixa e alta metalicidade média que permite portanto a observação mais profunda do bojo galáctico. Baade descobriu essa região em 1951 e inicialmente acreditou que ela consistisse de uma "estrutura brilhante", e não uma janela de extinção. 
Tabela 1: Dados gerais dos aglomerados globulares estudados, conforme Barbuy et al. (1998).

\begin{tabular}{lcc}
\hline & NGC 6528 & NGC 6553 \\
\hline$\alpha_{2000}$ (h m s) & 180449.6 & 180915.7 \\
$\delta_{2000}($ o “ ") & -300320.8 & -255427.9 \\
Longitude galáctica I () & 1.14 & 5.25 \\
Latitude galáctica b (ㅇ) & -4.18 & -3.03 \\
Distância do Sol (d kpc) & 7.83 & 5.10 \\
\hline
\end{tabular}

grade de espectros para síntese de populações e encontraram metalicidades de ordem da solar para NGC 6528 e NGC 6553. Um sumário dos valores de metalicidade encontrados na literatura para os dois aglomerados pode ser visto na tabela 2. A dispersão de valores encontrados pode ser explicada pela combinação de uma sobreabundância de elementos $\alpha$ e uma metalicidade pouco abaixo da solar.

O primeiro estudo fotoelétrico e fotográfico desses aglomerados foi feito por Hartwick (1975) e van den Bergh (1979) para NGC 6553 e NGC 6528 respectivamente. Ortolani, Barbuy \& Bica (1990) apresentaram o primeiro estudo fotométrico realizado com CCD de NGC 6553, onde pode ser observado que o ramo das gigantes deste aglomerado forma um arco de modo que as estrelas mais vermelhas do ramo são mais fracas do que as gigantes mais azuladas (figura 3). Esse comportamento também é visto em NGC 6528 (Ortolani, Bica \& Barbuy 1992) e nas gigantes de campo do bojo (Rich et al. 1998).

Essa característica é menos proeminente em diagramas cor-magnitude que envolvem cores mais vermelhas como I x V-I e não é vista em diagramas que envolvem apenas bandas infravermelhas, onde o ramo das gigantes se comporta como esperado, se tornando mais brilhante conforme mais vermelhas são as estrelas. A explicação proposta para este comportamento encontra-se no fato desses aglomerados serem muito metálicos de modo que 
as bandas moleculares presentes no espectro visível, principalmente as bandas de óxido de titânio (TiO), absorvem muito da luminosidade da estrela, de modo que estrelas cada vez mais frias se tornam menos luminosas.

Em Ortolani et al. (1995) estes aglomerados foram observados com o Telescópio Espacial Hubble (HST) usando a Wide Field and Planetary Camera 2 (WFPC2) e os dados obtidos, além de contribuirem para o estudo dos aglomerados em si, tiveram impacto na compreensão da formação da nossa galáxia.

Não há ainda um consenso sobre a formação da Galáxia. O primeiro modelo largamente aceito foi o de Eggen, Lynden-Bell \& Sandage (1962), onde o halo teria se formado via um

Tabela 2: Valores de metalicidade dos aglomerados encontrados na literatura.

\begin{tabular}{cccc}
\hline $\begin{array}{c}\text { NGC 6528 } \\
{[\mathrm{Fe} / \mathrm{H}]}\end{array}$ & $\begin{array}{c}\text { NGC 6553 } \\
{[\mathrm{Fe} / \mathrm{H}]}\end{array}$ & Referência & Método \\
\hline+0.01 & +0.04 & 1 & fotometria integrada Q39 \\
-0.18 & +0.47 & 2 & fotometria integrada DDO \\
& -0.46 & 3 & espectroscopia de alta resolução \\
& -0.29 & 4 & espectroscopia integrada \\
-0.71 & -0.70 & 5 & espectroscopia de alta resolução \\
-0.96 & -0.41 & 6 & compilação \\
-0.05 & +0.1 & 7 & espectroscopia integrada \\
& -0.2 & 8 & espectroscopia de alta resolução \\
-0.17 & -0.25 & 9 & espectroscopia integrada CO \\
-0.23 & -0.33 & 10 & espectroscopia de média resolução de gigantes \\
+0.12 & -0.18 & 11 & escala de metalicidade de aglomerados globulares \\
& -0.60 & 12 & espectroscopia de alta resolução \\
& -0.55 & 13 & espectroscopia de alta resolução \\
\hline
\end{tabular}

Referências: 1 Zinn (1980); 2 Bica \& Pastoriza (1983); 3 Cohen (1983); 4 Zinn \& West (1984); 5 Pilachowski (1984); 6 Webbink (1985); 7 Bica \& Alloin (1986); 8 Barbuy et al. (1992); 9 Harris (1996); 10 Origlia et al. (1997); 11 Rutledge et al. (1997); 12 Caretta \& Gratton (1997); 13 Barbuy et al. (1999); 14 Cohen et al. (1999). 

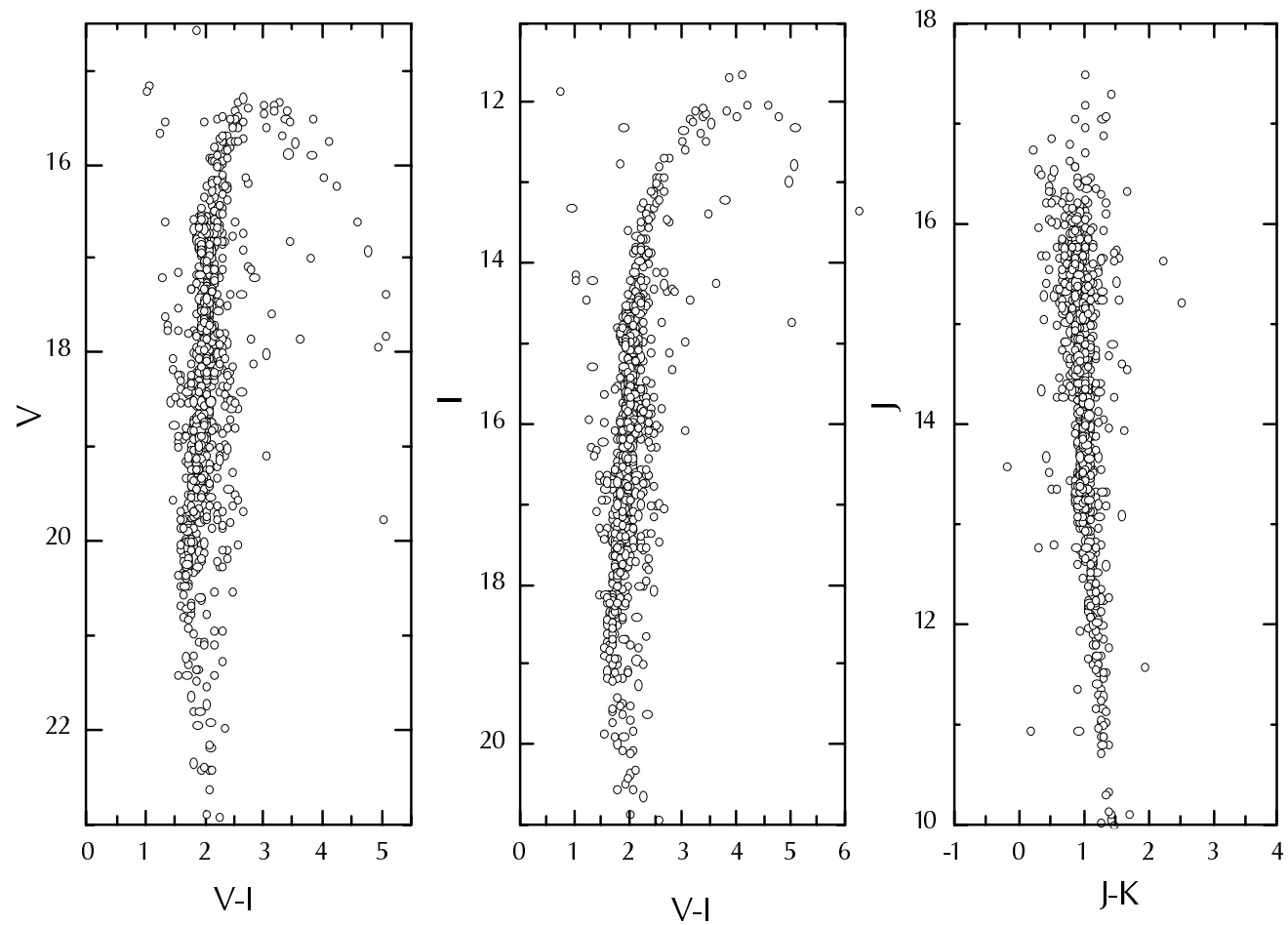

Figura 3: Diagramas cor-magnitude do aglomerado NGC 6553 confeccionados com os dados de Ortolani et al. (1995). Pode-se perceber que para diagramas que envolvem cores no visível há um comportamento anômalo do ramo das gigantes, onde estrelas mais frias podem ser menos luminosas do que as correspondentes mais quentes de mesma luminosidade. Esse efeito diminui e tende a desaparecer conforme observamos o diagrama em cores mais vermelhas.

colapso não dissipativo rápido. Searle \& Zinn (1978) propuseram uma formação mais caótica, onde pequenos fragmentos protogalácticos se fundiam durante uma certa extensão de tempo. Mais recentemente Zinn (1993) e van den Bergh (1993) propuseram um modelo híbrido onde parte da galáxia se formou por colapso dissipativo e a parte mais distante do centro se formou por fusão de fragmentos protogalácticos.

Até há algum tempo atrás, a formação do bojo galáctico como componente distinto não recebeu tanta atenção quanto a formação do halo, talvez devido às dificuldades observacionais de se estudar essa população. Mas é na nossa Galáxia onde podemos estudar melhor a distinção entre as diversas componentes e desvendar a cronologia e o mecanismo de formação galática.

No modelo de Eggen et al. (1962), o bojo era considerado uma parte do halo, tendo se formado como parte de um mesmo processo. O modelo de Larson (1990) considera que o bojo se formou primeiro, sendo mais velho que o halo (formação inside-out da Galáxia). Já 
modelos como os de Raha et al. (1991) e Pfenniger et al. (1991) propõem que o bojo tenha se formado por um processo distinto, como distorções dinâmicas nas regiões mais internas do disco. Nesse caso o bojo seria necessariamente mais novo que o halo.

A partir da hipótese de que o halo e o bojo possuem uma origem em comum, há duas versões básicas de formação do esferóide:

a) o processo de formação estelar se iniciou no halo, e o gás enriquecido pelas explosões de supernovas caiu em direção ao centro, de forma que bojo se formou depois a partir desses processo de condensação (Larson 1975), ou;

b) o processo de formação estelar se iniciou nas regiões centrais mais densas, ou seja no bojo, rapidamente enriquecendo o gás até metalicidades sobre-solares. O bojo teria se formado então pouco antes que o halo, sendo mais velho, apesar de mais metálico (Larson 1990, Matteucci et al. 1999, Lee 1992, Renzini \& Greggio 1990, Renzini 1993).

A determinação precisa das idades é dificultada pelo crowding, avermelhamento diferencial, dispersão de metalicidades e contaminação pelas estrelas do disco, efeitos esses que somados podem mascarar variações instrínsecas de idade. Muitas dessas limitações podem ser reduzidas se o estudo for realizado através de aglomerados globulares (que em sua maioria são constituídos de estrelas quimicamente homogêneas e de mesma idade) ricos em metais (o que garante que não são aglomerados do halo), motivos pelos quais os aglomerados NGC 6528 e NGC 6553 foram escolhidos para as observações do HST.

Com esses dados pode-se construir DCMs de alta qualidade que atingiram a sequência principal dos aglomerados. O erro máximo foi dado pelo avermelhamento diferencial de cerca de $0.2 \mathrm{mag}$ através do campo. O locus médio $^{2}$ foi calculado para os dois aglomerados e eles são 


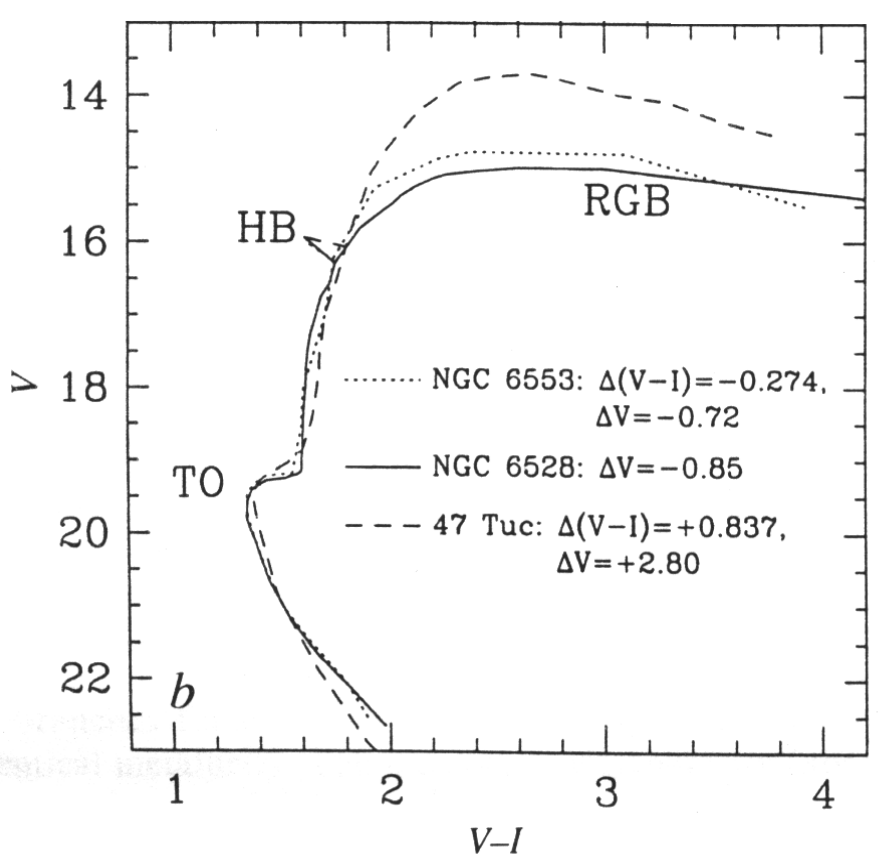

Figura 4: O locus médio dos dois aglomerados comparados ao locus médio do aglomerado 47 Tuc. O locus do NGC 6528 foi deslocado $\Delta V=-0.85$ para coincidir com o do NGC 6553, de modo a obter-se ao mesmo tempo o menor avermelhamento e distância (NGC 6528 e NGC 6553 respectivamente). O módulo de distância do NGC 6553 é quase 1 mag menor do que o de NGC 6528. Diagrama retirado de Ortolani et al. (1995).

notavelmente similares (figura 4).

Dentre os métodos possíveis de determinação de idade de aglomerados (Binney \& Merrifield 1998 capítulo 6 e referências nele contidas), o método que usa as diferenças de luminosidade entre o ramo horizontal (borizontal branch - HB) e o turnoff (TO), $\Delta V_{T O}^{H B}$, tem a vantagem de não depender da distância do aglomerado, do avermelhamento e depender pouco da metalicidade. A magnitude do HB essencialmente não varia com a massa (e portanto com a idade) enquanto que a magnitude do TO rapidamente aumenta com a idade, de modo que $\Delta V_{T O}^{H B}$ é altamente dependente da idade do aglomerado.

2. O locus médio representa uma linha da distribuição de estrelas. Operacionalmente, divide-se o DCM em "caixas" para as quais se calcula a posição mediana das estrelas, sendo a linha então traçada por essas medianas. 
Ao medir os $\Delta V_{T O}^{H B}$ dos aglomerados, Ortolani et al. (1995) mostrou que eles são diferentes em no máximo 0.1 mag o que sugere que os aglomerados não devem ter uma diferença de idade superior a $10 \%$.

Ao comparar o locus médio desses aglomerados com o de 47 Tuc, um dos aglomerados mais ricos em metais do halo $([\mathrm{Fe} / \mathrm{H}] \sim-0.7)$, pode-se ver que o $\Delta V_{T O}^{H B}$ deste aglomerado é menor ou igual aos dos dois aglomerados do bojo, o que garante que as idades dos três aglomerados são praticamente as mesmas, ou seja, os aglomerados do bojo estudados têm praticamente a mesma idade que o halo galáctico. Dessa forma, Ortolani et al. (1995) concluiram que toda a componente esferóide da Galáxia (halo e bojo) se formou em um processo único e a alta metalicidade dos aglomerados do bojo requer que o enriquecimento químico tenha sido muito rápido (menos que poucos bilhões de anos) ao longo de todo o bojo (até pelo menos $3 \mathrm{kpc}$ do centro galáctico).

Por outro lado, pode-se questionar o quanto os dois aglomerados NGC 6553 e NGC 6528 são realmente representativos da população estelar do bojo. Para responder a esta questão Ortolani et al. (1995) compararam a função de luminosidade (número de estrelas por intervalo de magnitude) desses aglomerados com a função de luminosidade observada na Janela de Baade (McWilliam \& Rich, 1994).

Essa comparação está apresentada na figura 5 e revela que a idade e a metalicidade da população do bojo é muito similar às dos aglomerados. Quando os picos que correspondem ao HB são postos um sobre o outro, as funções de luminosidade da seqüência principal também coincidem muito bem na região mais brilhante, que é mais dependente da idade e menos afetada pela incompleteza dos dados. Dessa forma, a idade da população da Janela de Baade é a mesma dos aglomerados, diferindo no máximo em 10\%. As inclinações idênticas das 
seqüências principais garantem que a dispersão de idades das estrelas da Janela de Baade também deve ser muito pequena, provavelmente $\leq 10 \%$.

Todos esses dados sugerem então fortemente um cenário onde o bojo se formou rapidamente, junto com todo o esferóide e passou por um enriquecimento químico rápido.

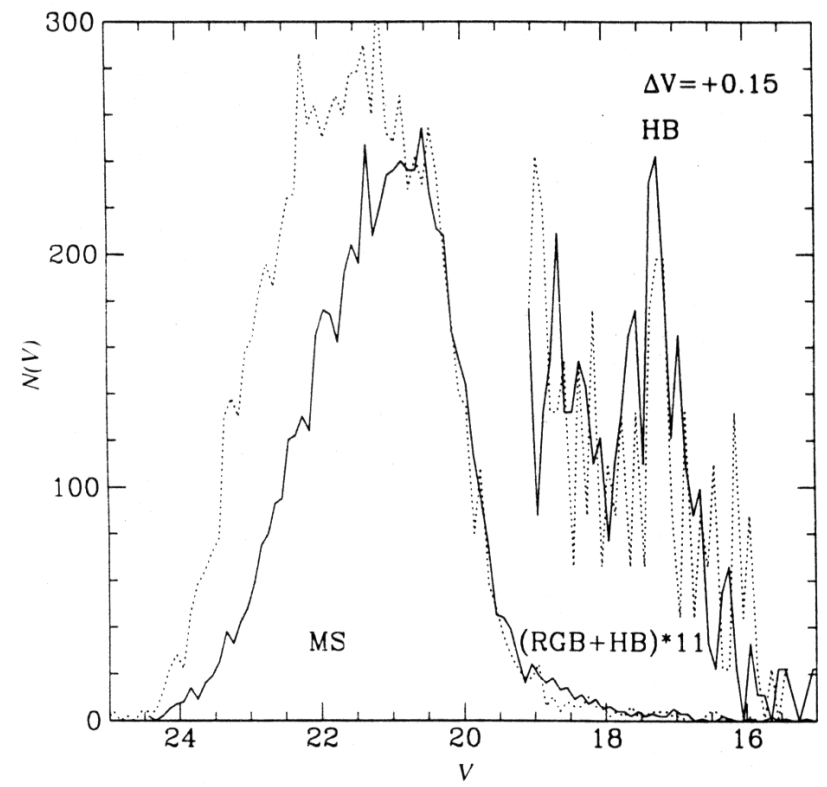

Figura 5: Funções de luminosidade da seqüência principal (MS) e gigantes (RGB+HB) das estrelas do NGC 6528 (linhas tracejadas) e de estrelas na Janela de Baade (linhas sólidas). A função de luminosidade do NGC 6528 foi deslocada $\Delta V=+0.15$ para que os picos correspondentes ao HB coincidissem e foi também multiplicada por 2 para normalizar as contagens em $\mathrm{V}=20.45$. Abaixo de $V=21$ a função de luminosidade do bojo é progressivamente mais incompleta. Figura retirada de Ortolani et al. (1995).

A calibração absoluta de idades, no entanto, ainda depende das abundâncias encontradas nesses aglomerados e particularmente da abundância de elementos $\alpha^{3}$. Potencialmente, a função de massa inicial (FMI) e a taxa de formação estelar (TFE) também podem ser recuperados pela análise de abundâncias (Rich \& McWilliam 2000).

Matteucci \& Brocato (1990) e Matteucci et al. (1999) previram que, se o bojo se formou

3. Os elementos $\alpha$ compreendem os elementos cujo número de massa atômico é múltiplo de 4 . Eles são chamados assim porque originalmente acreditava-se que eles eram produzidos pela captura de núcleos de He, o que hoje se sabe valer apenas para o Oxigênio, mas o nome se manteve. 
em um processo rápido, a razão de alguns elementos $\alpha(\mathrm{Si}, \mathrm{Mg}$ e O $)$ sobre o Fe nas estrelas do bojo devem ser maiores que a solar por toda a distribuição de metalicidades, de modo similar ao encontrado em estrelas do halo. Isso ocorreria porque os elementos $\alpha$ são ejetados no meio interestelar pelas Supernovas tipo II. Já os elementos do pico de Fe são ejetados essencialmente pelas Supernovas tipo Ia, o que se torna importante apenas após 1-2 Ganos, que é o tempo necessário à formação da primeira geração de anãs-brancas (ver por exemplo Greggio 1996).

Os valores de $[\alpha / \mathrm{Fe}] \times[\mathrm{Fe} / \mathrm{H}]$ podem fornecer outros vínculos sobre a formação do bojo. Se a IMF foi dominada por estrelas massivas, os elementos $\alpha$ podem ser sobreabundantes em relação ao Fe em mais do que +0.3 dex (Matteucci \& Brocato 1990). Se a taxa de formação tiver sido muito alta, serão produzidas estrelas de metalicidade solar com razões $[\alpha / \mathrm{Fe}]$ também sobreabundantes, como parece ter sido o caso do bojo.

Essa sobreabundância de elementos $\alpha$ não deve ser constante para todos os elementos, mas depende da produção relativa desses elementos por supernovas de diferentes tipos. Matteucci et al. (1999) previram que $[\mathrm{Si} / \mathrm{Fe}],[\mathrm{S} / \mathrm{Fe}]$ e $[\mathrm{Ca} / \mathrm{Fe}]$ devem ser menos sobreabundantes e mais constantes que $[\mathrm{O} / \mathrm{Fe}],[\mathrm{Mg} / \mathrm{Fe}]$ e $[\mathrm{Ne} / \mathrm{Fe}]$.

Barbuy et al. (1992) compilaram da literatura as metalicidades estimadas até então para o NGC 6553 e os valores cobriam $-0.7 \leq[\mathrm{Fe} / \mathrm{H}] \leq+0.5$. Com o objetivo de estudar essas abundâncias e de posse de um espectro échelle de alta resolução $(\Delta \lambda \sim 0.20 \AA)$ obtido no ESO, Barbuy et al. (1992) analisaram a estrela III-17 do NGC 6553 (como identificada por Hartwick 1975), que está entre as mais brilhantes (na banda V) gigantes do aglomerado e obtiveram [M/ $\mathrm{H}]=-0.2$. Uma análise detalhada de abundâncias de outras duas gigantes (estrelas II-85 e III-3) do NGC 6553 foi realizada em Barbuy et al. (1999) e da gigante I-2 do NGC 6528 em Barbuy (2000). As abundâncias encontradas nesses dois trabalhos estão indicadas na tabela 3. Também é apresentado para efeito de comparação os valores encontrados por McWilliam \& Rich (1994) 
com o estudo de gigantes $\mathrm{K}$ no campo da Janela de Baade, valores esses que foram confirmados pelo estudo recente com espectros do Keck apresentado em Rich \& McWilliam (2000) .

Essas razões de abundâncias sugerem que o enriquecimento químico do gás a partir do qual os aglomerados foram formados foi dominado por Supernovas tipo II (cujas progenitoras são estrelas massivas e portanto de vida curta) com pouca contaminação das Supernovas tipo Ia (cujas precursoras são estrelas de massa em torno da solar e de vida mais longa). Ou seja, é favorecido o cenário no qual o bojo passou por uma formação e um enriquecimento químico rápido, de acordo com a conclusão de Ortolani et al. (1995).

Através de espectros de alta resolução, cinco estrelas no HB do NGC 6553 (estrelas 30180, 30242, 30257, 40071 e 40123 conforme dados de Guarnieri et al. 1998) foram analisadas por Cohen et al. (1999), que encontraram $[\mathrm{Fe} / \mathrm{H}]=-0.16$ e $[\mathrm{Ca} / \mathrm{Fe}]=+0.26$, valores

Tabela 3: Abundâncias determinadas por Barbuy et al. (1999) para o NGC 6553, Barbuy (2000) para o NGC 6528 e McWilliam \& Rich (1994) para estrelas de campo do bojo.

\begin{tabular}{cccc}
\hline$[\mathrm{X} / \mathrm{Fe}]$ & NGC 6528 & NGC 6553 & $\begin{array}{c}\text { Gigantes K segundo } \\
\text { McWillian \& Rich } \\
(1994)\end{array}$ \\
\hline$[\mathrm{Fe} / \mathrm{H}]$ & -0.5 & -0.55 & -1.6 a 0.55 \\
$\mathrm{Na}$ & +0.4 & +0.65 & +0.20 \\
$\mathrm{O}$ & +0.25 & - & +0.03 \\
$\mathrm{Mg}$ & +0.40 & +0.33 & +0.35 \\
$\mathrm{Al}$ & +0.4 & +0.50 & +0.58 \\
$\mathrm{Si}$ & +0.6 & +0.35 & +0.14 \\
$\mathrm{Ca}$ & -0.2 & +0.32 & +0.14 \\
$\mathrm{Ti}$ & +0.2 & +0.60 & +0.37 \\
$\mathrm{Y}$ & - & -0.20 & +0.05 \\
$\mathrm{Zr}$ & -0.4 & -0.40 & -0.53 \\
$\mathrm{Ba}$ & -0.2 & -0.10 & +0.20 \\
$\mathrm{La}$ & - & +0.13 & +0.09 \\
$\mathrm{Eu}$ & 0 & 0 & +0.26 \\
\hline
\end{tabular}


consideravelmente mais altos que Barbuy et al. (1999) .

Discussões sobre essas diferenças podem ser encontradas em Cohen et al. (1999) e Barbuy (2000). Os principais comentários são:

- Cohen et al. (1999) utilizaram modelos de atmosfera da grade ATLAS de Kurucz et al. (1992) enquanto que Barbuy et al. (1999) usaram os modelos da grade NMARCS de Plez (1997). Essa diferença de modelos pode ser responsável por parte das discrepâncias encontradas;

- Os valores das forças de oscilador também foram um pouco diferentes. Barbuy et al. (1999) usaram dados de laboratório de Wiese et al. (1969, Furh et al. (1988) e Martin et al. (1988) enquanto que Cohen et al. (1999) usaram seus próprios valores obtidos do ajuste do espectro solar;

- Cohen et al. (1999) argumenta que o uso de estrelas mais quentes e um maior SNR e resolução dos espectros leva a uma melhor definição do contínuo, aumentando a metalicidade encontrada, e;

- Barbuy (2000) argumenta que a escala de temperaturas usada em Cohen et al. (1999) é alta em comparação à obtida pelo equílibrio de excitação, chegando a uma diferença de 250K para uma dada estrela estudada (40071), o que pode ser a principal causa da discrepância encontrada.

Certamente mais análises baseadas em espectros de alta resolução são necessárias para elucidar essa questão. Seria conveniente, no entanto, que se estudassem estrelas ao longo de vários estágios evolutivos, cobrindo portanto um grande intervalo de temperaturas e gravidades. 


\section{Os dados}

Para o estudo das estrelas propostas foram utilizados tanto dados fotométricos quanto espectroscópicos. Neste capítulo descrevemos os dados utilizados e o procedimento utilizado para a redução dos espectros.

\subsection{Dados fotométricos}

Como dados fotométricos dispomos de cores V-I para ambos os aglomerados obtidas com observações do HST (Ortolani et al. 1995), cores J-K obtidas para o NGC 6553 com o detetor IRAC2 no telescópio de 2.2 metros do European Southern Observatory (ESO) (Guarnieri et al. 1998) e a magnitude B foi obtida para o NGC 6528 com o telescópio dinamarquês de $1.5 \mathrm{~m}$ do ESO.

Os DCMs V x V-I dos dois aglomerados podem ser observados nas figuras 6 e 7. Nos painéis superiores de cada figura estão apresentadas todas as estrelas observadas no campo do HST onde as estrelas para as quais dispomos de espectros estão indicadas por círculos pretos. Nos painéis inferiores é apresentada uma ampliação da região do diagrama à qual pertencem as estrelas estudadas, com as respectivas identificações.

A fim de facilitar a classificação das estrelas observadas com relação ao seu estágio evolutivo, fizemos uma estimativa do locus médio de cada aglomerado como pode ser visto na figura 8. É possível então perceber que há:

- 4 estrelas no HB: estrelas I-23 e I-24 do NGC 6528 e estrelas II-52 e III-2 do NGC 

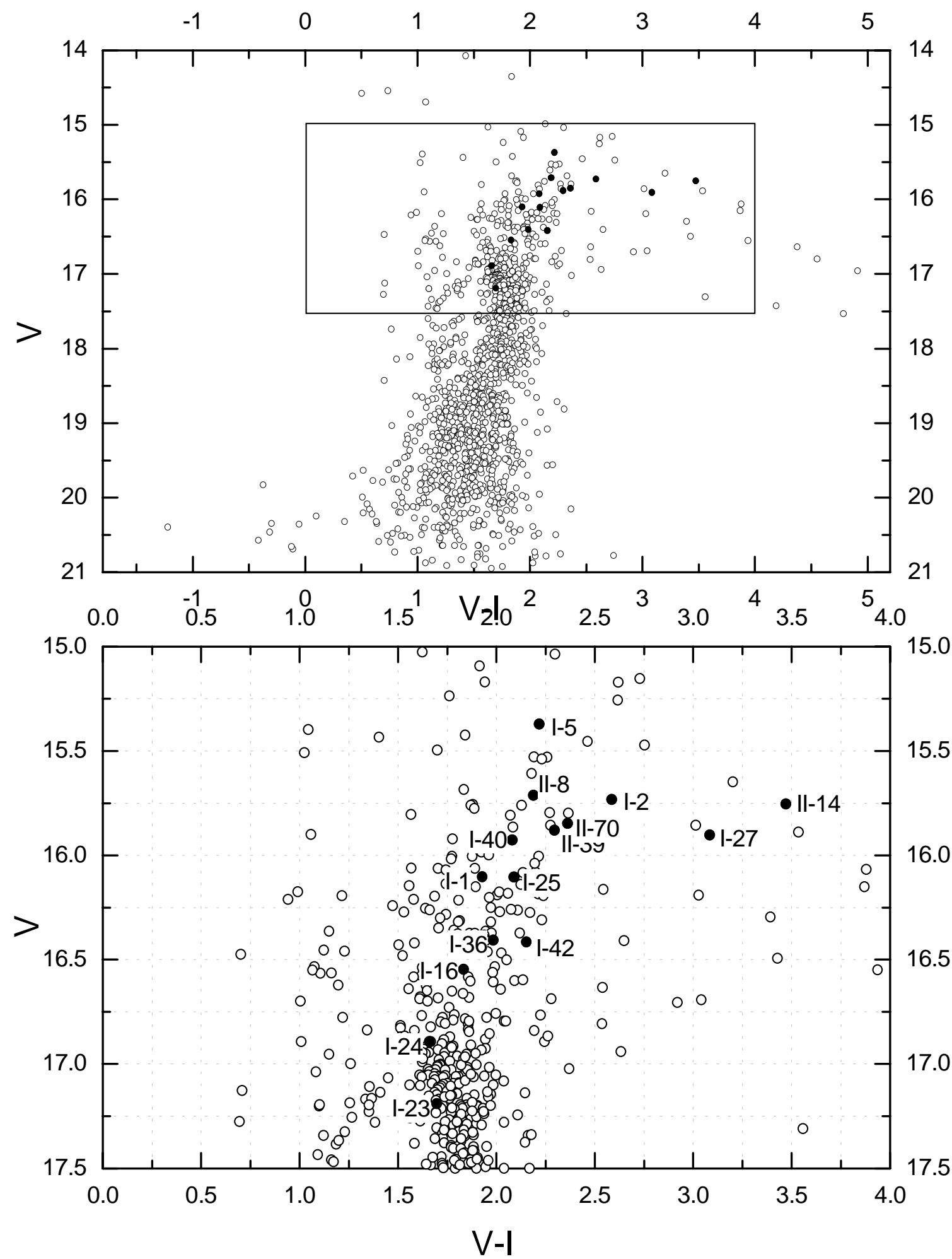

Figura 6: Diagramas cor-magnitude do aglomerado globular NGC 6528. No painel superior são mostradas todas as estrelas observadas pelo HST. O quadrado indica a região ampliada no painel inferior, onde podemos ver a indentificação das estrelas para as quais dispomos de espectros. A identificação das estrelas é a mesma utilizada em van den Bergh \& Younger (1979). 

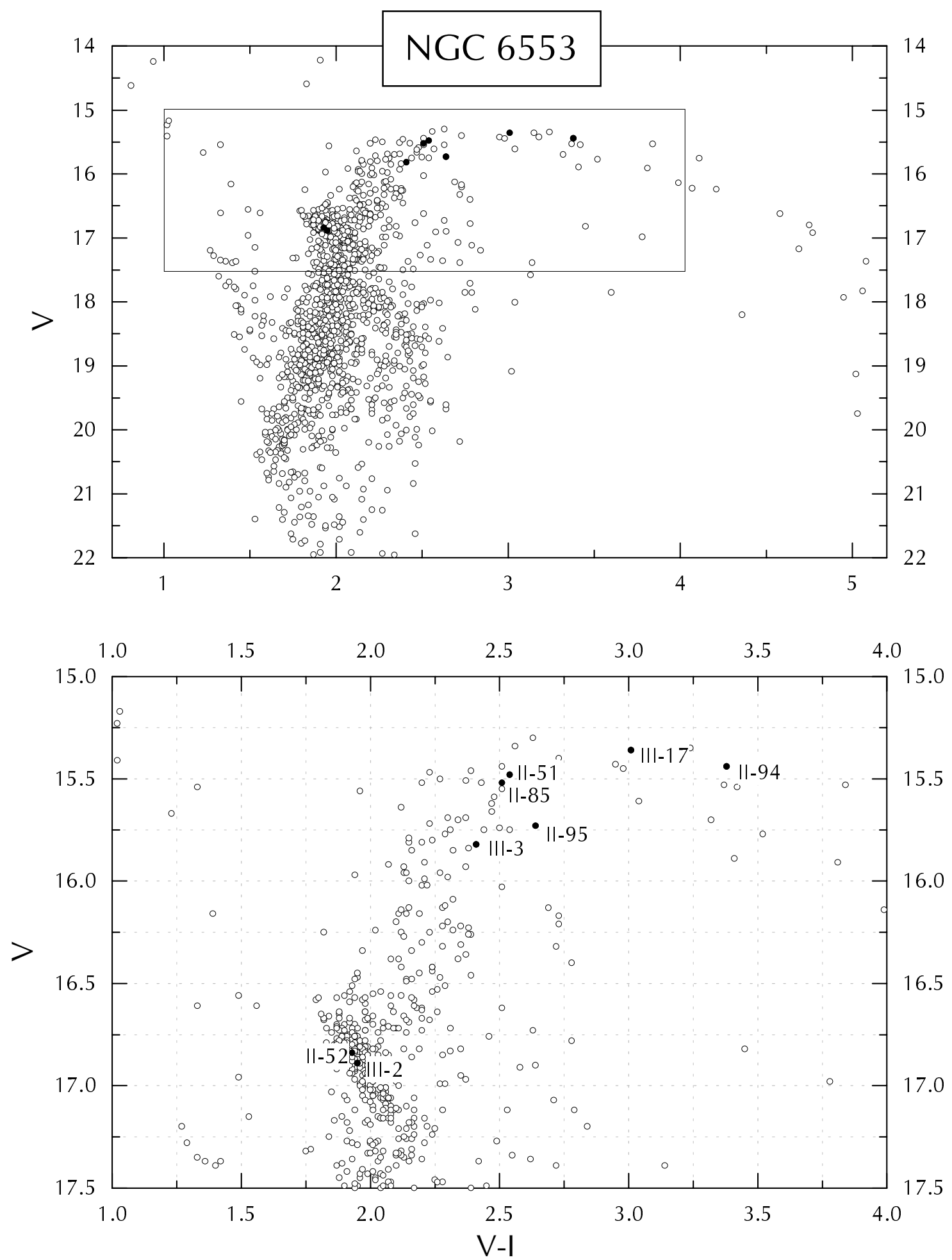

Figura 7: Diagramas cor-magnitude para o NGC 6553. À semelhança da figura anterior, o painel inferior corresponde a uma ampliação da região marcada no painel superior. A identificação usada para as estrelas é a de Hartwick (1975). 
6553, e;

- 19 estrelas no ramo das gigantes vermelhas (red giant branch - RGB): todas as outras estrelas, sendo as mais evoluídas a I-6 do NGC 6528 e a II-94 do NGC 6553.

Com isso estamos abrangendo um grande intervalo de temperaturas e gravidades superficiais.

\subsection{Dados espectroscópicos}

Quanto aos dados espectroscópicos dispomos de dois grupos de observações:

- grupo A: espectros obtidos em 1992 por L. Cremonese com o telescópio de 1.52m do ESO, CCD \# 18 de 1024 x 1024 pixeis (pixel de $19 \mu \mathrm{m}$ ). Esses espectros possuem $\Delta \lambda \sim 8 \AA \mathrm{e}$ cobrem uma região espectral de $4.800 \AA$ a $8.800 \AA$.

- grupo B: espectros obtidos em 1994 por A. Milone e B. Barbuy com o telescópio de 1.52m do ESO, CCD \# 24 (Ford Aerospace FA 2048 L) de 2048 x 2048 pixeis (pixel de 15 $\mu \mathrm{m}$ ). Essas observações resultaram em espectros de $\Delta \lambda \sim 4 \AA$ e cobrem uma região espectral de $4800 \AA$ a $7550 \AA$.

Esses grupos dispõem, além das estrelas do programa, observações de:

- bias: cerca de 10 observações por noite de observação. O bias corresponde ao ruído de leitura do CCD. Os arquivos de bias foram combinados em um único arquivo que foi subtraído de todos os outros arquivos;

- flatfield: Cerca de 15 por noite. O flatfield em questão foi feito tirando-se diversas imagens de uma tela branca iluminada por uma lâmpada incandescente. O objetivo é 
corrigir a imagem das diferentes respostas de cada pixel do CCD, introduzindo flutuações de contagem que não são inerentes às estrelas do programa que se deseja estudar. Neste caso em que foram observados espectros de grande cobertura espectral, os flatfields apresentavam, ao longo do eixo de dispersão, uma resposta que era também devida ao efeito somado da resposta do CCD ao longo do comprimento de onda e do fato de que a lâmpada que ilumina a cúpula durante a obtenção do flatfield não tem uma emissão plana. Antes do flatfield combinado ser aplicado às outras observações, essa resposta ao longo do comprimento de onda foi normalizada (tarefa response do IRAF).

- lâmpadas de calibração de Hélio e Argônio que foram usadas na calibração em comprimento de onda dos espectros, e;

- estrelas padrão espectro-fotométricas usadas na calibração de fluxo (Hamuy et al. 1994).

O grupo B também dispunha, para cada estrela do programa observada, da observação de uma estrela quente de alta rotação observada em massa de ar próxima à da estrela de programa. Essas estrelas foram usadas na extração das bandas telúricas dos espectros das estrelas do programa.

\subsection{Redução dos espectros}

Toda a redução de dados foi feita com o pacote IRAF. Na figura 9 está apresentado um fluxograma especificando as etapas que constituíram a redução de dados (o termo em parênteses corresponde ao nome da tarefa usada).

Para o grupo B os espectros também foram corrigidos das bandas telúricas: as estrelas quentes de alta rotação foram reduzidas de forma semelhante ao fluxograma indicado, exceto 

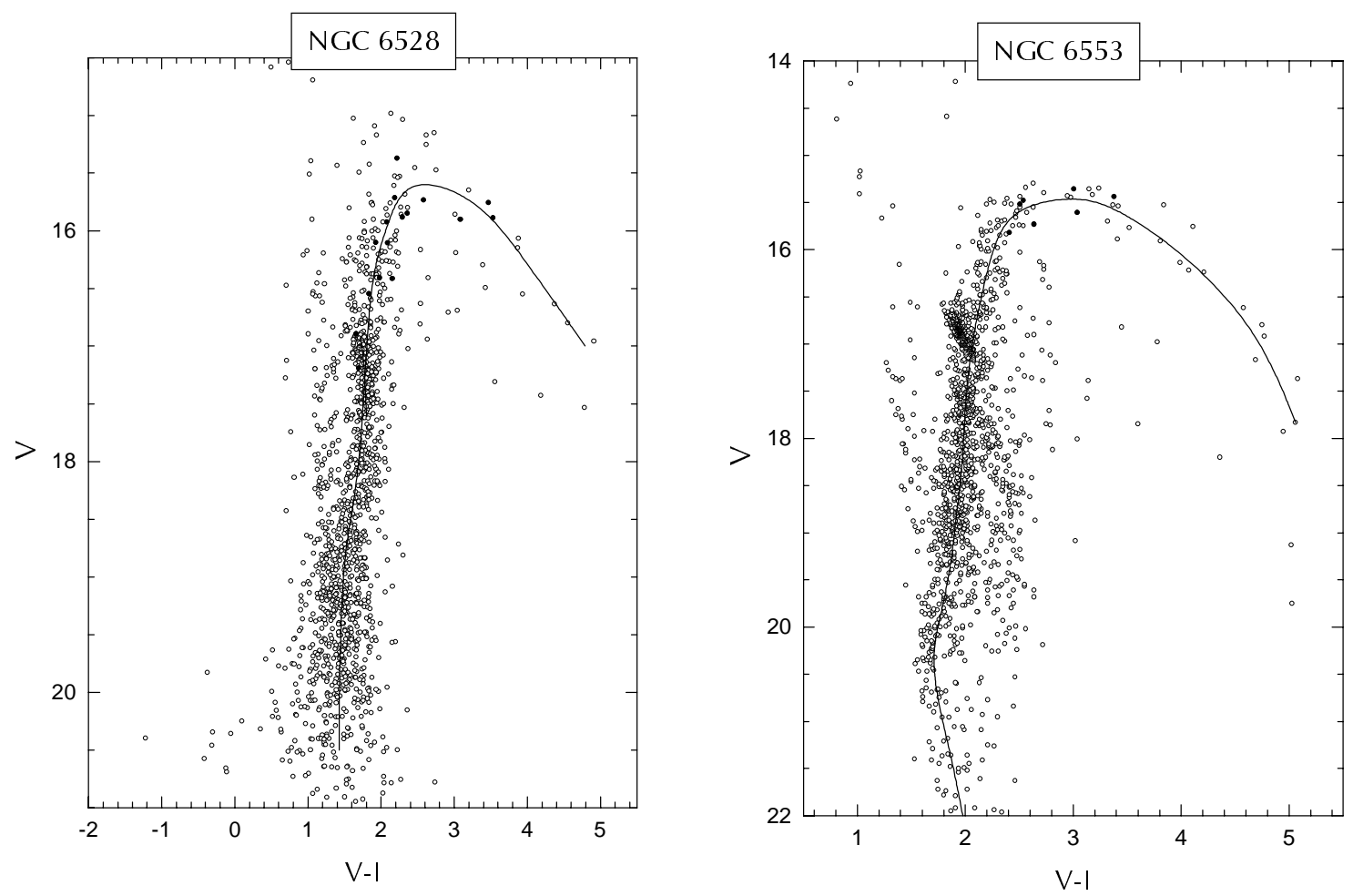

Figura 8: Os diagramas acima mostram o locus médio traçado para os aglomerados NGC 6528 e NGC 6553.

pelo fato de que após a calibração em comprimento de onda elas foram normalizadas, uma vez que não se fazia necessária a calibração em fluxo dessas estrelas. Usando o espectro telúrico apresentado em Curcio et al. (1964) como referência, o espectro foi editado para que todas as regiões que não continham bandas telúricas fossem identicamente igualadas a um. O espectro estudado foi então dividido pelo espectro editado da estrela quente, com o que obteve-se o espectro que utilizamos na comparação a espectros sintéticos (ver figura 10).

Para os espectros do grupo A não havia estrelas quentes de alta rotação. Mas em vista de que esses espectros tinham uma cobertura espectral maior onde eram visíveis muitas bandas telúricas e de oxigênio fortes, optou-se por usar uma estrela quente dentre as padrões espectrofotométricas para a extração das bandas telúricas. 


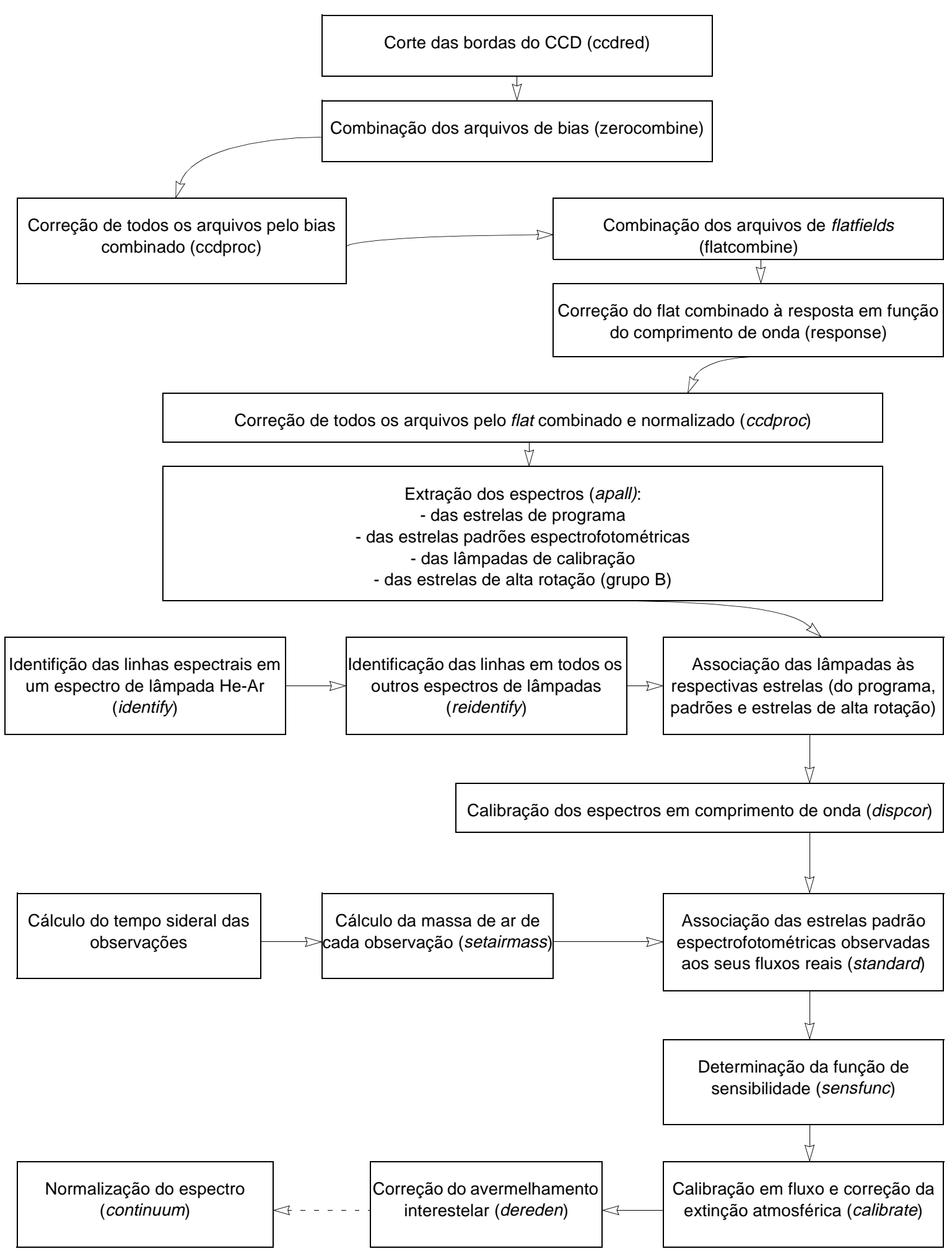

Figura 9: Fluxograma da redução dos dados espectroscópicos. Os nomes em parênteses identificam as tarefas do IRAF utilizadas. 


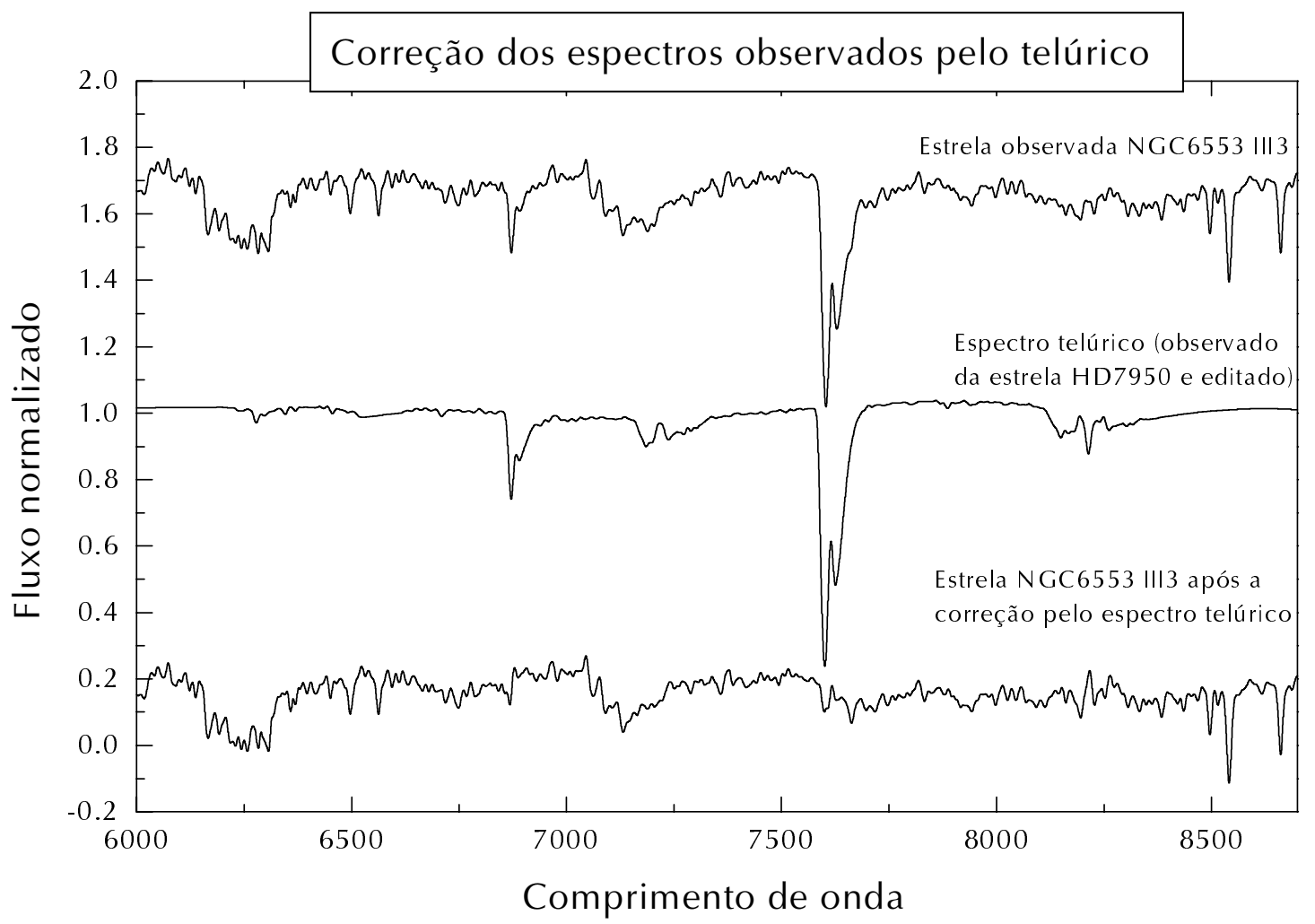

Figura 10: llustração do efeito das bandas telúricas nos espectros observados. Acima pode-se ver o espectro da estrela III3 do NGC 6553 normalizado, antes da correção pelo espectro telúrico. Ao meio tem-se o espectro observado e normalizado da estrela quente HD7950, já editado para apresentar apenas as linhas telúricas. Embaixo tem-se o espectro da estrela de programa já dividido pelo espectro telúrico, e pronto para a comparação com os espectros sintéticos.

\subsection{Espectros finais obtidos}

Ao final da redução dispunhamos dos espectros calibrados em fluxo e normalizados de 23 estrelas individuais dos aglomerados. No caso em que uma mesma estrela foi observada mais de uma vez em um mesmo grupo de observação, seus espectros foram combinados, usando-se como peso a variância dos espectros individuais (quadrado do sinal/ruído em uma região boa e sem linhas) de modo a termos um espectro de maior sinal/ruído. Os espectros obtidos ao final da redução estão apresentados na tabela 4. 
Tabela 4: Dados dos espectros utilizados.

\begin{tabular}{|c|c|c|c|c|}
\hline Estrela & $\begin{array}{l}\text { Magnitude na } \\
\text { banda } V\end{array}$ & $\begin{array}{l}\text { Tempo de } \\
\text { exposição } \\
\text { (segundos) }\end{array}$ & $\begin{array}{c}\text { Data de } \\
\text { observação } \\
\text { (dia.mês.ano) }\end{array}$ & $\begin{array}{l}\text { S/R (relação } \\
\text { sinal/ruído) }\end{array}$ \\
\hline \multicolumn{5}{|c|}{ NGC6528 } \\
\hline 11 & 16.104 & 5400 & 06.08 .92 & 187 \\
\hline \multirow[t]{2}{*}{12} & 15.733 & 1800 & 16.06 .94 & 26 \\
\hline & & 5400 & 06.08 .92 & 74 \\
\hline 15 & 15.371 & 2700 & 17.06 .94 & 19 \\
\hline 16 & 15.89 & 2700 & 17.06 .94 & 40 \\
\hline II 8 & 15.713 & 2100 & 17.06 .94 & 22 \\
\hline II 14 & 15.756 & 2700 & 17.06 .94 & 7 \\
\hline 123 & 17.19 & 1800 & 16.06 .94 & 10 \\
\hline I 24 & 16.893 & 4500 & 17.06 .94 & 17 \\
\hline 125 & 16.106 & 4500 & $16,17.06 .94$ & 40 \\
\hline \multirow[t]{2}{*}{127} & 15.904 & 1800 & 16.06 .94 & 20 \\
\hline & & 5400 & 06.08 .92 & 103 \\
\hline 136 & 16.407 & 2100 & 17.06 .94 & 21 \\
\hline II 39 & 15.882 & 2100 & 17.06 .94 & 28 \\
\hline 140 & 15.926 & 2100 & 17.06 .94 & 18 \\
\hline 142 & 16.417 & 2100 & 17.06 .94 & 28 \\
\hline 1170 & 15.849 & 1800 & 16.06 .94 & 21 \\
\hline \multicolumn{5}{|c|}{ NGC6553 } \\
\hline III 2 & 16.89 & 1800 & 16.06 .94 & 21 \\
\hline \multirow[t]{2}{*}{ III 3} & 15.82 & 3600 & $14,16.06 .94$ & 24 \\
\hline & & 5400 & 07.08 .92 & 98 \\
\hline III 17 & 15.36 & 1800 & 14.06 .94 & 32 \\
\hline \multirow[t]{2}{*}{ II 51} & 15.48 & 1800 & 17.06 .94 & 10 \\
\hline & & 5400 & 07.08 .92 & 77 \\
\hline \multirow[t]{2}{*}{ II 52} & 16.84 & 1800 & 17.06 .94 & 38 \\
\hline & & 5400 & 07.08 .92 & 232 \\
\hline II 85 & 15.52 & 3600 & $14,16.06 .94$ & 55 \\
\hline II 94 & 15.44 & 1800 & 17.06 .94 & 20 \\
\hline II 95 & 15.73 & 1800 & 17.06 .94 & 35 \\
\hline
\end{tabular}




\section{Determinação dos parâmetros astrofísicos}

O principal objetivo deste trabalho de mestrado é estudar a população estelar do bojo galáctico e contribuir para estudos que pretendem obter condições de contorno para os cenários de formação e enriquecimento químico dessa população. Esse estudo foi realizado através da determinação dos parâmetros atmosféricos de estrelas de aglomerados globulares que pertencem ao bojo, para as quais foram determinadas a velocidade radial, temperatura efetiva, gravidade superficial e metalicidade das estrelas estudadas. A seguir estão descritos os métodos e resultados encontrados na determinação dos parâmetros velocidade radial, temperatura efetiva e gravidade.

Um estudo inicial da metalicidade foi realizado através dos índices de metalicidade de LICK, e estão descritos no final deste capítulo. A determinação final das metalicidades foi realizada através da comparação a espectros sintéticos e está descrita no capítulo 5.

\subsection{Velocidades radiais}

A partir da hipótese fundamental de que as estrelas pertencentes ao aglomerado se movem em conjunto e portanto têm velocidades espaciais semelhantes, podemos utilizar a velocidade radial das estrelas individuais para segregar as estrelas que pertencem ao aglomerado das estrelas de campo. Conhecidas as estrelas que constituem o aglomerado é possível estimar a velocidade radial do aglomerado como um todo. 
A velocidade radial das estrelas usadas foram determinadas exclusivamente pelos espectros do grupo B, de maior resolução. Determinamos a velocidade radial das estrelas por dois métodos distintos:

- o método clássico que consiste na identificação de linhas atômicas, cálculo dos centróides das linhas, comparação com os valores de laboratório e determinação de $v_{\text {obs }}$ pela expressão $\frac{\Delta \lambda}{\lambda}=\frac{v}{c}, \mathrm{e} ;$

- através da determinação de uma função de correlação cruzada entre o espectro de programa e um espectro de referência de velocidade radial nula. O pico da função de correlação fornece a velocidade relativa entre os dois espectros.

Na prática, o método clássico foi empregado através da tarefa rvidlines do IRAF e o método de correlação cruzada foi empregado através da tarefa fxcor.

O método clássico de identificação de linhas possui certas desvantagens quando o espectro é de média e baixa resolução: em espectros de resolução como os de que dispomos é virtualmente impossível a existência de linhas "puras" (sem blend). Todas as linhas visíveis na verdade são blends de diversas linhas e ainda que exista numa dada região espectral uma única linha forte que predomina, o centróide real (dados todos os blends) não deve corresponder exatamente ao valor de laboratório para aquela linha. Essa situação é intensificada nas nossas estrelas uma vez que são todas estrelas frias (em torno de 4000K), onde até mesmo a localização de um contínuo sobre o qual uma linha poderia se destacar é difícil de definir. Para a determinação da velocidade radial por este método, procuramos apenas por linhas fortes e largas como o $\mathrm{H}_{\beta}$ e linhas do ferro, e no caso das estrelas mais frias, procuramos também por cabeças de bandas.

Em vista de avaliar a qualidade desses resultados também calculamos a velocidade radial pelo método de correlação cruzada. Foram usados como padrões os espectros de Jacobi et al. 
(1984), de resolução $\Delta \lambda \sim 4.5 \AA$, próxima à dos nossos espectros. Foram selecionados dentre esses, 12 espectros de tipo espectral G8 a M8. Esses espectros foram corrigidos de sua velocidade radial pelo método clássico antes de serem usados como padrões para nossas estrelas de programa. Apesar da resolução semelhante desses espectros e, portanto, deles estarem sujeitos às mesmas incertezas na determinação da velocidade radial descritas anteriormente, seu sinal/ruído maior permitiu que a velocidade radial dessas estrelas fossem determinadas e corrigidas com mais segurança do que o mesmo método para as nossas estrelas.

Foram selecionados, para cada uma das estrelas de programa, os espectros de referência de tipo espectral mais próximos ao da estrela estudada. O cálculo da função de correlação foi executada para cada par estrela programa - estrela padrão, e a velocidade radial final de cada estrela estudada foi calculada como sendo a média dos valores obtidos pela comparação com cada padrão. O erro da determinação foi considerado como sendo o desvio padrão dos valores obtidos para cada estrela. $\mathrm{Na}$ tabela 5 estão apresentados os resultados obtidos.

A estrela I 1 do NGC 6528 não foi observada em 1994, de modo que sua velocidade radial foi determinada através do método clássico com o espectro observado em 1992.

Com o intuito de comparar os resultados obtidos com cada método, foram criados no total quatro histogramas de modo a poder-se comparar cada aglomerado com cada método utilizado. Do ajuste de uma função gaussiana a cada um dos histogramas temos estimativas para as velocidades dos aglomerados como um todo. Os histogramas podem ser vistos na figura 11 e os intervalos de velocidade são de $20 \mathrm{~km} / \mathrm{s}$ para todos os histogramas.

Da análise dos histogramas pudemos perceber que:

- a estrela II-39 do NGC 6528 tem baixa probabilidade de pertinência ao aglomerado;

- as estrelas 94 II, 85 II e 51 II do NGC 6553 possuem as velocidades mais afastadas da 
Tabela 5: Velocidades heliocêntricas determinadas.

\begin{tabular}{|c|c|c|c|}
\hline \multirow[b]{2}{*}{ Estrela } & \multicolumn{2}{|c|}{ Método de correlação cruzada } & \multirow{2}{*}{$\frac{\text { Método clássico }}{\mathrm{V}_{\mathrm{r}}(\mathrm{km} / \mathrm{s})}$} \\
\hline & $\mathrm{V}_{\mathrm{r}}(\mathrm{km} / \mathrm{s})$ & $\begin{array}{l}\text { № de espectros de } \\
\text { referência usados }\end{array}$ & \\
\hline \multicolumn{4}{|c|}{ NGC6528 } \\
\hline 11 & & & $262 \pm 12$ \\
\hline 12 & $224 \pm 13$ & 8 & $239 \pm 6$ \\
\hline 15 & $136 \pm 12$ & 4 & $261 \pm 8$ \\
\hline 16 & $\begin{array}{l}232 \pm 9 \\
173 \pm 8\end{array}$ & $\begin{array}{c}8 \\
4 \text { (tipos espectrais mais } \\
\text { tardios) }\end{array}$ & $246 \pm 7$ \\
\hline II 8 & $289 \pm 10$ & 8 & $283 \pm 5$ \\
\hline II 14 & $143 \pm 12$ & 4 & $264 \pm 8$ \\
\hline 123 & $221 \pm 13$ & 8 & $251 \pm 10$ \\
\hline 124 & $238 \pm 15$ & 8 & $220 \pm 6$ \\
\hline 125 & $265 \pm 12$ & 8 & $257 \pm 6$ \\
\hline 127 & $138 \pm 17$ & 4 & $237 \pm 8$ \\
\hline 136 & $244 \pm 9$ & 8 & $249 \pm 8$ \\
\hline II 39 & $30 \pm 11$ & 8 & $17 \pm 6$ \\
\hline 140 & $246 \pm 10$ & 8 & $236 \pm 8$ \\
\hline 142 & $197 \pm 10$ & 8 & $235 \pm 6$ \\
\hline II 70 & $230 \pm 10$ & 8 & $263 \pm 6$ \\
\hline \multicolumn{4}{|c|}{ NGC6553 } \\
\hline III 2 & $-2 \pm 11$ & 8 & $-7 \pm 5$ \\
\hline III 3 & $5 \pm 11$ & 4 & $17 \pm 6$ \\
\hline III 17 & $3 \pm 12$ & 8 & $8 \pm 6$ \\
\hline II 51 & $34 \pm 27$ & 4 & $60 \pm 12$ \\
\hline II 52 & $-16 \pm 16$ & 8 & $-28 \pm 7$ \\
\hline II 85 & $35 \pm 14$ & 8 & $56 \pm 11$ \\
\hline II 94 & $-42 \pm 11$ & 8 & $-56 \pm 5$ \\
\hline II 95 & $11 \pm 21$ & 8 & $-12 \pm 8$ \\
\hline
\end{tabular}



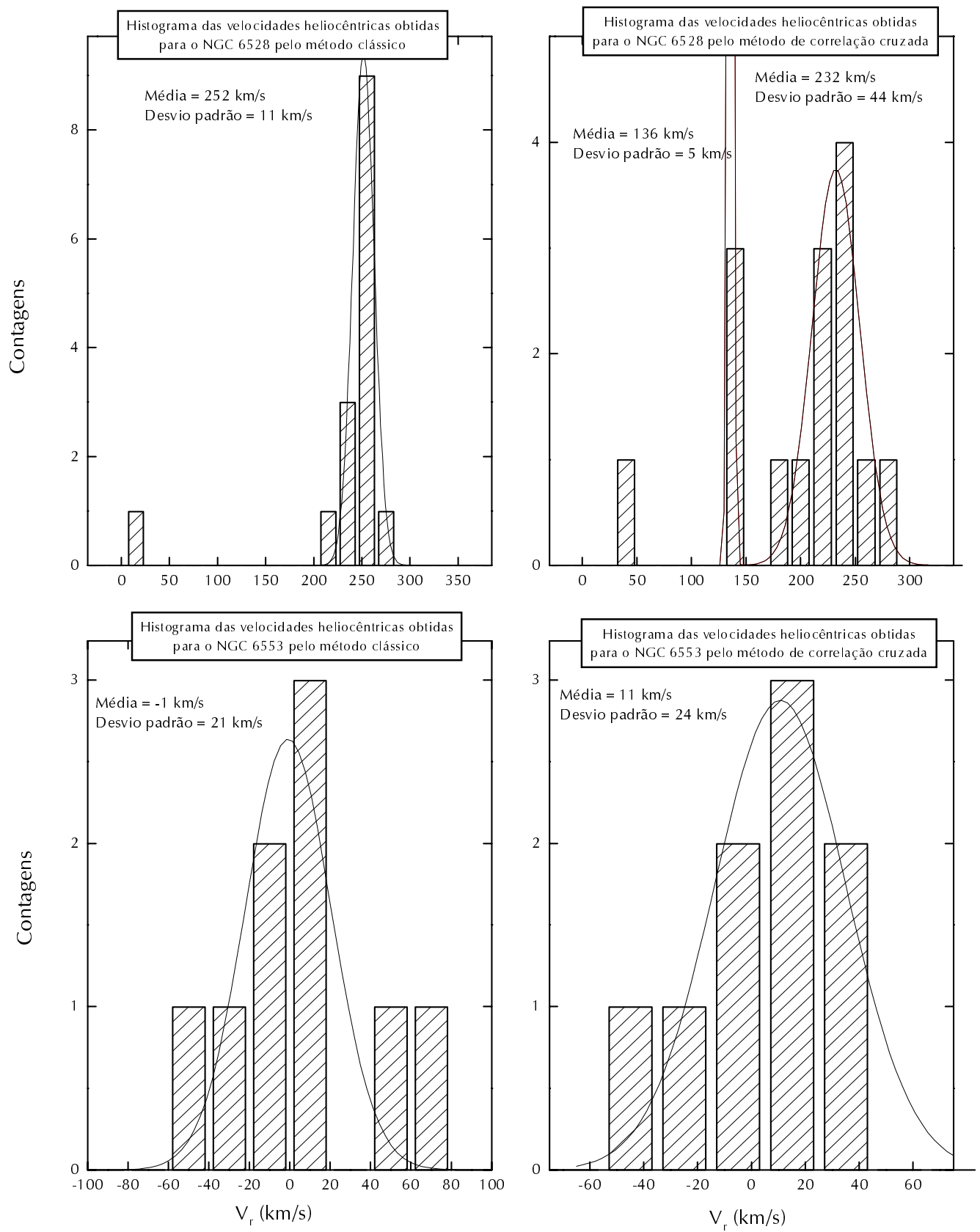

Figura 11: Os histogramas acima mostram as velocidades radiais heliocêntricas observadas no campo dos aglomerados NGC 6553 (à esquerda) e NGC 6528 (à direita). Para cada um dos aglomerados o diagrama superior refere-se à velocidade determinada pelo método clássico e o diagrama inferior refere-se à velocidade determinada pelo método de correlação cruzada. Os valores obtidos com os ajustes gaussianos podem ser observados nos próprios diagramas. 
média do aglomerado mas devido às poucas estrelas existentes para a construção do histograma, não é possível afirmar a pertinência ou não dessas estrelas;

- para o NGC 6528 do qual dispomos de mais estrelas, o método de correlação cruzada parece resultar em dois picos que não são visíveis no histograma das velocidades obtidas pelo método clássico. Ao verificarmos quais eram as estrelas que pareciam definir esse pico de velocidade mais baixa, percebemos que eram, sem exceção, estrelas de tipo espectral mais tardio. Acreditamos portanto que esse segundo pico é um resultado falso do método, que não deve ser aplicável a estrelas com fortes bandas moleculares. Essa hipótese foi testada com a estrela NGC 6528 I-6 que foi correlacionada com dois grupos de espectros de referência: um apropriado à comparação com estrelas frias e outro apropriado à comparação com estrelas quentes. De fato, como pode ser visto na tabela 5, o valor obtido com os padrões quentes é bem maior do que o valor obtido com os padrões frios, e;

- excetuando-se o pico comentado no item anterior, a velocidade média dos aglomerados determinadas pelos dois métodos concordam bem.

Na tabela 6 apresentamos a velocidade radial heliocêntrica determinada que encontramos para os aglomerados e as velocidades existentes na literatura. Podemos perceber que nossas estimativas concordam bem com os dados de outros trabalhos. 
Tabela 6: Comparação das velocidades radiais determinadas para os aglomerados com dados da literatura.

\begin{tabular}{cccl}
\hline Referência & $\begin{array}{c}\text { NGC 6553 } \\
(\mathrm{km} / \mathrm{s})\end{array}$ & $\begin{array}{c}\text { NGC 6528 } \\
(\mathrm{km} / \mathrm{s})\end{array}$ & \multicolumn{1}{c}{ Método } \\
\hline 1 & 6.4 & 218 & Clássico, alta resolução \\
2 & -24.5 & 164.8 & Compilação \\
3 & 48 & 208 & Correlação cruzada, média resolução \\
4 & 8.4 & 212 & Correlação cruzada, alta resolução \\
5 & & 189 & Correlação cruzada, média resoluçao \\
6 & -12 & 143 & Compilação, média resolução \\
7 & -5 & 160 & Correlação cruzada, média resolução \\
Este trabalho & 10 & 231 & Correlação cruzada, média resolução \\
Este trabalho & -1 & 252 & Clássico, média resolução \\
\hline
\end{tabular}

Referências: 1 Barbuy et al. (1999, 2000); 2 Harris (1996); 3 Minniti (1995); 4 Rutledge et al. (1997); 5

Armandroff \& Zinn (1988); 6 Zinn (1985); 7 Zinn \& West (1984) 


\subsection{Temperaturas}

Uma das questões críticas sobre o estudo de estrelas gigantes frias é a determinação de suas temperaturas efetivas Tefs. Tinsley (1972) comentou que uma melhor calibração das Tefs das estrelas gigantes é crucial para uma melhor compreensão da trajetória evolutiva dessas estrelas. Mais recentemente, modelos de atmosfera mais realistas são capazes de reproduzir as características globais das distribuições espectrais de energia de gigantes vermelhas em baixa resolução (Alvarez \& Plez 1998, Bessell et al. 1998, Plez et al. 1997). Ainda assim, as calibrações de Tefs em função das cores (ou quaisquer características observáveis) nas estrelas frias ainda contém muitas incertezas.

Em trabalhos como este onde se procura determinar os parâmetros atmosféricos de estrelas, uma boa determinação da temperatura efetiva é o primeiro parâmetro a ser buscado. Pequenos erros na temperatura podem fazer com que os outros parâmetros, gravidade e metalicidade, sejam mal determinados.

Neste trabalho determinamos as temperaturas das estrelas estudadas de duas formas independentes:

a) usando os dados fotométricos do HST já descritos. A temperatura é determinada pelo uso de uma calibração $\operatorname{cor} \times T_{e f}$ da literatura, adequada a estrelas frias, e;

b) através da calibração das larguras equivalentes de bandas de TiO em função de parâmetros atmosféricos.

\subsubsection{Temperaturas fotométricas}

O primeiro passo para a determinação das temperaturas efetivas a partir dos dados fotométricos foi relacionar a nomenclatura usada nos espectros do ESO (Hartwick 1975 para o 
NGC 6553 e de van den Bergh \& Younger 1979 para o NGC 6528) com os números HST das estrelas.

As observações de Hartwick e van den Bergh foram feitas em placas fotográficas e portanto não dispomos de suas imagens digitalizadas. Dessa forma, a identificação cruzada foi realizada visualmente, através da construção de um "mapa" do aglomerado com os dados fotométricos já reduzidos do HST, apenas para as magnitudes que compreendem as estrelas estudadas. Esses mapas foram visualmente comparados aos mapas apresentados nos artigos de Hartwick (1975) e van den Bergh \& Younger (1979). Os mapas dos dois aglomerados podem ser vistos nas figuras 12 e 13, ao lado de fotos digitalizadas dos aglomerados obtidas do Space Telescope Science Institute (STScI) e dos mapas fotográficos de Hartwick (1975) e van den Bergh \& Younger (1979).

A partir da tabela 5 de Bessell et al. (1998) selecionamos os valores de cores e temperaturas que correspondiam ao intervalo $0 \leq \log g \leq 2.5$ e $-0.6 \leq[\mathrm{Fe} / \mathrm{H}] \leq 0$. Com esses valores ajustamos para cada uma das cores uma função exponencial. Procuramos com este procedimento não impor hipóteses muito rígidas sobre a gravidade e a metalicidade das estrelas estudadas a não ser o que já sabemos: são todas gigantes $(\log g \leq 2.5)$ e a $[\mathrm{Fe} / \mathrm{H}]$ cobre os valores já apresentados na literatura, conforme a tabela 2. Os ajustes para as quatro cores podem ser vistos na figura 14.

As cores foram corrigidas de avermelhamento segundo os valores usados em Barbuy et al. (1998), conforme tabela 7. Da aplicação das funções ajustadas obtivemos então as temperaturas fotométricas para as estrelas conforme tabela 8.

Uma questão a ser abordada é se o fato de ter-se mantido intervalos seguros - e portanto razoavelmente grandes - de gravidade e $[\mathrm{Fe} / \mathrm{H}]$ nos ajustes possa ter aumentado consideravelmente o erro dessas medidas. Uma estimativa desses erros foi feita graficamente 

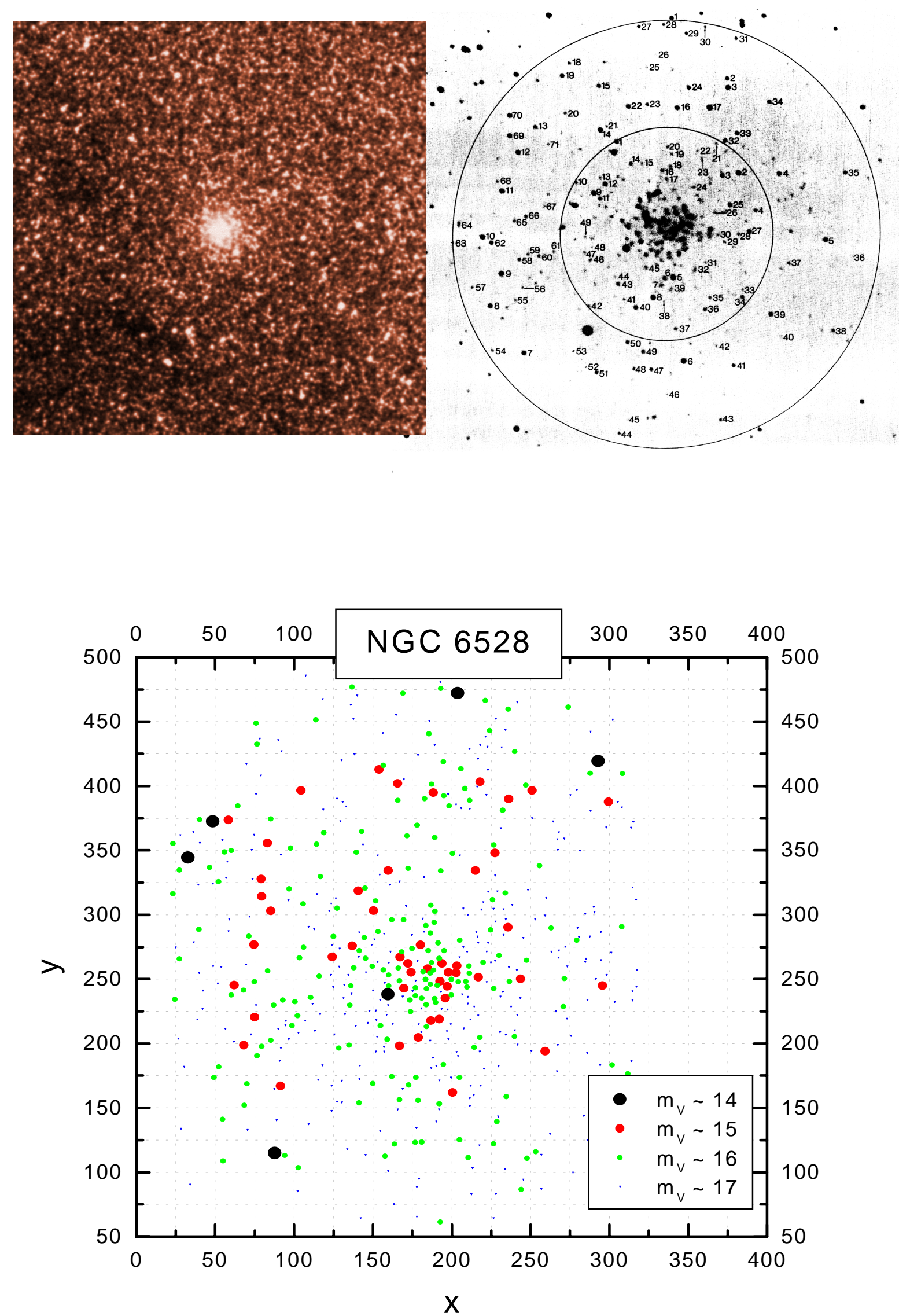

Figura 12: No alto à esquerda: imagem digitalizada do aglomerado NGC 6528 obtida no STScl. Alto à direita: mapa original de van den Bergh \& Younger (1979) que define as nomenclaturas usadas neste trabalho. Inferior: mapa criado com os dados do HST com o objetivo de realizar a identificação cruzada entre as diferentes nomenclaturas. 

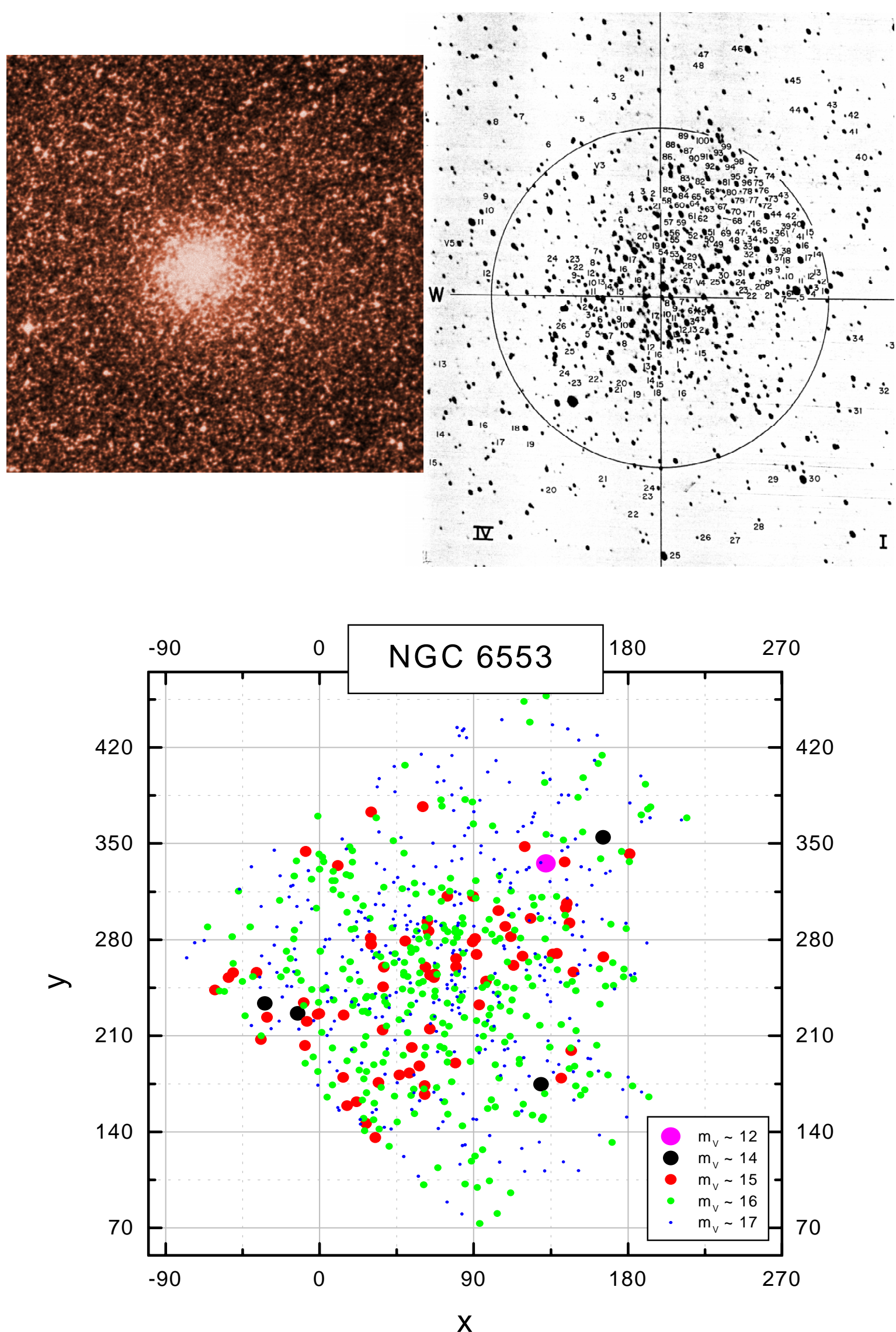

Figura 13: No alto à esquerda: imagem digitalizada do aglomerado NGC 6553 obtida no STScl. Alto à direita: mapa original de Hartwick (1975) que define as nomenclaturas usadas neste trabalho. Inferior: mapa criado com os dados do HST com o objetivo de realizar a identificação cruzada entre as diferentes nomenclaturas. 


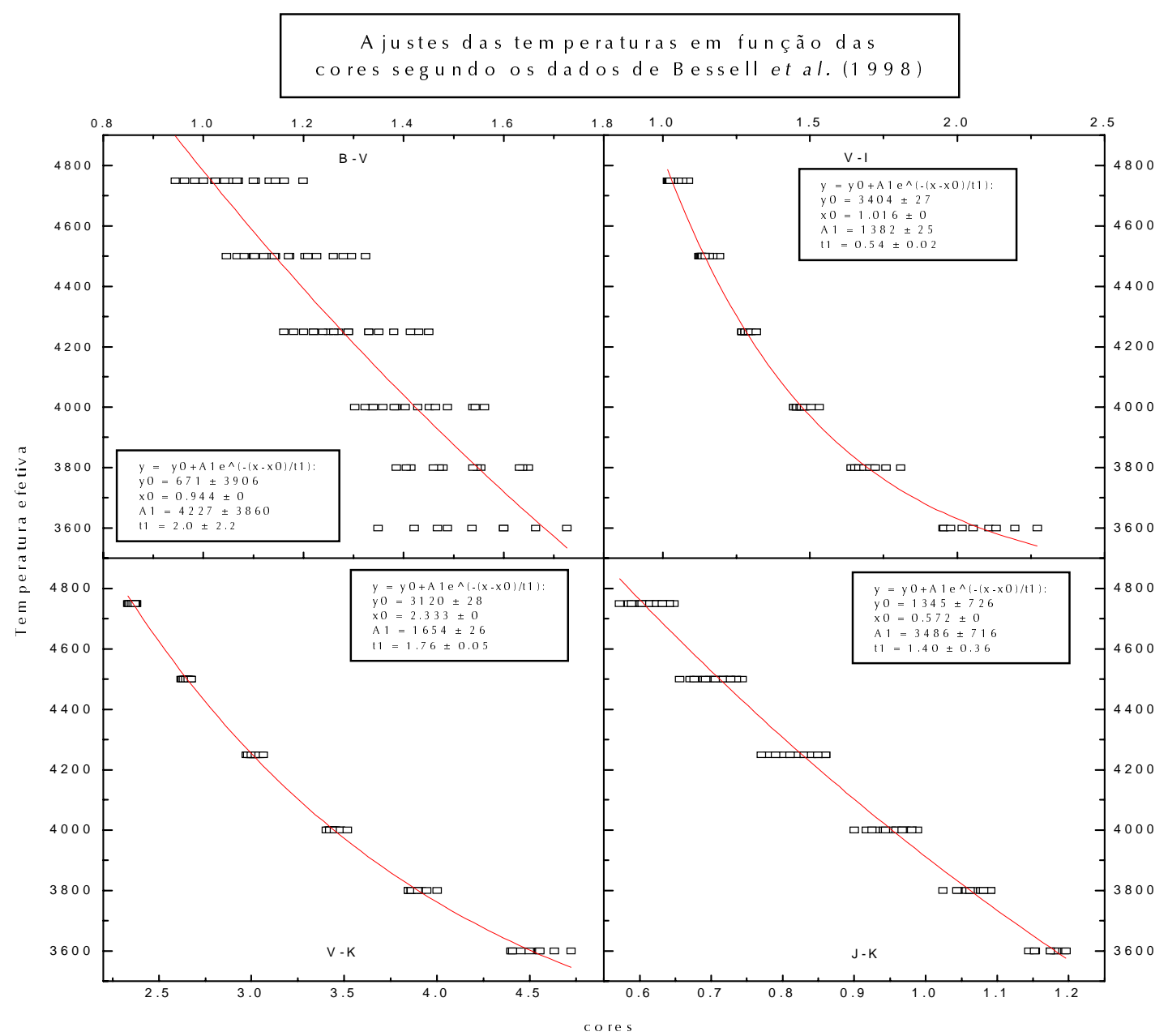

Figura 14: Ajustes utilizados na determinação das temperaturas fotométricas. Os dados usados foram os de Bessell et al. (1998). Para cada ajuste são apresentados os coeficientes ajustados e os respectivos erros. 
através do seguinte critério: para cada ajuste $T_{e f} \times$ cor, foi avaliado qual a área total coberta nos gráficos pelos pontos. Considerando que o erro na cor é desprezível frente ao erro da calibração, avaliamos o erro da medida como sendo o intervalo de temperaturas coberto para um dado valor de cor.

Esse procedimento está exemplificado na figura 15 que corresponde ao ajuste $T_{e f} \times B-V$, que corresponde ao maior erro entre as calibrações, como seria de se esperar, uma vez que a cor $B-V$ não é adequada à determinação de temperatura de estrelas frias quando desconhecemos a gravidade e a metalicidade.

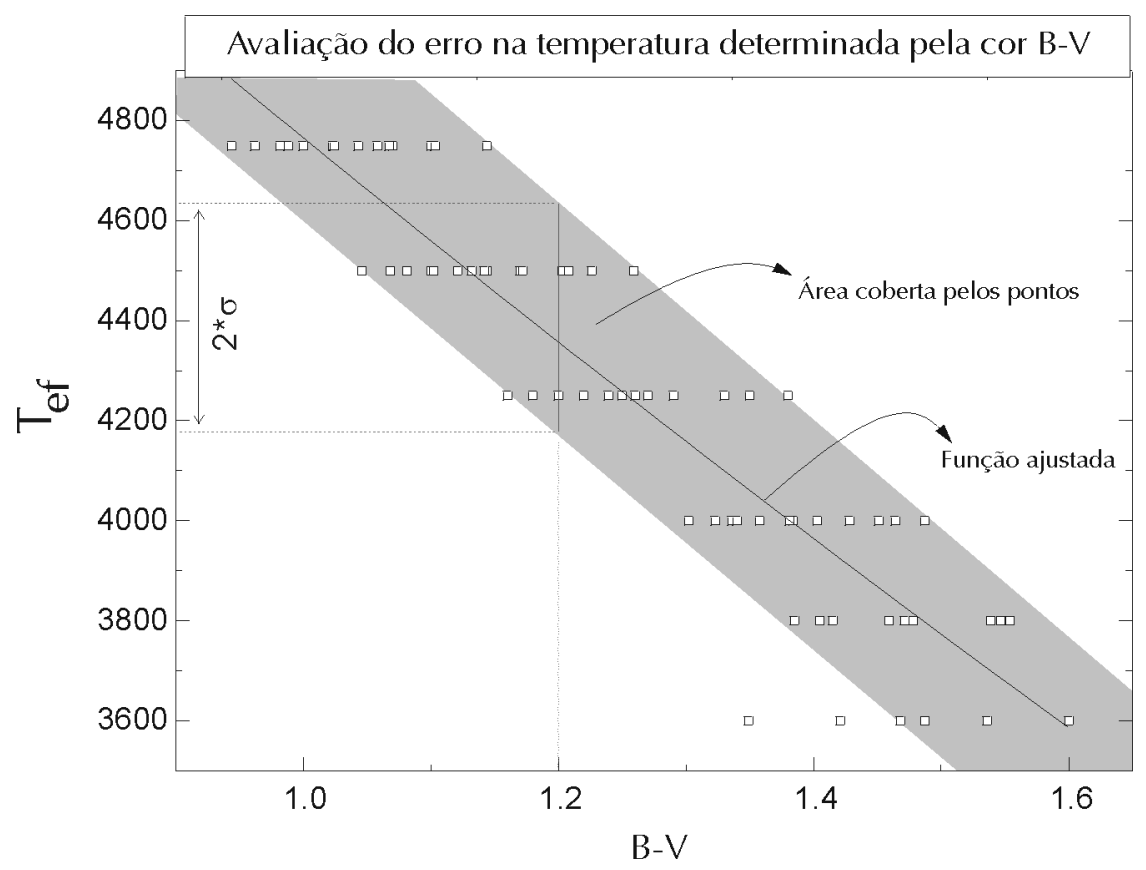

Figura 15: llustração do método usado para avaliação do erro das calibrações $T_{e f} x$ cor.

Os erros foram então estimados em $\pm 250 \mathrm{~K}$ para a calibração em função da cor B-V, $\pm 100 \mathrm{~K}$ para V-I, $\pm 75 \mathrm{~K}$ para $\mathrm{J}-\mathrm{K}$ e $\pm 40 \mathrm{~K}$ para $\mathrm{V}-\mathrm{K}$, valores típicos na determinação de temperaturas por cor.

Esses erros são estimados unicamente a partir do ajuste realizado com os dados de Bessell et al. (1998). A incerteza total deveria considerar os erros nas cores, que segundo 


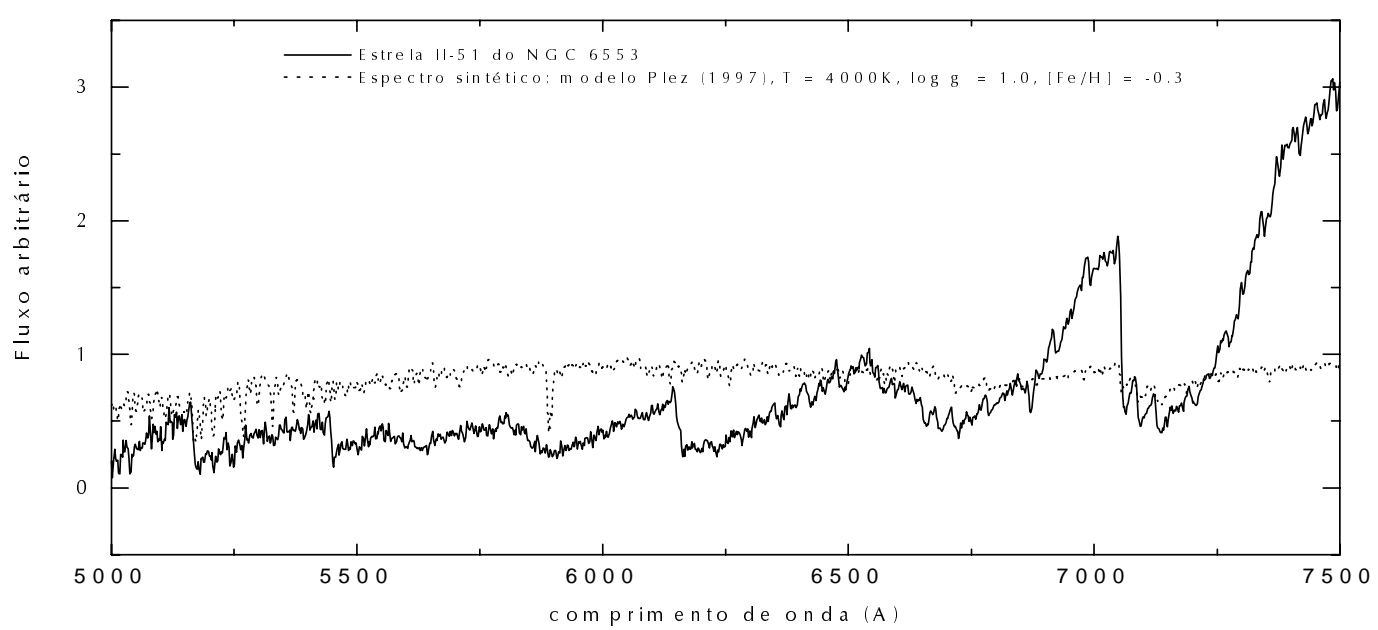

Figura 16: Comparação do espectro observado da estrela II-51 do NGC 6553 (temperatura fotométrica de 3900K) ao espectro sintético de parâmetros similares. É visível que a temperatura fotométrica estimada para esta estrela está muito distante do valor da temperatura efetiva real. Essa estrela é o caso mais extremo dentre um total de 9 estrelas cujas temperaturas fotométricas diferem significativamente da temperatura efetiva.

Ortolani et al. (1995) é devido essencialmente ao avermelhamento diferencial que pode chegar a 0.20 mag ao longo do campo do aglomerado, e a incerteza da própria calibração feita por Bessell et al. (1998), baseada em diversos modelos de atmosfera.

De posse dessas primeiras estimativas de temperatura baseadas nas cores pode-se detectar que para as estrelas de tipo espectral mais tardio as temperaturas fotométricas não correspondiam às temperaturas efetivas reais. Para ilustrar este fato está apresentado na figura 16 o espectro da estrela II-51 do NGC 6553, cuja temperatura fotométrica média é de 3900K, em comparação a um espectro sintético de parâmetros $\left(\mathrm{T}_{\mathrm{ef}}, \log \mathrm{g},[\mathrm{Fe} / \mathrm{H}]\right)=(4000,1.0,-0.3)$.

Tabela 7: Valores de avermelhamento e excesso de cor utilizados.

\begin{tabular}{|c|c|c|c|c|c|c|c|c|}
\hline Aglomerado & $E(V-I)$ & $\begin{array}{l}E(V-I) / \\
E(B-V)\end{array}$ & $\mathrm{E}(\mathrm{B}-\mathrm{V})$ & $\mathrm{R}$ & $A_{V}$ & $M_{V}^{H B}$ & $\left(\mathrm{~V}-\mathrm{M}_{\mathrm{V}}\right)$ & $(\mathrm{m}-\mathrm{M})_{0}$ \\
\hline NGC 6528 & 0.68 & 1.31 & 0.52 & 3.46 & 1.80 & 0.95 & 16.25 & 14.45 \\
\hline NGC 6553 & 0.95 & 1.31 & 0.7 & 3.47 & 2.43 & 0.95 & 15.97 & 13.54 \\
\hline
\end{tabular}


Tabela 8: Temperaturas efetivas determinadas a partir dos dados fotométricos.

\begin{tabular}{|c|c|c|c|c|}
\hline Estrela & $\mathrm{T}(\mathrm{V}-\mathrm{I})(\mathrm{K})$ & $\mathrm{T}(\mathrm{B}-\mathrm{V})(\mathrm{K})$ & $\mathrm{T}(\mathrm{J}-\mathrm{K})(\mathrm{K})$ & $\mathrm{T}(\mathrm{V}-\mathrm{K})(\mathrm{K})$ \\
\hline \multicolumn{5}{|c|}{ NGC 6528} \\
\hline 11 & 4305 & 4449 & & \\
\hline 12 & 3673 & 3883 & & \\
\hline 15 & 3933 & 3996 & & \\
\hline 16 & 3451 & 3890 & & \\
\hline 118 & 3963 & 3992 & & \\
\hline II 14 & 3457 & 3958 & & \\
\hline 123 & 4783 & 4770 & & \\
\hline I 24 & 4883 & 4707 & & \\
\hline I 25 & 4074 & 4092 & & \\
\hline 127 & 3512 & 3843 & & \\
\hline 136 & 4218 & 4216 & & \\
\hline 40 & 4084 & 4137 & & \\
\hline 42 & 3999 & 4149 & & \\
\hline II 70 & 3810 & 3951 & & \\
\hline \multicolumn{5}{|c|}{ NGC 6553} \\
\hline III 2 & 4828 & & 4809 & 4559 \\
\hline III 3 & 4015 & & 4221 & 3939 \\
\hline III 17 & 3606 & & 3966 & 3611 \\
\hline II 51 & 3885 & & 3966 & 3856 \\
\hline II 52 & 4881 & & 4593 & 4678 \\
\hline II 85 & 3912 & & 4140 & 3835 \\
\hline II 94 & 3506 & & 3984 & 3432 \\
\hline II 95 & 3804 & & 4180 & 3740 \\
\hline
\end{tabular}


Dessa forma, era necessário uma determinação independente das temperaturas.

\subsubsection{Temperatura através da calibração TiO $\times \mathrm{T}_{\text {ef }}$}

As bandas de TiO são responsáveis pela maior parte da opacidade na região espectral compreendida entre o óptico e o infravermelho próximo nas atmosferas de estrelas com $\mathrm{T}_{\mathrm{ef}}<$ 4000K, dominando quase integralmente os espectros das estrelas M mais frias (Allard \& Hauschildt 1995, Frogel \& Whitford 1987). Como essas estrelas contribuem com uma parcela da luz integrada de galáxias elípticas e aglomerados globulares, as bandas de TiO aparecem claramente nos espectros integrados destes sistemas (Bica \& Alloin, 1986).

Em virtude da alta sensibilidade das bandas de TiO à variação da temperatura efetiva, elas se tornaram a base do sistema de classificação espectral de estrelas M (Lockwood 1972, Keenan 1963, Sharpless 1956). Um estudo das bandas de TiO como função de temperatura efetiva, gravidade superficial e metalicidade foi realizado por Milone \& Barbuy (1994) baseado nos modelos de atmosfera de Kurucz (1992) e por Schiavon \& Barbuy $(1999,2000)$ baseado em modelos de Kurucz (1992) e Plez $(1992,1997)$, abrangendo portanto um intervalo maior de temperaturas.

Os índices de $\mathrm{TiO}$ medidos neste trabalho (tabela 9) são diferentes daqueles apresentados em Schiavon \& Barbuy $(1999,2000)$ de modo que foram necessárias novas medidas e calibrações. Isso permitiu que as medidas dos espectros sintéticos, com as quais as calibrações foram feitas, fossem realizadas exatamente da mesma maneira que foram feitas as medidas nos índices das estrelas estudadas. O procedimento de medida dos índices de TiO (que é o mesmo utilizado nas medidas dos índices de LICK em 4.4), é feito segundo o método de medida de índices descrito em Faber et al. (1985). O índice de absorção é definido por uma banda passante e por dois contínuos (um de cada lado da banda) e a medida consiste dos 
seguintes passos:

a) calcula-se o ponto médio de cada um dos contínuos;

b) traça-se uma reta que passa por esses dois pontos, e;

c) usando como limites a reta traçada pelos contínuos e o intervalo espectral da banda passante, mede-se a largura equivalente em $\AA$.

$\mathrm{O}$ índice $\mathrm{Mg}_{2}$ é ainda convertido em magnitudes segundo $m a g=-2.5 \log \left(F_{s} / F_{t}\right)$, onde $F_{t}$ é a área total definida pelo intervalo em comprimento de onda da banda passante e a reta definida a partir dos contínuos e $F_{s}$ é a área total subtraída da área da banda. Uma representação da medida dos índices pode ser visto na figura 17.

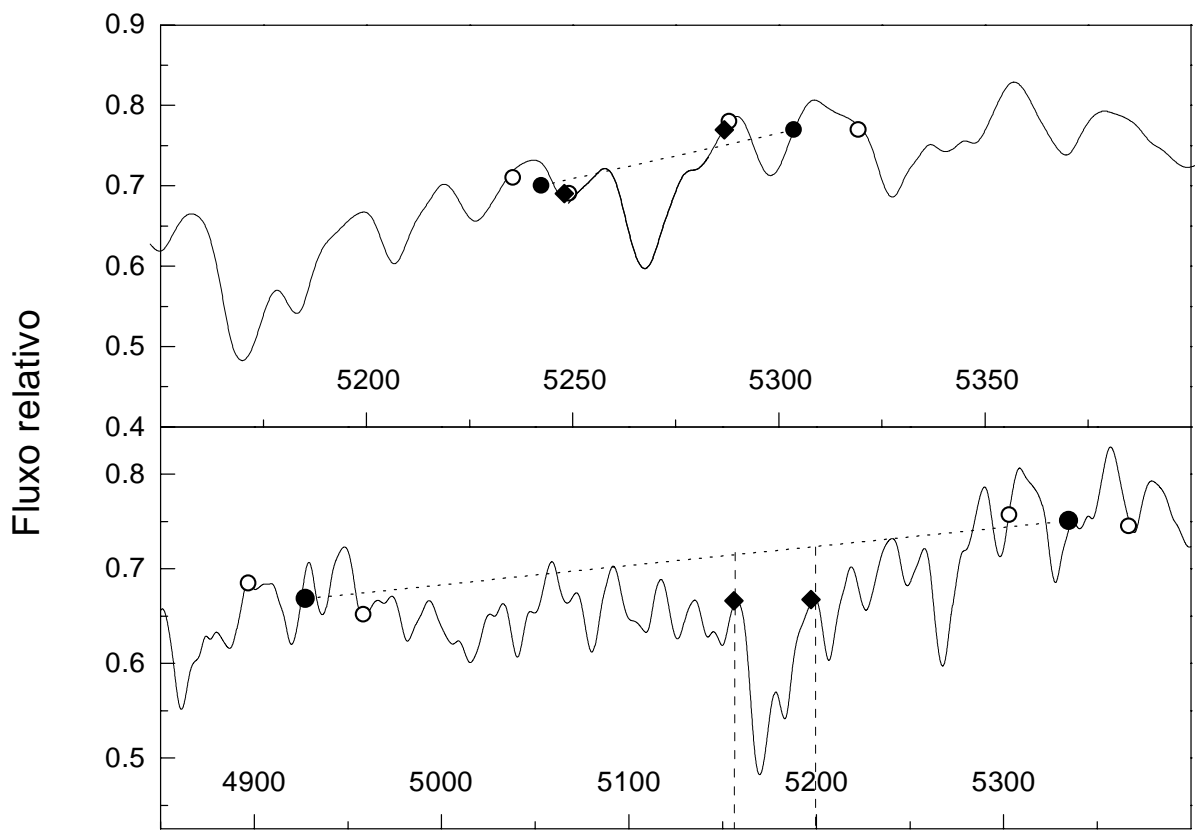

Comprimento de onda $(\AA)$

Figura 17: Representação da medida dos índices Fe5270 e $\mathrm{Mg}_{2}$ para a estrela NGC 6528 I 27. Os círculos brancos indicam os limites dos contínuos, os círculos pretos representam os pontos médios de cada contínuo e a reta pontilhada define o contínuo local. Os diamantes indicam os limites da banda passante. No painel superior, a linha mais grossa sobre o espectro indica a região para a qual será calculada a largura equivalente. No painel inferior, as linhas tracejadas e pontilhadas definem então a região para o cálculo em magnitudes da banda. 
Para a realização desse procedimento foi escrita uma rotina em IRAF que recebe como parâmetros de entrada os comprimentos de onda iniciais e finais dos contínuos e banda passante, e mede os índices para um dado conjunto de espectros em formato IMH ou FITS. A rotina foi testada com observações de padrões espectrais do LICK feitas por Dr. Bruno Castilho e Paula Coelho durante um turno de observações de galáxias (projeto de B. Barbuy, B. Castilho, R. Schiavon, P. Coelho) em março de 2000 no LNA.

Tabela 9: Definições utilizadas para os índices de TiO.

\begin{tabular}{cccc}
\hline $\begin{array}{c}\text { Identificação do } \\
\text { Índice }\end{array}$ & Contínuo azul $(\AA)$ & Banda $(\AA)$ & $\begin{array}{c}\text { Contínuo vermelho } \\
(\AA)\end{array}$ \\
\hline TiO2 & $6033.6-6050.6$ & $6300.0-6455.0$ & $6525.0-6538.0$ \\
TiO3 & $6525.0-6539.0$ & $6617.6-6860.0$ & $7036.0-7046.6$ \\
TiO4 & $7036.0-7046.6$ & $7053.0-7163.0$ & $7534.2-7546.8$ \\
\hline
\end{tabular}

As calibrações foram feitas com a grade de espectros sintéticos calculada em Schiavon (1998), a mesma utilizada em Schiavon \& Barbuy (1999, 2000). Os espectros sintéticos utilizados possuíam $\Delta \lambda \sim 2 \AA$. Como é conhecido que o valor de um índice espectral medido é dependente da resolução os espectros sintéticos foram convoluídos para $\Delta \lambda \sim 4 \AA$ e $\Delta \lambda \sim 8 \AA$, que são as resoluções dos espectros estudados.

O comportamento dos índices em função dos parâmetros atmosféricos pode ser visto na figura 18. Podemos ver que o índice é altamente dependente da temperatura (como esperado) para valores inferiores a $3600 \mathrm{~K}$. Para $T_{e f} s$ superiores a $4000 \mathrm{~K}$, no entanto, começa a haver uma degenerescência que impede a determinação precisa de temperaturas e onde pequenos erros nos valores dos índices podem causar variações muito grandes na temperatura. Isso sugere que esse método de determinação de temperatura é robusto apenas para $T_{e f}<4000 \mathrm{~K}$, justamente a 
Temperaturas em função dos índices de TiO para $\Delta \lambda \sim 8 \AA$

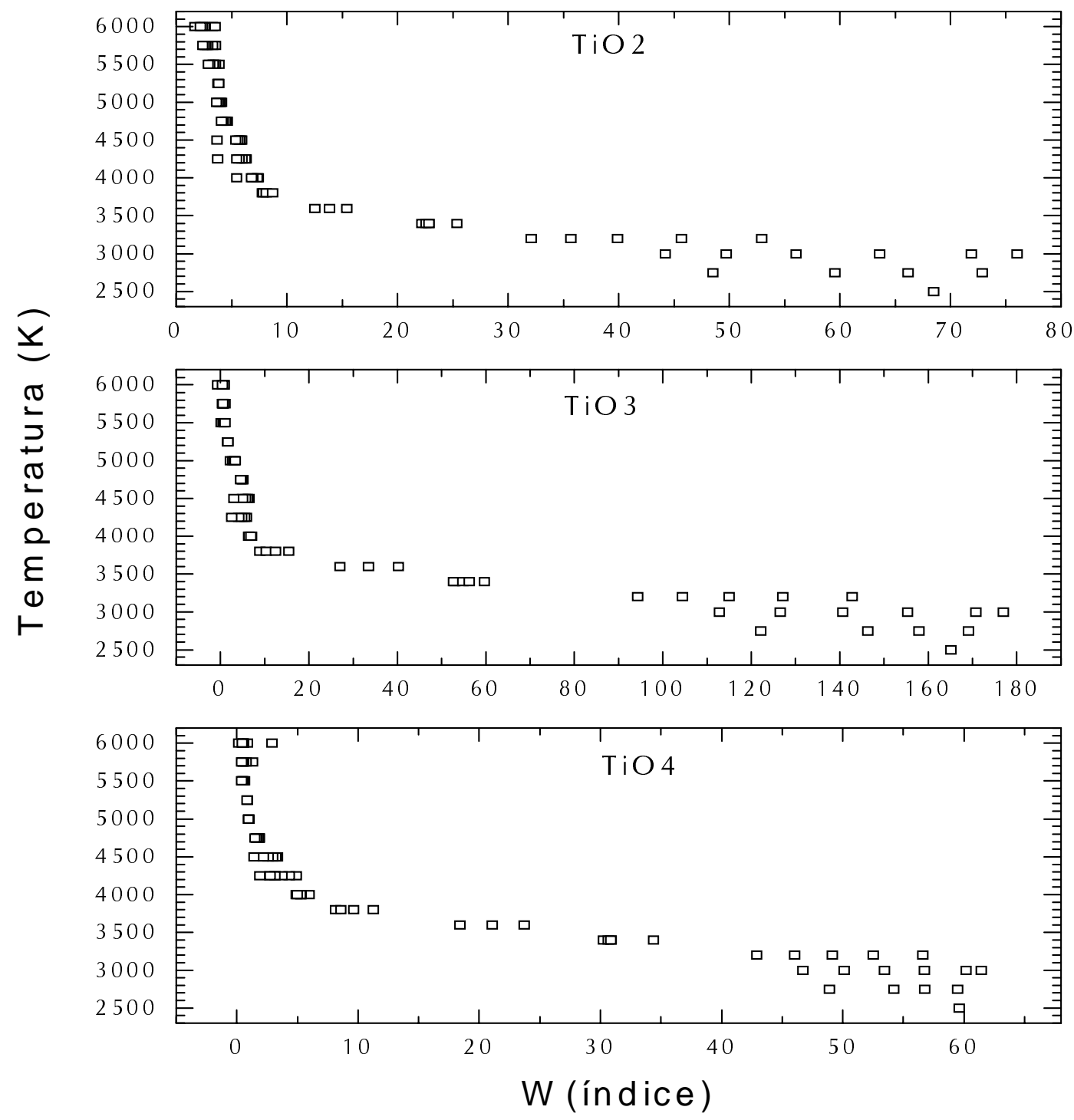

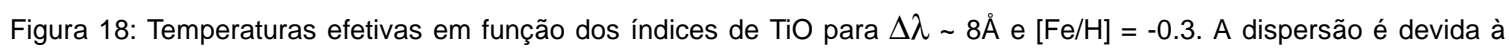
gravidade superficial que compreende o intervalo $-0.5 \leq \log \mathrm{g} \leq 2.5$. 
região onde a calibração por cor parece falhar.

Devido ao comportamento da curva próximo à temperatura de $3700 \mathrm{~K}$, nenhuma função de baixa ordem pode ajustar bem todo o intervalo de índices medidos. Funções polinomiais da forma $\mathrm{TiO}=f\left(T_{e p} \log g,[\mathrm{Fe} / \mathrm{H}]\right)$ podem ser determinadas como é mostrado no apêndice I, mas uma vez que não dispomos de medidas independentes de $\log g$ e $[\mathrm{Fe} / \mathrm{H}]$, precisou-se de um ajuste que só dependa do valor medido do índice. Para isso, dividiu-se a amostra dos índices medidos em duas, uma de $T_{e f} s$ superiores e outra de $T_{e f} s$ inferiores a $3750 \mathrm{~K}$. Para cada uma das regiões foi ajustada uma função polinomial distinta, e procurou-se manter uma certa continuidade em torno de $T_{e f}=3750 \mathrm{~K}$. Os índices foram restringidos ao intervalo de temperatura $3000 \mathrm{~K}<T_{e f}<5000:$ acima desse intervalo a degenerescência dos índices em função da temperatura é muito acentuada e abaixo de $3000 \mathrm{~K}$ a forte dependência com $\log g$ impede que uma função razoável possa ser ajustada apenas em termos de $T_{e f}=$ f(índice). Um exemplo desse ajuste pode ser visto na figura 19.

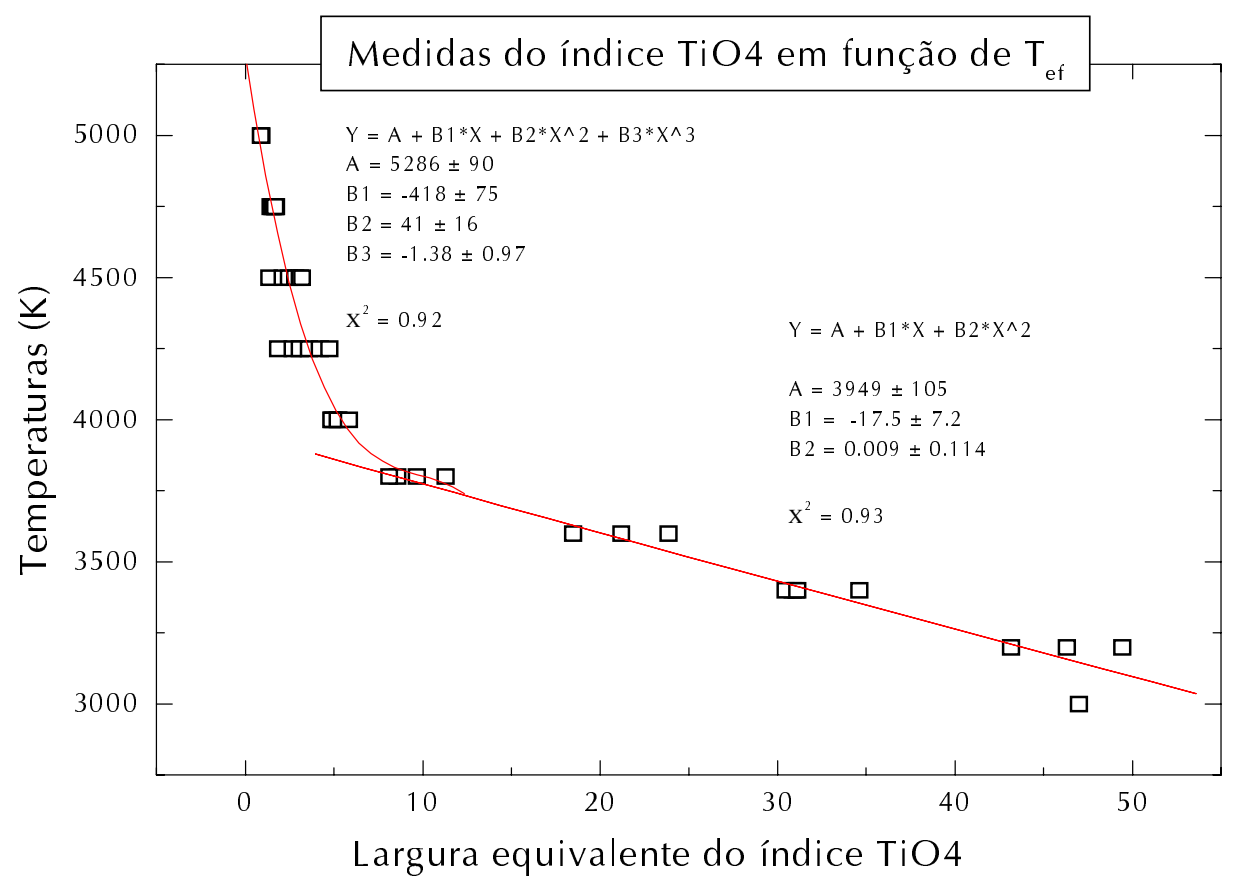

Figura 19: Ajuste do índice de TiO4 em função da temperatura. Foram realizados dois ajustes distintos cujos coeficientes podem ser vistos no próprio gráfico. 
Com os ajustes obtidos desta forma temos as temperaturas apresentadas na tabela 10 . Todos os índices de TiO da estrela NGC 6553 II 95 estavam fora dos limites do ajuste e indicavam uma temperatura superior a $5000 \mathrm{~K}$. Apesar das cores fotométricas apresentarem valores em torno de $4000 \mathrm{~K}$, a intensidade da linha $\mathrm{H}_{\alpha}$ no espectro desta estrela de fato era compatível com estrelas mais quentes.

Os desvios padrões obtidos para o grupo $\mathrm{A}(\Delta \lambda \sim 8 \AA)$ de espectros é de $200 \mathrm{~K}$ e para o grupo B $(\Delta \lambda \sim 4 \AA)$ é de $300 \mathrm{~K}$, sugerindo que os índices são bastante dependentes da relação sinal/ruído dos espectros (os espectros do grupo A têm sinal/ruído bem superior) e da resolução. Essa dependência com a resolução foi discutida em Milone \& Barbuy (1994) e Milone et al. (2000).

A temperatura efetiva final de cada estrela foi adotada como sendo a média das temperaturas fotométricas (exceto a cor $\mathrm{B}-\mathrm{V}$ ) para estrelas cuja $T_{e f}$ média de TiO fosse maior que 3750K (dispersão típica de 150K). Para as outras estrelas foi adotada a média das temperaturas de TiO (dispersão típica de 200K).

O valores finais adotados então para as estrelas estão apresentados na tabela 11. Para finalizar a discussão de temperaturas, está apresentado na figura 20 uma comparação dos espectros de estrelas de diferentes temperaturas do NGC 6528. É visível o aumento das bandas de TiO quanto mais baixas são as temperaturas, de acordo com a explicação dada no capítulo 2 para o arco formado pelo RGB nos DCMs dos aglomerados. 
Tabela 10: Temperaturas obtidas através dos índices de TiO. As temperaturas em branco correspondem a índices que estavam fora dos limites dos ajustes.

\begin{tabular}{|c|c|c|c|}
\hline Estrela & $\mathrm{T}_{\mathrm{ef}}(\mathrm{TiO} 2)$ & $\mathrm{T}_{\mathrm{ef}}(\mathrm{TiO} 3)$ & $\mathrm{T}_{\text {ef }}(\mathrm{TiO} 4)$ \\
\hline \multicolumn{4}{|c|}{ NGC 6528} \\
\hline 11 & 4123 & - & 3990 \\
\hline 12 & 3922 & 3698 & 3506 \\
\hline 15 & 3468 & 3053 & - \\
\hline 16 & 3612 & 3585 & 3405 \\
\hline II 8 & 3776 & 4049 & 3789 \\
\hline II 14 & 3468 & 3053 & - \\
\hline 123 & 5245 & - & 4536 \\
\hline I 24 & 4710 & - & 4469 \\
\hline 125 & 4287 & - & 4000 \\
\hline I 27 & 3673 & 3280 & 3001 \\
\hline 136 & 4852 & - & 4147 \\
\hline 40 & 4794 & - & 4528 \\
\hline 42 & 4474 & - & 3986 \\
\hline 1170 & 3569 & 3635 & - \\
\hline \multicolumn{4}{|c|}{ NGC6553 } \\
\hline III 2 & 4259 & 3842 & 3776 \\
\hline III 3 & 3782 & 3800 & 3775 \\
\hline III 17 & 4052 & 3698 & 3503 \\
\hline II 51 & 3281 & 3206 & - \\
\hline II 52 & 4241 & 3703 & 3752 \\
\hline II 85 & 4434 & - & 4227 \\
\hline II 94 & 4802 & 4408 & 3832 \\
\hline II 95 & - & - & - \\
\hline
\end{tabular}


Tabela 11: Temperaturas finais determinadas para as estrelas. Os desvios típicos estão estimados em $150 \mathrm{~K}$ para $\mathrm{T}_{\text {ef }}>3750$ e $200 \mathrm{~K}$ para $\mathrm{T}_{\text {ef }}<3750 \mathrm{~K}$.

\begin{tabular}{|c|c|}
\hline Estrela & $\mathrm{T}_{\text {ef }}$ \\
\hline \multicolumn{2}{|c|}{ NGC 6528} \\
\hline 11 & 4300 \\
\hline 12 & 3700 \\
\hline 15 & 3300 \\
\hline 16 & 3600 \\
\hline II 8 & 3900 \\
\hline II 14 & 3300 \\
\hline 123 & 4800 \\
\hline 124 & 4900 \\
\hline 125 & 4100 \\
\hline 127 & 3400 \\
\hline 136 & 4200 \\
\hline 140 & 4100 \\
\hline 142 & 4000 \\
\hline 1170 & 3700 \\
\hline \multicolumn{2}{|c|}{ NGC 6553} \\
\hline III 2 & 4700 \\
\hline III 3 & 3900 \\
\hline III 17 & 3700 \\
\hline II 51 & 3200 \\
\hline II 52 & 3900 \\
\hline II 85 & 4000 \\
\hline II 94 & 3600 \\
\hline II 95 & $>5000$ \\
\hline
\end{tabular}




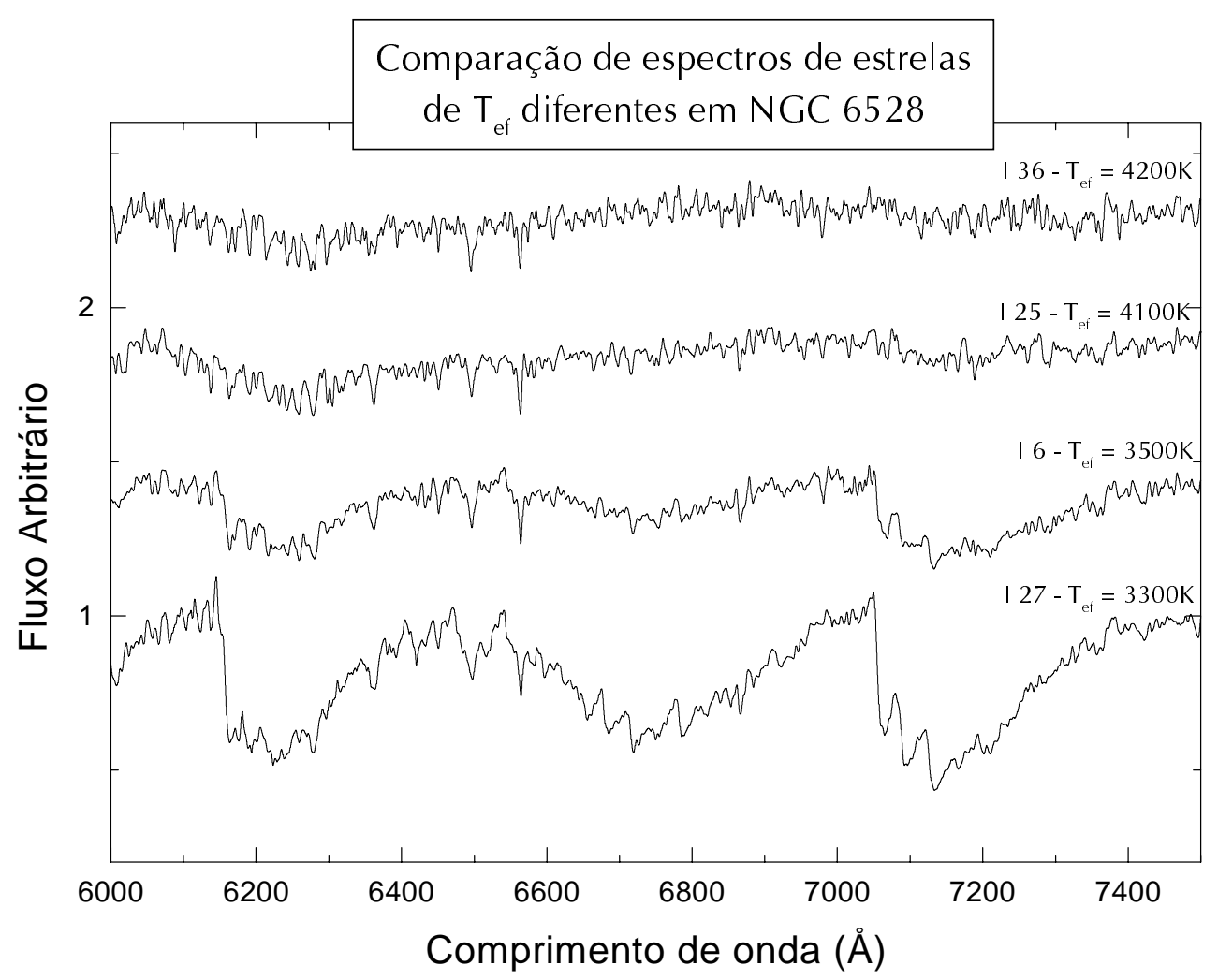

Figura 20: Comparação entre espectros de estrelas de temperaturas diferentes. O formato de arco apresentado pelo RGB desses aglomerados foi explicado como sendo devido a grande absorção devida às bandas de TiO nas estrelas mais frias desses aglomerados ricos em metais. A evolução dessa absorção com a temperatura é visível na figura acima. 


\subsection{Gravidades superficiais}

De posse das temperaturas efetivas, o segundo passo no estudo dessas estrelas é a determinação da gravidade superficial.

A gravidade superficial foi determinada através da relação clássica:

$$
\log g=4.44+4 \log \frac{T_{e f}}{T_{\odot}}+0.4\left(M_{b o l}-M_{b o l_{\odot}}\right)+\log m
$$

Onde: $M_{b o l} \odot=4.67$ é a magnitude bolométrica do Sol;

$T_{\odot}=5770 \mathrm{~K}$ é a temperatura efetiva do Sol;

$M_{b o l}$ é a magnitude bolométrica da estrela;

$T_{e f}$ é a temperatura efetiva da estrela, e;

$m=0.8 m_{\odot}$ é a massa da estrela em massas solares.

O correção bolómetrica (CB) utilizada para cada estrela foi calculada utilizando-se a tabela 5 de Bessell et al. (1998). À semelhança do cálculo de temperaturas, foi ajustada uma função polinomial usando como dados os valores de $\mathrm{CB}(\mathrm{V})$ e V-I que correspondessem ao intervalo $0 \leq \log g \leq 2.5$ e $0 \leq[M / H] \leq-0.6$. O ajuste pode ser visto na figura 21. Para as estrelas I 2, I 5, I 6, I 14, I 27, I 70 do NGC 6528 e II 51, II 94 e II 95 do NGC 6553, que apresentaram problemas na temperatura fotométrica, foram consideradas cores típicas para as temperaturas efetivas adotadas segundo a tabela 11. Os resultados encontrados para a gravidade superficial podem ser vistos na tabela 12 .

O erro na gravidade foi determinado através da fórmula tradicional de propagação de erros, $\sigma_{\log g}^{2}=\left(\frac{4 \log e}{T_{e f}}\right)^{2} \sigma_{T_{e f}}^{2}+\left(\frac{\log e}{m}\right)^{2} \sigma_{m}^{2}+0.4^{2}{\sigma_{M}}_{b o l}^{2}+0.4^{2} \sigma_{M_{b o l}}^{2}+\left(\frac{4 \log e}{T_{\odot}}\right)^{2} \sigma_{\odot}^{2}$. 


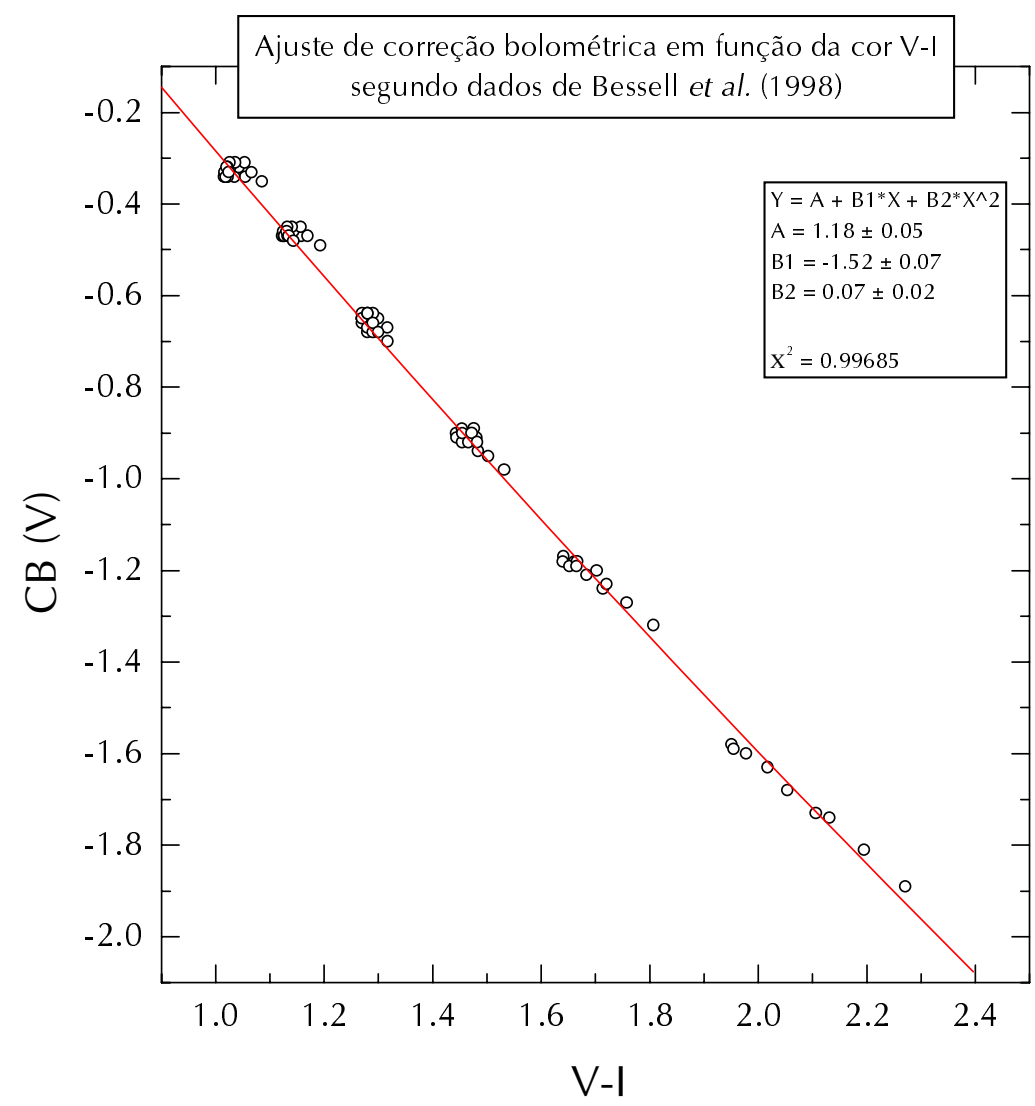

Figura 21: CB em função da cor V-I segundo dados de Bessell et al. (1998). Os valores do ajuste podem ser vistos no próprio diagrama.

Considerando nulos os erros relativos aos dados do Sol, supondo a incerteza na massa como sendo 0.1 massas solares e a incerteza em $M_{b o l}$ como sendo 0.2 mags, o erro em log g é estimado em 0.3 . 
Tabela 12: Valores de $\log g$ determinados

\begin{tabular}{|c|c|c|}
\hline Estrela & $M_{b o l}$ & $\log g$ \\
\hline \multicolumn{3}{|c|}{ NGC 6528} \\
\hline 11 & -0.8 & 1.7 \\
\hline 12 & -2.0 & 0.9 \\
\hline 15 & -3.5 & 0.0 \\
\hline 16 & -3.0 & 0.4 \\
\hline II 8 & -1.5 & 1.2 \\
\hline II 14 & -3.2 & 0.2 \\
\hline 123 & 0.6 & 2.4 \\
\hline 24 & 0.4 & 2.3 \\
\hline 25 & -1.0 & 1.5 \\
\hline 127 & -3.0 & 0.3 \\
\hline 136 & -0.5 & 1.7 \\
\hline 140 & -1.2 & 1.4 \\
\hline 42 & -0.8 & 1.5 \\
\hline II 70 & -2.4 & 0.7 \\
\hline \multicolumn{3}{|c|}{ NGC 6553} \\
\hline III 2 & 0.5 & 2.1 \\
\hline III 3 & -1.0 & 1.0 \\
\hline III 17 & -2.3 & 0.3 \\
\hline II 51 & -3.1 & -0.5 \\
\hline II 52 & -0.1 & 1.3 \\
\hline II 85 & -1.4 & 0.9 \\
\hline II 94 & -2.6 & 0.0 \\
\hline II 95 & -0.2 & 2.0 \\
\hline
\end{tabular}




\section{4 Índices de metalicidade}

Os índices de metalicidade são regiões de absorção proeminentes nos espectros integrados de galáxias e populações integradas em geral. $\mathrm{Na}$ impossibilidade instrumental (ainda) de observar espectros de galáxias em alta resolução com bom sinal/ruído, é imprescindível a identificação e compreensão de características espectrais visíveis a baixa resolução que possam nos dar informações sobre as populações estelares da galáxia estudada. A compreensão da origem física dessas regiões de absorção proeminentes na luz integrada de populações estelares requer que conheçamos como esses índices variam com estrelas ao longo da nossa Galáxia e em função da temperatura, gravidade e abundância.

Esse estudo pode ser feito teoricamente, empíricamente, ou numa combinação dos dois. Estudos essencialmente teóricos incluem os trabalhos de Mould (1978), Johnson et al. (1982), Tripicco \& Bell (1990), Gulati et al. (1991), Barbuy et al. (1992) e Barbuy (1994). Estudos empíricos incluem os de Spinrad \& Taylor (1969, 1971), Aaronson et al. (1978), Buzzoni et al. (1992), Idiart \& Pacheco (1995), Faber et al. (1985), Burstein et al. (1994), Gorgas et al. (1993), Worthey (1994) e Tantalo et al. (1998).

Os índices de metalicidade mais amplamente conhecidos hoje foram definidos pelo grupo do Observatório de Lick (Faber e colaboradores) e fazem parte de um projeto cujo principal objetivo é a síntese de galáxias elípticas. Três desses índices, Fe5270, Fe5355 e $\mathrm{Mg}_{2}$, foram medidos nas estrelas estudadas nesta dissertação.

A medida dos índices foi feita segundo o mesmo procedimento utilizado na medida dos índices de TiO, conforme descrito em 4.2.2. Os índices foram medidos segundo duas definições distintas conforme pode ser visto na tabela 13.

A fim de podermos comparar os valores encontrados para nossas estrelas com outras da 
Tabela 13: Definições dos índices de metalicidade medidos. As diferenças entre as duas definições foram tipicamente de $0.01 \mathrm{mag}$ para o Mg2, e $0.4 \AA$ para os índices do ferro.

\begin{tabular}{|c|c|c|c|c|c|}
\hline \multirow[b]{2}{*}{ Índice } & \multirow[b]{2}{*}{$\begin{array}{l}\text { Linhas/banda } \\
\text { medida }\end{array}$} & \multicolumn{2}{|c|}{ Definição de Burstein et al. (1994) } & \multicolumn{2}{|c|}{ Definição de Worthey et al. (1994) } \\
\hline & & Banda $(\AA)$ & Contínuo $(\AA ̊)$ & Banda $(\AA)$ & Contínuo $(\AA ̊)$ \\
\hline Mg2 & $M g H+M g b$ & $5156.00-5197.25$ & $\begin{array}{l}4897.00-4957.25 \\
5303.00-5366.74\end{array}$ & $5154.125-5196.625$ & $\begin{array}{l}4895.125-4957.625 \\
5301.125-5366.125\end{array}$ \\
\hline Fe5270 & Fe I, Ca I & $5248.00-5286.75$ & $\begin{array}{l}5235.50-5249.25 \\
5288.00-5319.25\end{array}$ & $5245.650-5285.650$ & $\begin{array}{l}5233.150-5248.150 \\
5285.650-5318.150\end{array}$ \\
\hline Fe5335 & $\begin{array}{c}\text { Fe I, Cr I, Ca I, } \\
\text { Ti II }\end{array}$ & 5314.75-5353.50 & $\begin{array}{l}5307.25-5317.25 \\
5356.00-5364.75\end{array}$ & $5312.125-5352.125$ & $\begin{array}{l}5304.625-5315.875 \\
5353.735-5363.375\end{array}$ \\
\hline
\end{tabular}

literatura e uma vez que as estrelas do LICK foram observadas com resolução $\Delta \lambda \sim 9 \AA$, um filtro gaussiano foi aplicado aos nossos espectros de modo que os espectros finais tivessem uma resolução próxima a $\Delta \lambda \sim 9 \AA$. Deve-se comentar, no entanto, que uma vez que as observações utilizadas neste trabalho não foram inicialmente realizadas com o intuito de medir esses índices, não dispomos de observações de estrelas padrões LICK para verificar a existência e corrigir possíveis desvios sistemáticos. Dessa forma, nossas medidas não estão a priori reduzidas ao que se pode chamar de sistema Lick. Os índices medidos para todas as estrelas estudadas estão apresentados na tabela 15.

Nas observações do grupo A todas as estrelas foram observadas mais de uma vez. Para uma dada estrela, medimos o índice em cada uma de suas observações e no espectro combinado dessas, obtendo assim uma certa distribuição de valores para cada estrela. Escolhemos como sendo o erro da medida a média dos desvios padrões obtidos para cada estrela. Para as observações do grupo B, nem todas as estrelas foram observadas mais de uma vez mas determinamos o erro da medida da mesma forma descrita acima com as estrelas com mais de uma observação. Dessa forma, os erros típicos foram estimados em:

- grupo A: 0.02 mag para o $\mathrm{Mg}_{2}, 0.4 \AA$ para o Fe5270 e $0.6 \AA$ para o Fe5335, e; 
- grupo B: 0.04mag para o $\mathrm{Mg}_{2}, 0.6 \AA$ para o Fe 5270 e $0.7 \AA$ para o Fe5335.

Aqui, à semelhança dos índices de TiO, verifica-se uma dependência considerável dos índices com relação ao sinal/ruído dos espectros. Essa dependência dos índices de metalicidade de Lick com o sinal/ruído foi comentada em mais detalhes em Idiart (1995).

Com os espectros do grupo A, aplicou-se os ajustes polinomiais feitos por Worthey et al. (1994) que descrevem o índice em termos dos parâmetros atmosféricos das estrelas. Dado como conhecido o índice, a temperatura e a gravidade, procurou-se obter estimativas do valor de $[\mathrm{Fe} / \mathrm{H}]$. Uma vez que esses ajustes foram inicialmente feitos considerando como variável dependente o índice, a determinação do valor de $[\mathrm{Fe} / \mathrm{H}]$ requeria a solução de funções polinomiais de até terceira ordem. Essas funções foram resolvidas com o software Mathematica 2.2, que calculou todas as raízes das equações dentre as quais foi escolhida a raiz mais fisicamente significativa. As estimativas encontradas para $[\mathrm{Fe} / \mathrm{H}]$ estão apresentadas na tabela 14.

Tabela 14: Valores de $[\mathrm{Fe} / \mathrm{H}]$ determinados para algumas estrelas através dos ajustes polinomiais de Worthey et al. (1994)

\begin{tabular}{cccc}
\hline Estrela & $\begin{array}{r}{[\mathrm{Fe} / \mathrm{H}] \text { determinado }} \\
\text { pelo índice Fe5270 }\end{array}$ & $\begin{array}{c}{[\mathrm{Fe} / \mathrm{H}] \text { determinado }} \\
\text { pelo índice Fe5335 }\end{array}$ & $\begin{array}{c}{[\mathrm{Fe} / \mathrm{H}] \text { determinado }} \\
\text { pelo índice } \mathrm{Mg}_{2}\end{array}$ \\
\hline NGC 6528 & & & \\
1 & -0.7 & -0.6 & +0.1 \\
2 & 0 & - & -0.4 \\
NGC 6553 & & & -0.2 \\
3 & -0.6 & -0.5 & -0.2 \\
52 & -0.5 & -0.5 & \\
\hline
\end{tabular}

As outras estrelas do grupo A, NGC 6528 I 27e NGC 6553 II 51 não puderam ser usadas pois suas temperaturas estão fora dos intervalos válidos para uso dos ajustes polinomiais. O mesmo ocorreu para a estimativa de $[\mathrm{Fe} / \mathrm{H}]$ pelo índice Fe5335 da estrela 
NGC 6528 I 2.

Apesar de nominalmente os ajustes polinomiais de Worthey et al. (1994) cobrirem o intervalo $3570 \mathrm{~K}<T_{e f}<5160 \mathrm{~K}$ (exceto para o índice Fe5335 que é válido apenas para $T_{e f}>$ $3830 \mathrm{~K})$, acreditamos que os valores destoantes de $[\mathrm{Fe} / \mathrm{H}]$ encontrados para a estrela NGC 6528 I 2 se deva ao fato de que para estrelas mais frias que $T_{\text {ef }} \sim 3800 \mathrm{~K}$ o comportamento desses índices ainda não é tão bem conhecido e as moléculas de TiO existentes na região passam a ter uma contribuição significativa.

Pode-se ver na tabela 14 que, a menos da estrela NGC 6528 I 2, os valores de $[\mathrm{Fe} / \mathrm{H}]$ estimados pelo índice $\mathrm{Mg}_{2}$ são sistematicamente superiores aos valores encontrados pelos índices do ferro.

$\mathrm{O}$ fato das estimativas de $[\mathrm{Fe} / \mathrm{H}]$ pelo índice $\mathrm{Mg}_{2}$ serem sistematicamente maiores que outros índices pode ser interpretado como indício de excesso de elementos $\alpha$ nesses aglomerados, o que de fato tem sido encontrado conforme já comentado no capítulo 2.

A fim de averiguar melhor essa conclusão, esses valores foram comparados com duas calibrações existentes de $[\mathrm{Mg} / \mathrm{Fe}] \times[\mathrm{Fe} / \mathrm{H}]:$ a calibração de Barbuy (1994) baseada em espectros sintéticos e a calibração empírica de Idiart (1995).

Em Barbuy (1994) foram apresentadas calibrações do $\mathrm{Mg} 2 \times[\mathrm{Fe} / \mathrm{H}]$ e $[\mathrm{Mg} / \mathrm{Fe}]$ para os valores $[\mathrm{Fe} / \mathrm{H}]=-2.0,-1.0,-0.5,0.0,+0.5,[\mathrm{Mg} / \mathrm{Fe}]=0.0,+0.25,0.0<\log \mathrm{g}<4.4$ e $3500<T_{e f}$ $<$ 5000. A maioria dos valores obtidos para as estrelas estudadas foram reproduzidos pelas combinações de parâmetros $[\mathrm{Fe} / \mathrm{H}]=-0.5$ e $[\mathrm{Mg} / \mathrm{Fe}]=+0.25$ ou $[\mathrm{Fe} / \mathrm{H}]=0$ e $[\mathrm{Mg} / \mathrm{Fe}]=0$.

Com a calibração empírica de Idiart (1995) de Mg2 em função de $T_{e f} \log$ g, [Fe/H], [Mg/ Fe], testamos os valores medidos de $\mathrm{Mg} 2$ para o intervalo $-0.6<[\mathrm{Fe} / \mathrm{H}]<0$. Todos os testes sem exceção apresentaram $[\mathrm{Mg} / \mathrm{Fe}]$ sobreabundantes, tipicamente $[\mathrm{Mg} / \mathrm{Fe}]=+0.5$ para $[\mathrm{Fe} / \mathrm{H}]$ 
$=-0.3$.

Esses testes parecem então convergir no sentido de confirmar a existência de uma sobreabundância de $[\mathrm{Mg} / \mathrm{Fe}]$ nas estrelas estudadas. 
Tabela 15: Índices espectrais medidos.

\begin{tabular}{|c|c|c|c|c|c|c|}
\hline \multirow[b]{2}{*}{ Estrela } & \multicolumn{3}{|c|}{ Burstein et al. (1984) } & \multicolumn{3}{|c|}{ Worthey et al. (1994) } \\
\hline & Mg2 (mag) & Fe5270 ( $(\AA)$ & Fe5335 $(\AA)$ & Mg2 (mag) & Fe5270 $(\AA)$ & Fe5335 (§) \\
\hline \multicolumn{7}{|c|}{ Grupo B (Observações de 1994) } \\
\hline \multicolumn{7}{|c|}{ NGC 6528} \\
\hline 12 & 0.30 & 6.67 & 4.25 & 0.30 & 6.07 & 3.91 \\
\hline 15 & 0.34 & 3.44 & 2.54 & 0.32 & 3.57 & 2.25 \\
\hline 16 & 0.31 & 3.19 & 2.95 & 0.31 & 3.28 & 2.90 \\
\hline 118 & 0.30 & 0.88 & 2.60 & 0.30 & 0.47 & 1.65 \\
\hline II 14 & 0.59 & 0.79 & 0.27 & 0.54 & 2.67 & 1.66 \\
\hline 123 & 0.10 & 1.76 & 0.50 & 0.10 & 2.08 & 1.26 \\
\hline 24 & 0.16 & 3.41 & 1.91 & 0.15 & 3.05 & 1.98 \\
\hline 125 & 0.33 & 3.08 & 2.98 & 0.33 & 3.07 & 2.46 \\
\hline I 27 & 0.39 & 3.83 & 2.95 & 0.38 & 4.25 & 2.94 \\
\hline 136 & 0.30 & 1.48 & 4.63 & 0.30 & 1.35 & 4.20 \\
\hline 1139 & 0.38 & 3.94 & 2.28 & 0.37 & 3.89 & 2.18 \\
\hline 40 & 0.46 & 3.44 & 4.59 & 0.46 & 3.52 & 3.36 \\
\hline 42 & 0.32 & 2.27 & 3.69 & 0.30 & 2.52 & 2.77 \\
\hline 1170 & 0.42 & 3.87 & 3.97 & 0.41 & 4.18 & 3.42 \\
\hline \multicolumn{7}{|c|}{ NGC 6553} \\
\hline III 2 & 0.46 & 4.05 & 3.44 & 0.46 & 4.47 & 3.09 \\
\hline III 3 & 0.37 & 3.22 & 3.93 & 0.36 & 3.56 & 3.68 \\
\hline III 17 & 0.30 & 1.54 & 1.85 & 0.29 & 2.02 & 2.19 \\
\hline II 51 & 0.28 & - & 2.60 & 0.25 & 1.92 & 2.91 \\
\hline 1152 & 0.21 & 2.62 & 3.10 & 0.21 & 2.38 & 2.44 \\
\hline 1185 & 0.15 & 3.21 & 2.10 & 0.14 & 3.05 & 2.00 \\
\hline 1194 & 0.58 & 6.46 & 4.17 & 0.58 & 6.52 & 3.64 \\
\hline 1195 & 0.04 & 1.45 & 0.94 & 0.030 & 1.38 & 0.78 \\
\hline \multicolumn{7}{|c|}{ Grupo A (Observações de 1992) } \\
\hline \multicolumn{7}{|c|}{ NGC 6528} \\
\hline 11 & 0.31 & 3.12 & 2.96 & 0.31 & 3.01 & 2.59 \\
\hline 12 & 0.44 & 3.56 & 3.28 & 0.43 & 3.91 & 3.07 \\
\hline 127 & 0.24 & 2.62 & 2.60 & 0.24 & 2.66 & 2.24 \\
\hline \multicolumn{7}{|c|}{ NCG 6553} \\
\hline III3 & 0.37 & 3.27 & 3.60 & 0.36 & 3.38 & 3.26 \\
\hline II51 & 0.17 & 1.43 & 1.32 & 0.15 & 2.14 & 2.18 \\
\hline II52 & 0.38 & 3.41 & 4.24 & 0.38 & 3.32 & 3.56 \\
\hline
\end{tabular}




\section{Determinação de metalicidades através de síntese espectral}

A radiação eletromagnética observada de uma estrela é proveniente da região que chamamos de atmosfera. Desta forma, a atmosfera é a mais importante fonte de informações de que dispomos de uma estrela, sendo uma interface entre o que ocorre no interior estelar, onde ocorre a produção de energia, e o que observamos. A atmosfera não é uma camada única, sendo constituída de fotosfera, cromosfera e coroa. A maior parte da radiação observada do UV ao IV próximo em estrelas é produzida na fotosfera.

Um modelo de atmosfera descreve como a temperatura, pressão total do gás, pressão eletrônica, densidade de matéria e pressão de radiação variam com a profundidade óptica num comprimento de onda de referência.

Portanto, com base em um modelo de atmosfera e uma lista de transições atômicas e moleculares com constantes atômicas bem determinadas, é possível reproduzir o fluxo observado de estrelas através de um processo chamado de síntese espectral.

A síntese espectral consiste no cálculo de um espectro baseado em um modelo de atmosfera e numa lista de constantes atômicas e moleculares, assumindo equilíbrio termodinâmico local (ETL). O espectro sintético procura reproduzir um espectro estelar de condições atmosféricas dadas pelo modelo de atmosfera usado e apresenta todas as linhas e bandas constantes da lista atômico-molecular. A síntese espectral é um dos poucos métodos que permite inferir abundâncias através de espectros quando o blend de linhas é intenso, mas 
necessita de modelos de fotosfera ${ }^{1}$ realistas e de uma lista completa de dados atômicos e moleculares.

De posse das $T_{e f} \mathcal{s}$ e $\log g$ das estrelas estudadas partimos para a deteminação de metalicidades, que foi realizada por comparação a espectros sintéticos. O programa utilizado para o cálculo de síntese espectral foi o elaborado por Barbuy (1982) que consiste numa generalização do programa de Spite (1967) para incluir o cálculo de linhas moleculares. Um sumário do método de síntese espectral estelar em equilíbrio termodinâmico local pode ser encontrado em Spite (1967), Barbuy (1982), Cayrel et al. (1991), Schiavon (1998, Apêndice A) e maiores detalhes podem ser encontrados em Gray (1992).

A lista de linhas atômicas utilizada tem sido desenvolvida e atualizada constantemente pelo grupo, que mais recentemente incluiu a região do UV próximo com o trabalho de Castilho (1999) e está preparando a lista na região do IV com o trabalho de J. Meléndez. Essa lista cobre a região $4000 \AA$ a $10000 \AA$ e inclui as bandas moleculares de $\mathrm{MgH} A^{2} \Pi-X^{2} \Sigma, \mathrm{CH}$ $A^{2} \Delta-X^{2} \Pi$ (banda G), $\mathrm{CN}$ azul $B^{2} \Sigma-X^{2} \Sigma, \mathrm{CN}$ vermelho $A^{2} \Pi-X^{2} \Sigma$, TiO $A^{3} \Phi-X^{3} \Delta \gamma$ e $\mathrm{C}_{2}$ Swan $4^{3} \Pi-X^{3} \Pi$. As forças de oscilador adotadas foram os valores de laboratório de Fuhr et al. (1988), Martin et al. (1988) e Wiese et al. (1969). Quando valores de laboratório não estavam disponíveis, os valores das forças de oscilador foram obtidos pelo ajuste do espectro solar, conforme discussão em Barbuy et al. (1999).

Para a maioria das estrelas $\left(3800 \leq \mathrm{T}_{\text {ef }} \leq 4500 \mathrm{~K}\right)$ foi utilizada a grade de modelos de atmosfera de B. Plez (comunicação privada), que são uma extensão da grade de Plez et al. (1992) e Gustafsson et al. (1975). Para estrelas mais quentes utilizamos os modelos de Kurucz (1992). Para estrelas mais frias, utilizamos a grade de espectros sintéticos de Schiavon (1998), que

1. Os modelos de fotosfera utilizados neste trabalho serão daqui em diante chamados genericamente de modelos de atmosfera. 
foram calculados com base nos modelos de Plez et al. (1992). Essa grade inclui as moléculas de FeH $A^{4} \Delta-X^{4} \Delta$ e TiO sistemas $\gamma^{\prime}, \gamma, \delta, \varepsilon, \phi$ visíveis apenas para estrelas mais frias que $3800 \mathrm{~K}$ e acima de $6000 \AA$.

Quando a temperatura ou a gravidade de uma estrela não correspondia exatamente aos parâmetros disponíveis pelos modelos, foi utilizado um espectro combinado de parâmetros estelares próximos. Ou seja, uma estrela de $\mathrm{T}_{\mathrm{ef}}=3900 \mathrm{~K}$ e log $\mathrm{g}=1$ foi comparada à média dos espectros $\left(\mathrm{T}_{\mathrm{ef}}, \log \mathrm{g}\right)=(4000,1.0)$ e $(3800,1.0)$.

Alguns elementos tiveram suas abundâncias alteradas com relação à solar. Espectros com resoluções como os que foram usados neste trabalho são pouco sensíveis a variações da razão de abundâncias, ainda assim, manter abundâncias solares em estrelas cujos estudos de alta resolução indicam um excesso de elementos $\alpha$ pode fazer com que os valores de $[\mathrm{Fe} / \mathrm{H}]$ determinados sejam artificialmente altos.

$\mathrm{Na}$ figura 24 são apresentadas comparações entre espectros sintéticos de abundância solar, sintéticos com sobreabundância de elementos $\alpha$ e um espectro observado. Verificou-se que as linhas que mais têm impacto no aspecto geral dos espectros sintéticos utilizados são $\mathrm{Mg}_{2}$ e TiO, e portanto as abundâncias de $\mathrm{Mg}$, Ti e $\mathrm{O}$ foram adotadas como sendo $[\mathrm{X} / \mathrm{Fe}]=+0.3$. As linhas fortes de Ca II, como mostrada na figura 24, sugere aparentemente a necessidade de aumentar a abundância deste elemento. No entanto, o fundo dessas linhas muito intensas é formado em regime de Não-ETL, portanto a síntese espectral (que assume ETL) não é capaz de reproduzir essas linhas, motivo pela qual optou-se por manter a abundância solar para o Ca.

Alguns procedimentos foram adotados antes de comparar os espectros sintéticos aos observados. Inicialmente todos os espectros das estrelas estudadas foram corrigidos da velocidade radial observada. Em seguida, foram definidos 5 ou 4 intervalos espectrais (grupo A e B respectivamente) no qual foram divididos todos os espectros (sintéticos e observados). Para 
cada uma dessas regiões foram definidas regiões de psendo-continum sobre as quais os espectros foram normalizados, ou seja, a mesma região espectral foi normalizada exatamente da mesma forma (o que inclui mesmo pseudo-continnum, mesma função e ordem de ajuste) para qualquer espectro, sintético ou observado. Esse procedimento foi feito com o objetivo de minimizar incertezas na determinação de metalicidades provenientes de variações no nível do contínuo entre os espectros que estão sendo comparados.

Com as comparações aos espectros sintéticos, verificou-se que a maioria das estrelas era razoavelmente bem reproduzida tanto por modelos com $[\mathrm{Fe} / \mathrm{H}]=-0.3$ quanto por modelos com $[\mathrm{Fe} / \mathrm{H}]=-0.6$. Com o objetivo de estimar um valor intermediário foram realizadas interpolações lineares entre os espectros sintéticos de $[\mathrm{Fe} / \mathrm{H}]=-0.6$ e -0.3 e temperatura e gravidade correspondentes às da estrela estudada. Nas figuras 25 a 29 são apresentadas comparações entre os espectros observados e os sintéticos (com as duas metalicidades) para diversas estrelas.

Foi verificado que esse procedimento de interpolação era impróprio para estrelas cujo espectro apresentava baixa relação sinal/ruído. Quando as estrelas nessa situação eram frias $\left(\mathrm{T}_{\mathrm{ef}} \leq 3800 \mathrm{~K}\right)$, a metalicidade foi estimada a partir das calibrações da largura equivalente de bandas de TiO em função de parâmetros atmosféricos $W(\mathrm{TiO})=f($ arâmetros atmosféricos), apresentadas no Apêndice I.

Para as estrelas com baixo sinal/ruído e $\mathrm{T}_{\mathrm{ef}}>3800 \mathrm{~K}$, foi adotado um critério para escolher entre um ou outro dos valores discretos de metalicidade. Os espectros observados e sintéticos foram tranformados em arquivo texto de modo que todos apresentassem o mesmo intervalo em comprimento de onda ponto a ponto e os mesmos comprimentos de onda iniciais e finais. Foram então construídos dois gráficos (contagens estrelas $\times$ contagens modelo 1 e contagens estrelas $x$ contagens modelo 2) e para cada um deles foi ajustada uma reta. Escolheu-se como sendo 
a metalicidade da estrela estudada o modelo para o qual o ajuste linear apresentasse o coeficiente angular mais próximo de 1 , ou seja, o modelo com o qual o gráfico possuía maior correlação. Quando os ajustes eram iguais dentro do erro, foi adotado o valor $[\mathrm{Fe} / \mathrm{H}]=-0.45$.

Para a determinação de metalicidades por este último método ou pela interpolação linear não foram utilizados todos os intervalos espectrais, apenas as regiões mais sensíveis à metalicidade. Essas regiões foram escolhidas dividindo-se um espectro sintético de $[\mathrm{Fe} / \mathrm{H}]=$ 0.3 por outro de mesma temperatura e gravidade mas $[\mathrm{Fe} / \mathrm{H}]=-0.6 . \mathrm{O}$ resultado dessa divisão, apresentado na figura 22, distingue claramente as regiões mais sensíveis à metalicidade. As regiões menos sensíveis, portanto, foram excluídas da análise, uma vez que só estariam contribuindo para o ruído da determinação de $[\mathrm{Fe} / \mathrm{H}]$.

As estimativas finais de metalicidade obtidas para as estrelas estudadas estão apresentadas na tabela 16, onde estão indicados também os procedimentos.

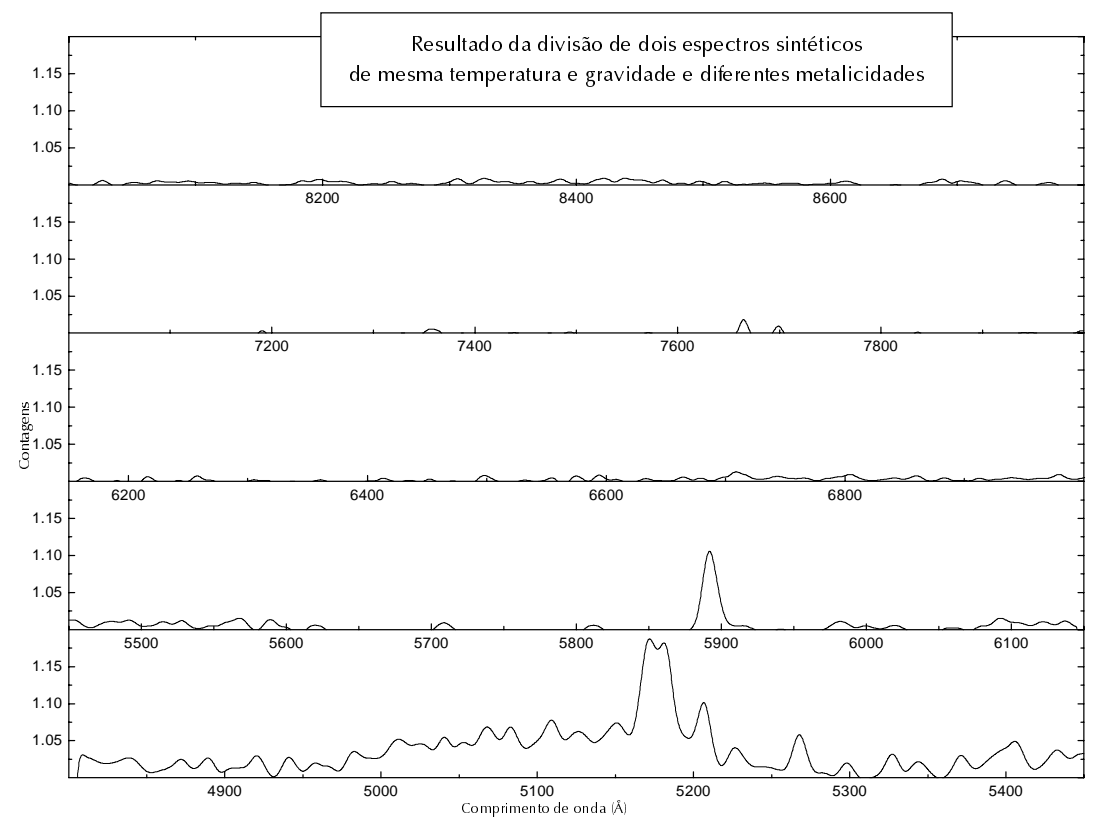

Figura 22: Divisão entre espectros sintéticos de mesma temperatura e gravidade superficial mas diferentes metalicidades. São claramente visíveis as regiões mais sensíveis à metalicidade (maiores contagens). 
Tabela 16: Metalicidades estimadas para as estrelas estudadas.

\begin{tabular}{ccc}
\hline Estrela & [Fe/H] & Método \\
\hline 1 & NGC 6528 & 1 \\
2 I I & -0.4 & 1 \\
5 I & -0.5 & 1 \\
6 I & -0.5 & 2 \\
8 II & -0.5 & 3 \\
14 II & -0.3 & 1 e 2 \\
23 I & 0.1 & 1 e 3 \\
24 I & 0 & 1 e 3 \\
25 I & -0.6 & 1 \\
27 I & -0.3 & 2 \\
36 I & -0.6 & 1 \\
40 I & -0.4 & 1 \\
42 I & -0.4 & 1 \\
70 II & -0.5 & 2 \\
\hline & NGC 6553 & \\
\hline 2 III & 0 & 1 e 3 \\
3 III & -0.5 & 1 \\
17 III & -0.6 & 2 \\
51 II & -0.4 & 1 \\
52 II & -0.45 & 3 \\
85 II & -0.6 & 2 \\
94 II & -1.4 & 1 \\
95 II & -0.6 & 1 \\
\hline & & \\
\hline
\end{tabular}

Métodos: 1: interpolação linear entre os espectros sintéticos; 2 : aplicação das calibrações de TiO em função dos parâmetros atmosféricos; 3: comparação entre ajustes lineares. 
As estrelas que apresentaram maiores metalicidades II 14, I 23 e I 24 do NGC 6528 e III 2 do NGC 6553, tinham em comum uma baixa relação sinal/ruído. Já a estrela de mais baixa metalicidade, NGC 6553 II 94, possui uma velocidade radial afastada da média do aglomerado e talvez ela de fato seja uma estrela de campo.

Os valores de $[\mathrm{Fe} / \mathrm{H}]$ para cada aglomerado foram estimados pela média dos valores obtidos para cada estrela, excetuando-se as cinco estrelas indicadas acima. Os histogramas dos valores obtidos para as estrelas de cada aglomerado pode ser visto na figura 23.

Obtevê-se então $[\mathrm{Fe} / \mathrm{H}]_{\mathrm{NGC} 6528}=[\mathrm{Fe} / \mathrm{H}]_{\mathrm{NGC}} 6553=-0.5 \pm 0.1$, valores mais de acordo com Barbuy et al. (1999,2000) do que com Barbuy et al. (1992) e Cohen et al. (1999).

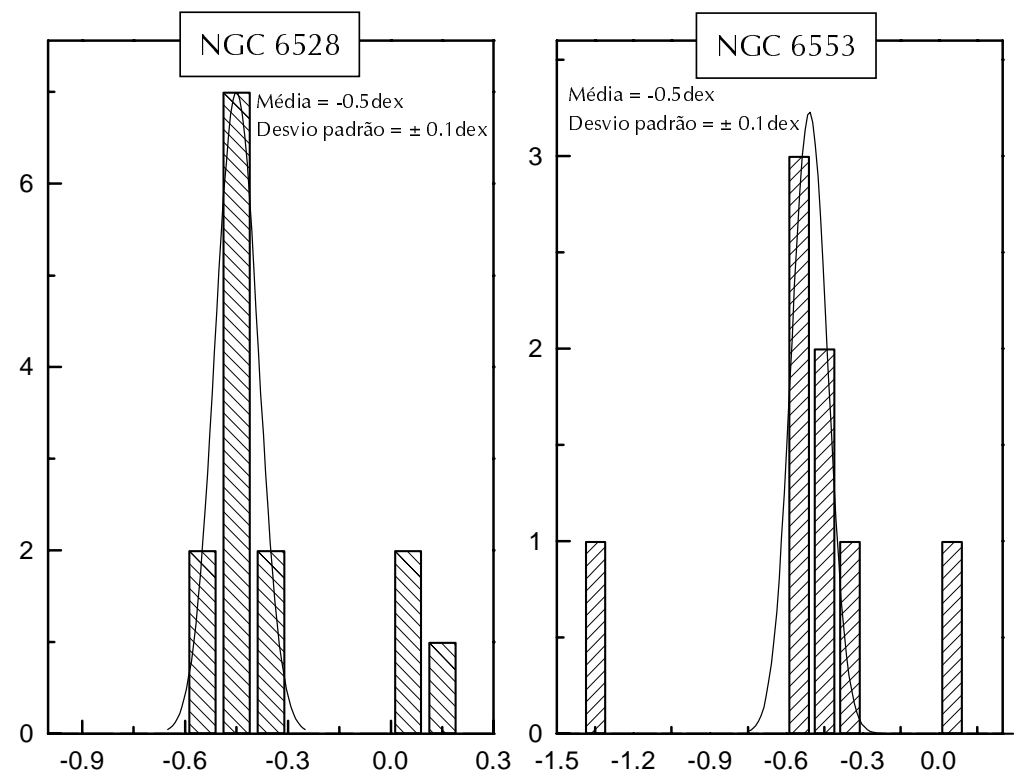

Figura 23: Histogramas dos valores de $[\mathrm{Fe} / \mathrm{H}]$ obtidos para cada estrela estudada, conforme tabela 16. Os valores de $[\mathrm{Fe} / \mathrm{H}]$ para cada aglomerado foram estimados pela média dos valores obtidos para cada estrela, exceto aquelas cujos valores são mais discrepantes. 

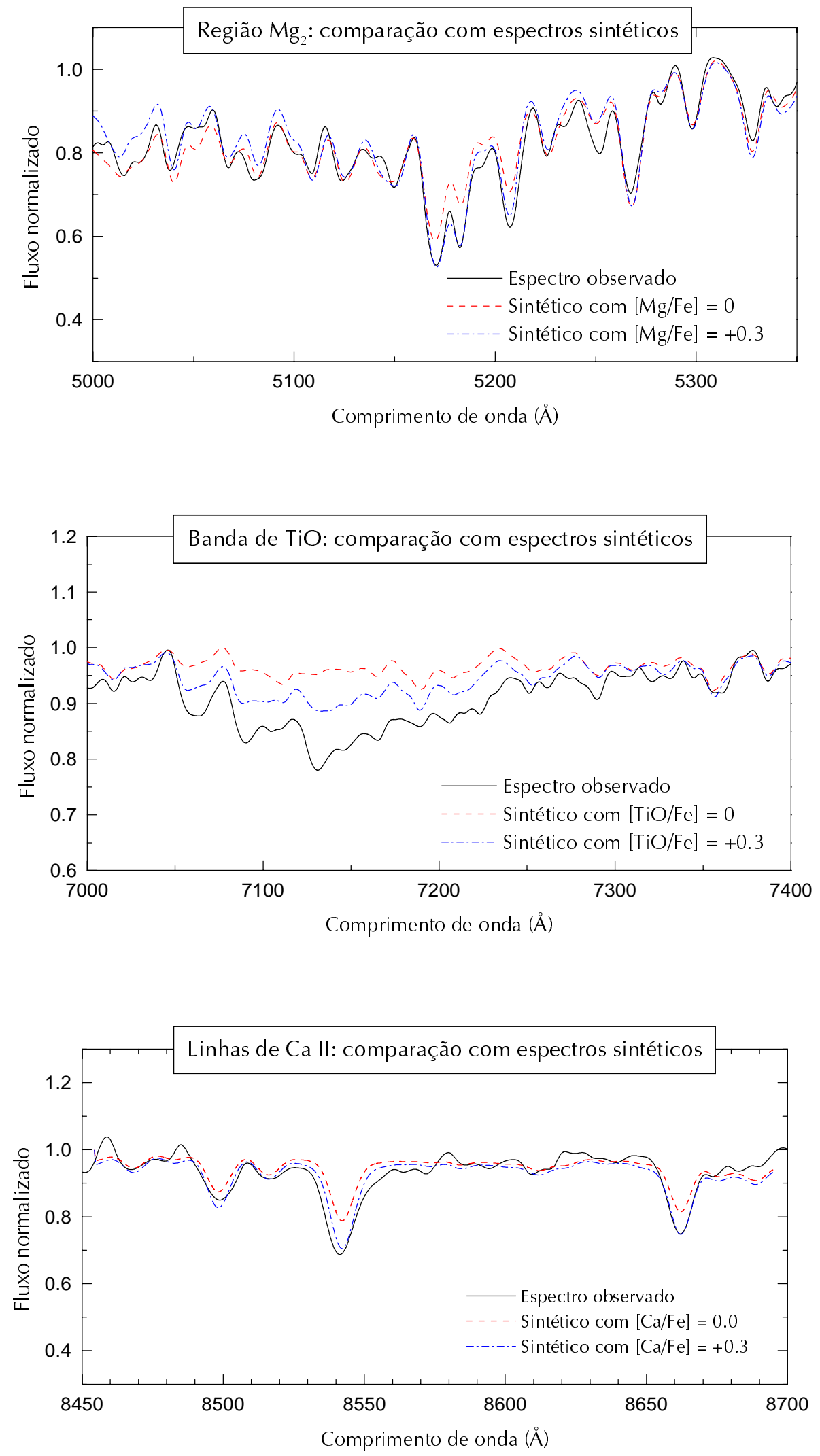

Figura 24: Comparação entre espectros observados e sintéticos para as regiões sensíveis às abundâncias não-solares adotadas. 


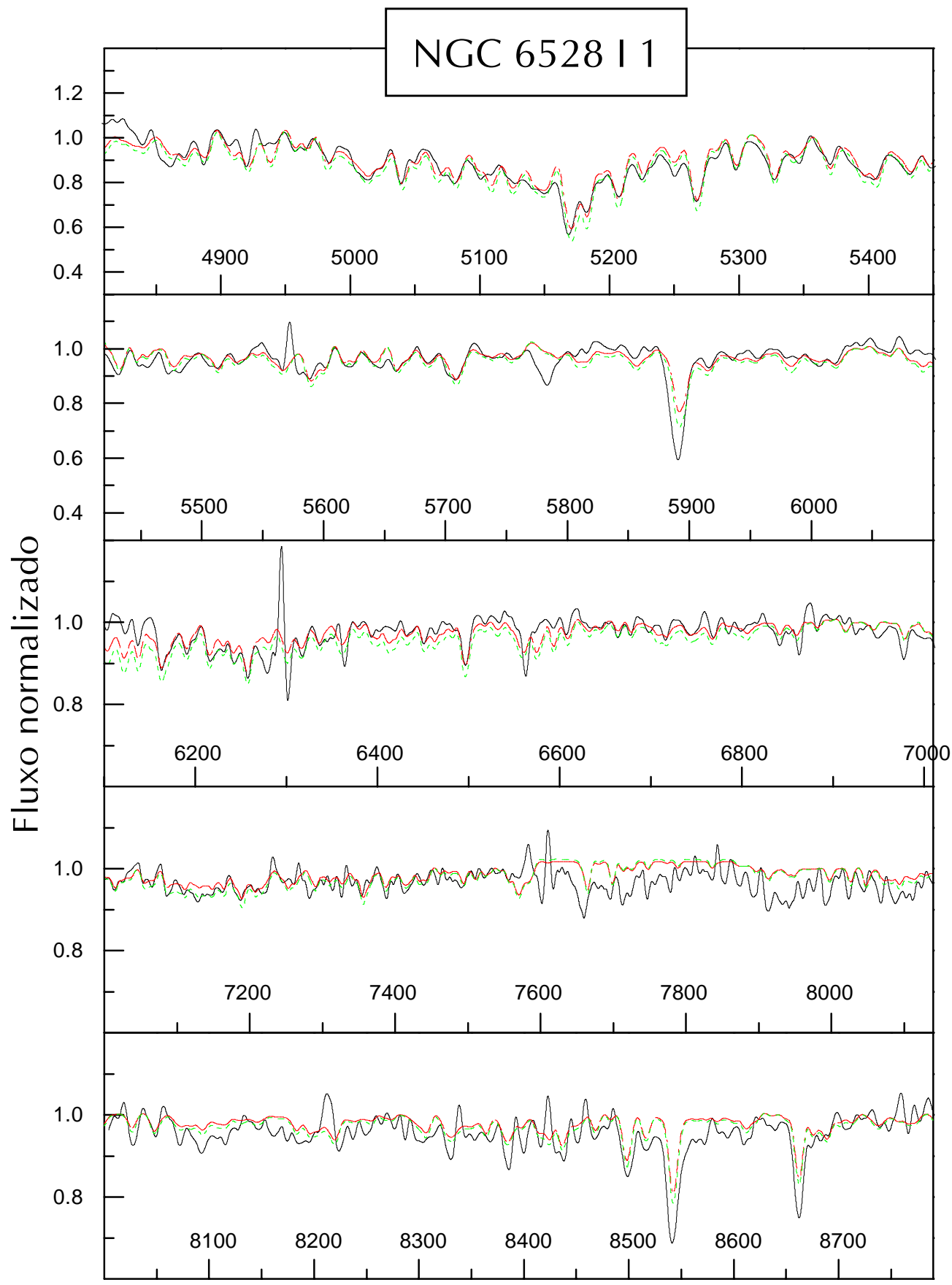

Comprimento de onda $(\AA)$

Figura 25: Espectro observado da estrela NGC 6528 I 1 (em preto, $T_{\text {ef }}=4300 \mathrm{~K}, \log g=1.7$ ) e espectros sintéticos de $[\mathrm{Fe} / \mathrm{H}]=-0.6$ (em vermelho) e $[\mathrm{Fe} / \mathrm{H}]=-0.3$ (em verde), ambos com $\mathrm{T}_{\mathrm{ef}}=4250 \mathrm{~K}$ e log g $=1.5 . \Delta \lambda \sim 8 \AA$. 


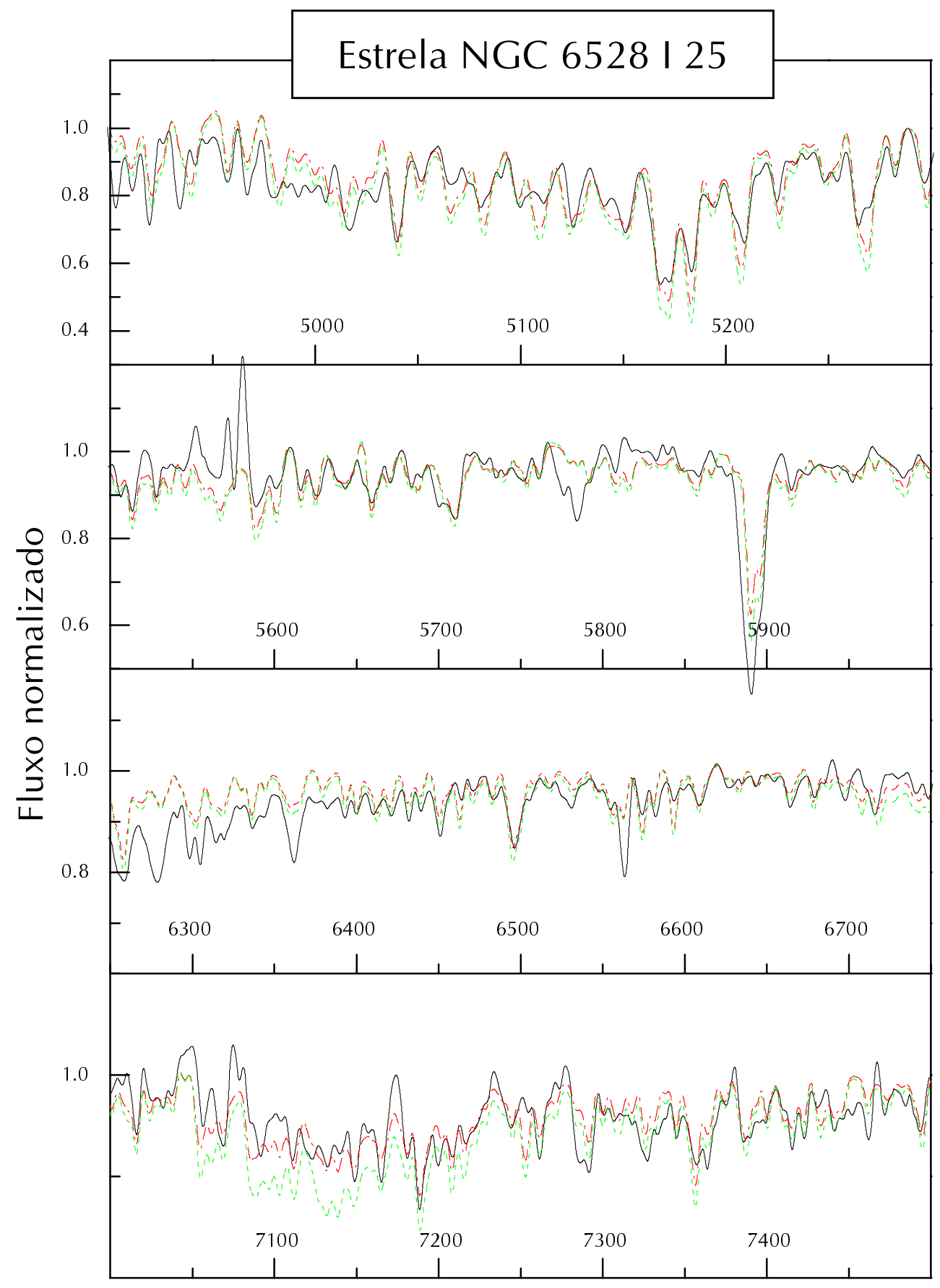

Comprimento de onda $(\AA)$

Figura 26: Espectro observado da estrela NGC $6528 \mathrm{I} 25$ (em preto, $\mathrm{T}_{\mathrm{ef}}=4100 \mathrm{~K}$, log $\mathrm{g}=1.5$ ) e espectros sintéticos de [Fe/ $\mathrm{H}]=-0.6$ (em vermelho) e $[\mathrm{Fe} / \mathrm{H}]=-0.3$ (em verde), ambos com $\mathrm{T}_{\mathrm{ef}}=4000 \mathrm{~K}$ e log g $=1.5 . \Delta \lambda \sim 4 \AA$. 

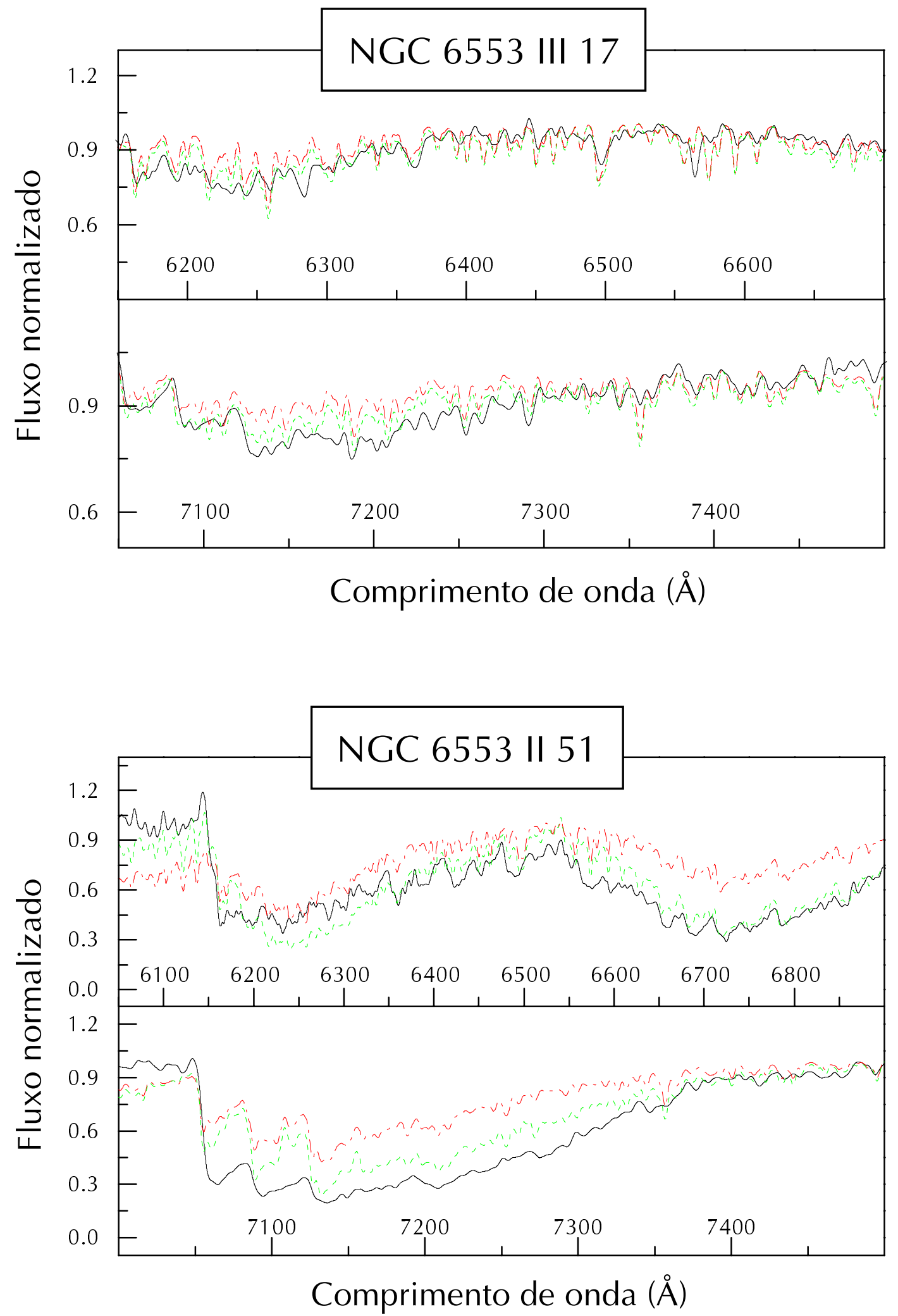

Figura 27: No topo: espectro observado da estrela NGC $6553 \mathrm{III} 17$ (em preto, $\mathrm{T}_{\mathrm{ef}}=3700 \mathrm{~K}, \log \mathrm{g}=0.3$ ) e espectros sintéticos de $[\mathrm{Fe} / \mathrm{H}]=-0.6$ (em vermelho) e $[\mathrm{Fe} / \mathrm{H}]=-0.3$ (em verde), ambos com $\mathrm{T}_{\text {ef }}=3700 \mathrm{~K}$, log $\mathrm{g}=0.5$. Embaixo: espectro observado da estrela NGC 6553 II 51 (em preto, $\mathrm{T}_{\text {ef }}=3200 \mathrm{~K}, \log \mathrm{g}=-0.5$ ) e espectros sintéticos de $[\mathrm{Fe} / \mathrm{H}$ ] $=-0.6$ (em vermelho) e $[\mathrm{Fe} / \mathrm{H}]=-0.3$ (em verde), ambos com $\mathrm{T}_{\text {ef }}=3200 \mathrm{~K}$ e log $\mathrm{g}=0 . \Delta \lambda \sim 4 \AA$. 


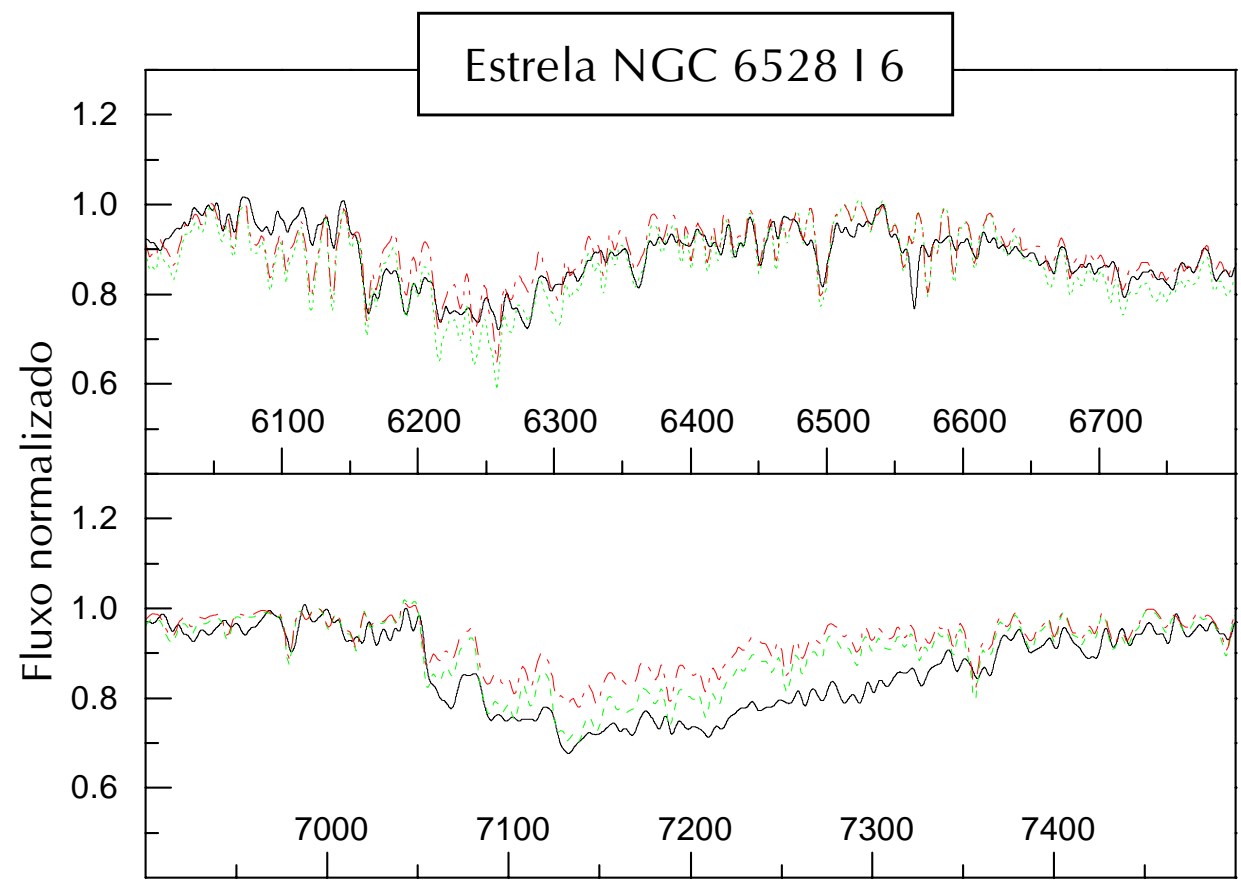

Comprimento de onda $(\AA)$

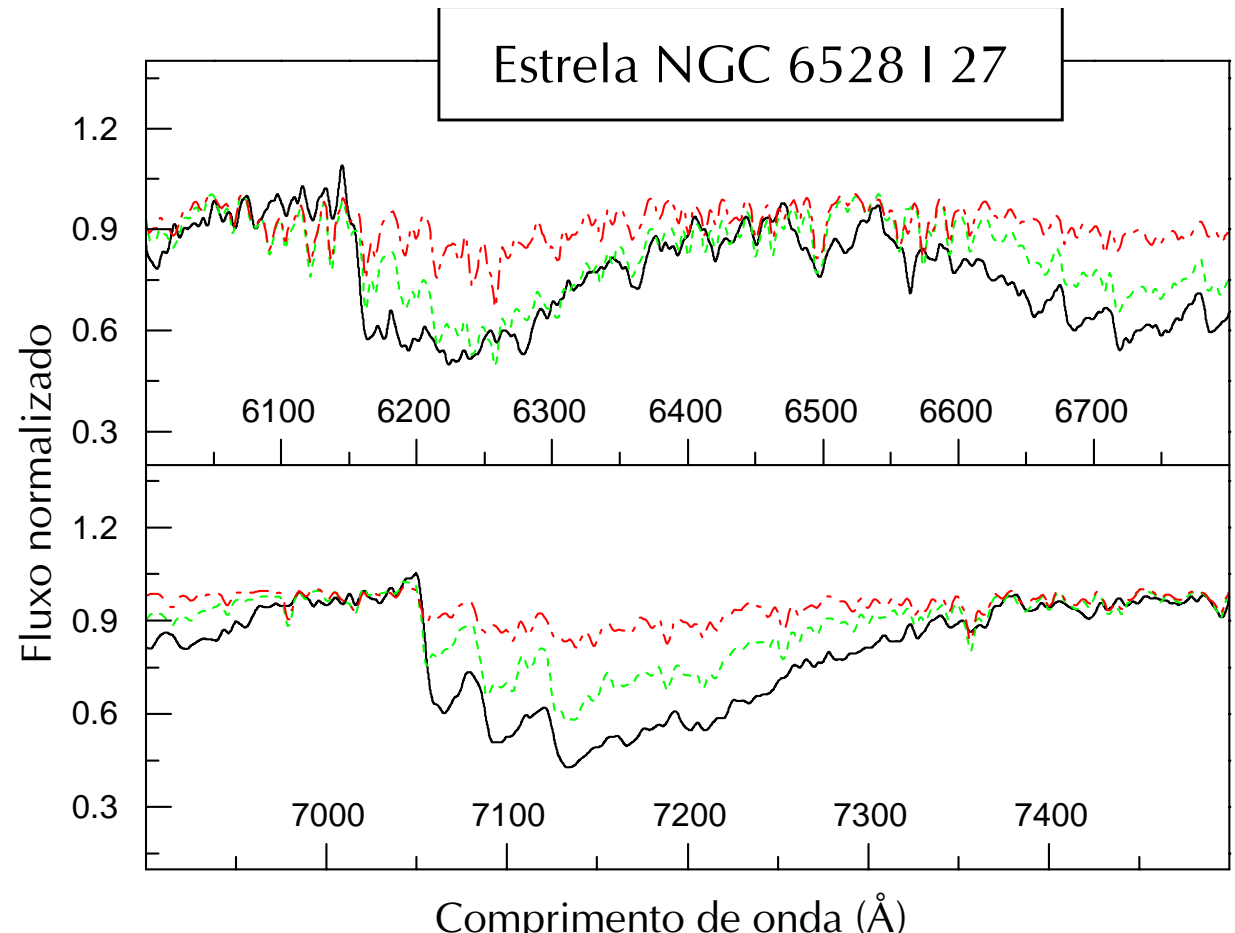

Figura 28: No topo: espectro observado da estrela NGC 6528 I 6 (em preto, $T_{\text {ef }}=3600 \mathrm{~K}, \log \mathrm{g}=0.4$ ) e espectros sintéticos de $[\mathrm{Fe} / \mathrm{H}]=-0.6$ (em vermelho) e $[\mathrm{Fe} / \mathrm{H}]=-0.3$ (em verde), ambos com $\mathrm{T}_{\text {ef }}=3600 \mathrm{~K}$, log g $=0.5$. Embaixo: espectro observado da estrela NGC $6528 \mathrm{I} 27$ (em preto, $\mathrm{T}_{\text {ef }}=3400 \mathrm{~K}, \log \mathrm{g}=0.3$ ) e espectros sintéticos de $[\mathrm{Fe} / \mathrm{H}]=-0.6$ (em vermelho) e $[\mathrm{Fe} / \mathrm{H}]=-0.3$ (em verde), ambos com $\mathrm{T}_{\text {ef }}=3400 \mathrm{~K}$, log g $=0.5 . \Delta \lambda \sim 4 \AA$. 


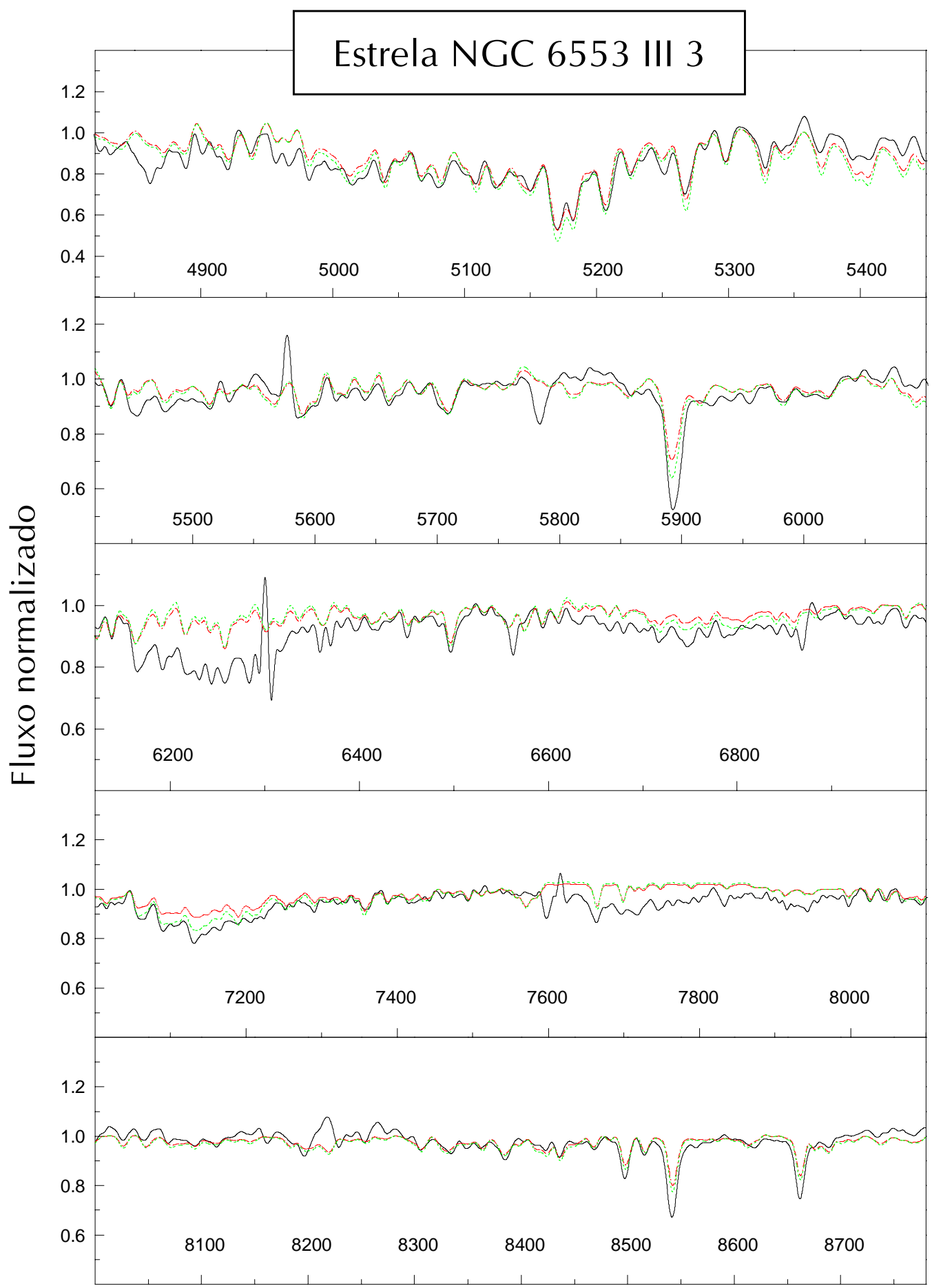

Comprimento de onda $(\AA)$

Figura 29: Espectro observado da estrela NGC $6553 \mathrm{III} 3$ (em preto, $T_{\text {ef }}=3900 \mathrm{~K}$, log g $=1.0$ ) e espectros sintéticos de $[\mathrm{Fe} / \mathrm{H}]=-0.6$ (em vermelho) e $[\mathrm{Fe} / \mathrm{H}]=-0.3$ (em verde), ambos com $\mathrm{T}_{\text {ef }}=3900 \mathrm{~K}$ e log g $=1.0 . \Delta \lambda \sim 8 \AA$. 


\section{Conclusões}

Neste trabalho foram determinados os parâmetros atmosféricos de estrelas que até então não tinham sido estudadas espectroscopicamente o que contribuiu para o conhecimento da metalicidade e abundância dos aglomerados NGC 6528 e NGC 6553.

Foram testadas duas formas independentes de determinação de velocidades radiais (capítulo 4.1) e foi aplicada pela primeira vez a determinação de temperaturas $\left(\mathrm{T}_{\mathrm{ef}}<4000 \mathrm{~K}\right)$ através das bandas de $\mathrm{TiO}$ (capítulo 4.2.2), um dos poucos métodos disponíveis de determinação de temperaturas espectroscópicas em espectros de baixa e média resolução.

Este trabalho também testou a qualidade dos espectros sintéticos quanto à reprodução do espectro estelar em baixa e média resolução. Esse teste era imprescindível de ser verificado antes do uso desses espectros em síntese de populações de galáxias.

Dentro da idéia de que há conclusões a serem obtidas tanto com relação aos resultados em si quanto com relação aos métodos empregados, estão apresentadas a seguir as principais conclusões tiradas deste trabalho.

\section{Quanto aos resultados}

Os parâmetros atmosféricos determinados para as estrelas cobrem os intervalos $3200 \mathrm{~K} \leq$ $\mathrm{T}_{\text {ef }} \leq 5000 \mathrm{~K}$ e $-0.5 \leq \log \mathrm{g} \leq 2.4$, representando portanto mais de um estágio evolutivo do aglomerado, sendo útil para a seleção de candidatas para observação em alta resolução.

As metalicidades foram estudadas através dos índices de metalicidade de Lick, de 
calibrações $W(T i O)=f($ parâmetros atmosféricos) e principalmente através de espectros sintéticos. Esses estudos convergiram para fornecer um valor médio de $[\mathrm{Fe} / \mathrm{H}]=-0.5$ para os dois aglomerados, o que está mais de acordo com os resultados de Barbuy et al. (1999) do que com Barbuy et al. (1992) e Cohen et al. (1999).

Também pelos estudos dos índices de metalicidade de Lick e por calibrações $[\mathrm{Mg} / \mathrm{Fe}] \mathrm{x}$ $[\mathrm{Fe} / \mathrm{H}]$ encontramos para essas estrelas um excesso de $\mathrm{Mg}$ da ordem de $[\mathrm{Mg} / \mathrm{Fe}] \sim+0.4$. Embora não seja possível determinar abundâncias precisamente, esses valores também estão de acordo com os valores que foram necessários para melhor reproduzir os espectros das estrelas com os espectros sintéticos.

São apresentados na tabela 17 os parâmetros atmosféricos determinados para cada estrela estudada neste trabalho.

\section{Quanto aos métodos empregados}

Com relação à determinação de velocidades radiais através de espectros de média resolução, concluímos que o método de correlação cruzada pode ser aplicado com sucesso apenas para estrelas com $T_{e f}>3800$. Apesar disso, em estrelas frias como as estudadas aqui em que é difícil definir contínuos e encontrar linhas sem blends, a correlação cruzada parece ser um método mais robusto. De fato, os resultados encontrados com esse método estão mais próximos dos valores obtidos através de espectroscopia de alta resolução.

Com relação às temperaturas, os melhores valores foram obtidos com as calibrações $T_{e f} \mathcal{x}$ cores para $T_{e f}>3800 \mathrm{~K}$ e com as calibrações pelos índices de TiO para $T_{e f}<3800 \mathrm{~K}$. Esse último método mostrou ter um grande potencial de se efetivar como uma escala robusta de temperaturas para estrelas $T_{e f}<4000 \mathrm{~K}$. Por outro lado, ajustes polinomiais dos índices de TiO 
podem ser bons estimadores de metalicidade quando a temperatura é conhecida, como foi aplicado no capítulo 5 para estrelas que apresentavam baixa relação sinal/ruído.

Por fim, a síntese espectral foi capaz de reproduzir bem os espectros observados, o que sugere que o procedimento de síntese usado neste trabalho assim como grades de espectros que sejam geradas a partir dele possam ser úteis para uma grande variedade de aplicações, desde a determinação de parâmetros atmosféricos estelares com espectros de baixa e média resolução (Cayrel et al. 1991) até síntese de populações estelares. 
Tabela 17: Parâmetros atmosféricos finais determinados para as estrelas estudadas.

\begin{tabular}{|c|c|c|c|c|}
\hline Estrela & $\begin{array}{l}\text { Vel. heliocêntrica }{ }^{a} \\
(\mathrm{~km} / \mathrm{s}) \pm 12\end{array}$ & $\mathrm{~T}_{\mathrm{ef}} \pm 200 \mathrm{~K}$ & $\log g \pm 0.3$ dex & {$[\mathrm{Fe} / \mathrm{H}] \pm 0.3 \mathrm{dex}$} \\
\hline \multicolumn{5}{|c|}{ NGC 6528} \\
\hline 11 & $262^{*}$ & 4300 & 1.7 & -0.4 \\
\hline 12 & 224 & 3700 & 0.9 & -0.5 \\
\hline 15 & $261^{*}$ & 3300 & 0.1 & -0.5 \\
\hline 16 & $232^{*}$ & 3600 & 0.4 & -0.5 \\
\hline II 8 & 289 & 3900 & 1.2 & -0.3 \\
\hline II 14 & 264 & 3300 & 0.2 & +0.1 \\
\hline 123 & 221 & 4800 & 2.4 & 0 \\
\hline 124 & 238 & 4900 & 2.3 & 0 \\
\hline 125 & 265 & 4100 & 1.5 & -0.6 \\
\hline 127 & 237 & 3400 & 0.3 & -0.3 \\
\hline 136 & 244 & 4200 & 1.7 & -0.6 \\
\hline II 39 & 30 & - & - & - \\
\hline 140 & 246 & 4100 & 1.4 & -0.4 \\
\hline 142 & 197 & 4000 & 1.5 & -0.4 \\
\hline II 70 & 230 & 3700 & 0.7 & -0.5 \\
\hline \multicolumn{5}{|c|}{ NGC 6553} \\
\hline III 2 & -2 & 4700 & 2.1 & 0 \\
\hline III 3 & 5 & 3900 & 1.0 & -0.5 \\
\hline III 17 & 3 & 3700 & 0.3 & -0.6 \\
\hline II 51 & $60^{*}$ & 3200 & -0.5 & -0.4 \\
\hline II 52 & -16 & 3900 & 1.3 & -0.45 \\
\hline II 85 & 35 & 4000 & 0.9 & -0.6 \\
\hline II 94 & -42 & 3600 & 0.0 & -1.4 \\
\hline II 95 & 11 & 5000 & 2.0 & -0.6 \\
\hline
\end{tabular}

a. Determinada pelo método de correlação cruzada, exceto para as estrelas indicadas por *, para as quais está fornecido o valor obtido pelo método clássico. 


\section{Perspectivas}

Os resultados obtidos com esse trabalho podem contribuir para diferentes áreas, desde o estudo da abundância desses aglomerados através de espectros de alta resolução até aplicações a síntese de populações de elípticas. A seguir, apresentamos estudos possíveis de serem realizados ou já em andamento que podem se beneficiar dos resultados aqui obtidos.

\section{Determinação de metalicidades e abundâncias pelo programa $H A L O$}

A perspectiva mais imediata desse trabalho de mestrado é que, tendo os espectros sintéticos sido testados e calibrados por comparação aos espectros estelares, pode-se completar e utilizar a grade de espectros sintéticos acoplada ao programa HALO (Cayrel et al. 1991). Nesse programa, um espectro observado que se deseja estudar é automaticamente comparado com vários espectros sintéticos da grade até obter a determinação de parâmetros atmosféricos que se deseja.

De fato, completar a grade de espectros sintéticos para temperaturas mais frias e implementá-la ao programa HALO é um trabalho que está planejado para ser posto em andamento nos próximos meses, junto com a composição das diferentes partes dos espectros sintéticos, necessária à síntese de populações estelares.

\section{Seleção de candidatas para observação em alta resolução}

Como comentado no capítulo 2, um maior conhecimento dos cenários da formação da 
Galáxia e do bojo, requerem maiores estudos de abundâncias de estrelas de referência das populações a serem estudadas, como as estrelas que foram estudadas aqui. Uma análise de abundância, bem como determinações espectroscópicas precisas de temperaturas efetivas e gravidades, requerem, no entanto, espectros de alta resolução e bom sinal/ruído.

Esse estudo, ao analisar estrelas ao longo de um grande intervalo de temperaturas e gravidades, permitiu a criação de uma lista de candidatas a serem observadas em alta resolução. Já foram concedidas duas noites de observações no VLT (projeto de Ortolani/Barbuy/Hill/ Renzini/Bica/Pasquini/Rich), onde serão utilizados os mapas HST criados nesta dissertação (ver capítulo 4.2) e as estimativas de parâmetros atmosféricos e pertinência ao aglomerado obtidos com esse trabalho de mestrado.

\section{Estudo do avermelhamento diferencial no campo dos aglomerados}

Como descrito nos capítulo 4.2 e comentado no capítulo 6, as discrepâncias encontradas entre as temperaturas fotométricas e as temperaturas efetivas de algumas estrelas se deve essencialmente às falhas ainda existentes na calibração cor $x T_{e f}$ para estrelas mais frias que $\mathrm{T}$ $\sim 3800 \mathrm{~K}$. No entanto, parte do erro pode ser devido ao avermelhamento diferencial presente nesses campos.

Um estudo detalhado desse avermelhamento diferencial deve, além de fornecer melhores estimativas de temperaturas fotométricas para essas estrelas, diminuir a dispersão nos DCMs desses aglomerados, permitindo um refinamento de todas as informações que podem ser obtidas pelo DCM, como por exemplo a posição do TO e do HB e consequentemente, a idade dos aglomerados.

Este projeto de R. Schiavon, B. Barbuy, E. Bica e T. Idiart, e do qual deverei participar, já está em andamento e um primeiro turno de observações já foi realizado em 1999 pela Dra. T. 
Idiart e Dr. R. Schiavon.

\section{Calibração dos índices de TiO em função dos parâmetros atmosféricos}

As calibrações dos índices de TiO, baseada nos trabalhos de Schiavon \& Barbuy (1999, 2000), Milone \& Barbuy (1994) e Milone et al. (2000), foram aplicadas neste trabalho de mestrado, de tal forma que foi confirmado que esses índices apresentam um grande potencial de serem uma escala robusta de temperaturas para estrelas frias, uma área que ainda carece de boas calibrações.

Essas calibrações poderiam ter uma aplicação mais ampla se fossem obtidos ajustes polinomiais do tipo $W(\mathrm{TiO})=f\left(T_{e f}, \log g,[\mathrm{Fe} / \mathrm{H}]\right)$ e de fato ajustes preliminares foram apresentados no Apêndice I. Testar e ampliar esses ajustes, tanto com relação a intervalos maiores de parâmetros atmosféricos quanto a verifição da influência da abundância de TiO [TiO/Fe], é certamente uma perspectiva muito interessente, tendo aplicações importantes no estudo de estrelas frias e em espectros compostos de populações estelares velhas.

\section{Calibração dos espectros estelares}

Os espectros sintéticos já vêm sendo extensivamente utilizados pelo grupo e já foram relizadas a síntese do espectro integrado dos dois aglomerados aqui estudados, NGC 6528 (em

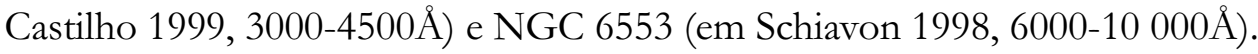

O uso desses espectros para compor espectros de populações estelares requer que estes também reproduzam bem características espectrais estelares em baixa e média resolução, particularmente de estrelas de referência para o estudo das populações que se deseja realizar.

Meu projeto de doutorado se estenderá para a síntese de populações de elípticas. Sendo 
essa população caracterizada por populações estelares ricas em metais, era imprescindível ser verificado se os espectros sintéticos reproduziam bem espectros estelares de populações ricas em metais da nossa galáxia, como de fato são as estrelas estudadas aqui.

Dessa forma, as comparações realizadas aqui entre os espectros estelares de baixa resolução e os espectros sintéticos foram um importante teste para averiguar a qualidade dos espectros estelares sintéticos e garantir que a reprodução de populações estelares ricas em metais como galáxias elípticas terá grandes chances de sucesso.

\section{Sintese de populaçôes estelares usando a grade de espectros sintéticos: M32}

As falhas que existem no nosso conhecimento sobre as galáxias elípticas se devem principalmente ao fato de que não há galáxias elípticas gigantes próximas o suficiente para permitir o estudo de suas populações detalhadamente. Por outro lado, informações diretas podem ser obtidas através do estudo de elípticas anãs e compactas pertencentes ao Grupo Local, como por exemplo a galáxia satélite de Andrômeda, M32.

Entre as satélites de Andrômeda, M32 tem o maior brilho superficial e é a mais rica em metais, possuindo também características muito semelhantes às elípticas gigantes. Devido ao seu alto brilho superficial comparado às outras satélites de Andrômeda, da similaridade de suas estruturas com elípticas gigantes e por causa de sua proximidade, grande interesse tem sido depositado em M32 como a galáxia elíptica padrão para os estudos de populações estelares.

No entanto, M32 é uma galáxia com características pouco usuais. Comparada a galáxias anãs que possuem brilho absoluto semelhantes, seu brilho superficial central é quatro ordens de grandeza maior e seu raio nuclear é três ordens de grandeza menor (Kormendy 1985).

Até o momento, pouquíssimas galáxias com propriedades similares a M32 foram encontradas (Sandage \& Binggeli 1984; Nieto \& Prugniel 1987; Davidge 1991; Kormendy \& 
Bender 1994), mas nenhuma delas tem propriedades tão extremas quanto M32. Ziegler \& Bender (1998) estudaram galáxias no grupo de Leo que eram consideradas possíveis semelhantes a M32 e concluiram que M32 ainda é um objeto único com pouquíssimas outras galáxias apresentando propriedades semelhantes, mas nenhuma dessas sendo tão fraca quanto M32.

Os estudos de populações estelares em M32 têm se baseado em espectros integrados e em diagramas cor-magnitude (CMDs) mas têm apresentado resultados controversos, em particular com relação à questão sobre se houve atividade de formação estelar até 4-6 Ganos atrás ou se a formação estelar terminou muito antes.

A maioria dos estudos espectroscópicos realizados mostram a necessidade de inclusão de uma população estelar de idade intermediária (O'Connell 1980, Boulade, Rose \& Vigroux 1988, Bica, Alloin \& Schmidt 1990, Magris \& Bruzual 1993, Bressan et al. 1994, Hardy et al. 1994, Worthey 1994 e Rose 1994, 1999). Já Barbuy et al. (1994) concluíram que a população intermediária não é necessária para reproduzir o espectro de M32 na região 4500-5500 .

Alguns diagramas cor-magnitude de M32 detectaram estrelas do Asymptotic Giant Branch (AGB) mais brilhantes do que o topo do Red Giant Branch (RGB) (Grillmair et al. 1996) o que seria uma evidência fotométrica de uma população jovem. Interpretações posteriores mostraram, no entanto, que essas detecções podem ser devido a efeitos de crowding (Renzini 1998) ou a variáveis de longo período e blue-straglers (Guarnieri, Renzini \& Ortolani 1997), como encontrado em aglomerados globulares ricos em metais como 47 Tuc e NGC6553.

Mais recentemente Brown et al. (1998) resolveram estrelas no UV próximo de M32 e mostraram evidências de que a luz UV de M32 poderia ser produzida por estrelas velhas em trajetórias evolutivas razoavelmente raras como Extreme Horizontal Branch (EHB) e descendentes Post Early Asymptotic Giant Branch - PEAGB e AGB-manqué. Mostraram também 
que o diagrama cor-magnitude obtido é inconsistente com uma contribuição majoritária de PAGBs mais massivas que $0.56 \mathrm{M}_{\text {, }}$, estrelas da sequência principal ou blue-stragglers. De fato em Brown et al. (2000) observações de imageamento feitas com o Space Telescope Imaging Spectrograph (STIS) detectaram diretamente estrelas do EHB de $\mathrm{T}>8500 \mathrm{~K}$ confirmando o trabalho anterior, embora a ausência de informações de cor tenha impedido a determinação da morfologia e da distribuição de massa dessas estrelas. Os autores mostram também que a função de luminosidade observada pode ser reproduzida com uma população minoritária de EHB (cerca de 5\% de toda a população do HB).

Esses dados portanto diminuem a necessidade de se introduzir uma população mais jovem em M32, embora a intensidade do H $\beta$ (mais forte em M32 do que em outras elípticas ricas em metais e mais fraca do que em aglomerados globulares pobres em metais) ainda não possa ser totalmente explicado por essas estrelas velhas quentes.

Estudos de síntese espectral usando isócronas como o trabalho de Worthey (1994) assumem que o HB possui uma morfologia contendo apenas um clump no vermelho ("pure red clump HB morphology"). Mas os dados apresentados por Brown et al. $(1998,2000)$ mostram que, dependendo do quanto o $\mathrm{HB}$ se estende para o azul, uma análise que assume essa morfologia pode estar seriamente incorreta. Dentre toda essa controvérsia, é claro que se não pudermos entender a M32, dificilmente seremos capazes de entender as populações estelares de galáxias mais distantes.

Com o objetivo de estudar essa questão a fundo, o trabalho de doutorado que se segue a esta dissertação procurará reproduzir o espectro integrado de M32, levando em conta as recentes descobertas sobre a morfologia de seu $\mathrm{HB}$ e usando os espectros disponíveis no arquivo do STScI.

Será criada, inicialmente, uma grade de espectros estelares, sintetizados da mesma forma 
como realizado neste trabalho para o estudo das estrelas do NGC 6528 e NGC 6553. Uma importante componente do trabalho de tese a ser desenvolvido é a composição das diferentes partes das grades de espectros, com a devida correção de contínuo.

Posteriormente, será montada uma grade de populações simples, com a qual partiremos para síntese de populações compostas. $\mathrm{Na}$ síntese de populações composta utilizaremos as frações de populações estelares disponíveis na literatura (particularmente o de Bica et al. 1990) bem como as frações de populações resultantes de modelos de evolução galáctica como os modelos de Friaça e Terlevich (1998) e de Bruzual \& Charlot (1993, revisto)

A partir das populações estelares resultantes dos modelos contruíremos espectros sintéticos integrados. Com a comparação do espectro resultante com as observações, e em um processo iterativo, pretende-se obter condições de contorno aos modelos e traçar a história evolutiva de M32. 


\section{Apêndice I: Calibrações dos índices de TiO em função de parâmetros atmosféricos}

Nos espectros estelares, as bandas de TiO se tornaram a base do sistemas de classificação espectral para as estrelas de tipo espectral tardio. Vísiveis também em espectros compostos de população estelar velha, essas bandas foram medidas nesses sistemas por Bica \& Alloin (1986), Burstein et al. (1984), Brodie \& Huchra (1990) e Gorgas et al. (1993) entre outros autores.

De fato a compreensão de como essas bandas variam em função dos parâmetros atmosféricos pode ser útil tanto no estudo estelar quanto no estudo de sistemas compostos em geral. Estudos do comportamento dessas bandas em função dos parâmetros atmosféricos foram feitos com espectros sintéticos nos trabalhos de Milone \& Barbuy (1994), Milone et al. (2000) e Schiavon \& Barbuy $(1999,2000)$.

Dentro do contexto desses trabalhos anteriores, neste trabalho foram feitas novas medidas dos índices de $\mathrm{TiO}$ e pela primeira vez essas calibrações foram usadas, na prática, para determinar a temperatura de estrelas frias $\left(T_{e f} \leq 3750 \mathrm{~K}\right)$, o que de fato resultou em temperaturas melhor determinadas do que pelas calibrações $T_{e f} x$ cor.

Como o objetivo neste trabalho era usar os índices de TiO para determinar temperaturas efetivas, foram obtidos ajustes $T_{e f}=W(T i O)$, conforme descrito no item 4.2.2. Mas de posse dos valores de outros parâmetros atmosféricos, é possível também ajustar funções do tipo $W(T i \mathrm{O})=f\left(T_{e f} \log g,[\mathrm{Fe} / \mathrm{H}]\right)$ que permitem uma aplicação mais geral dos índices de TiO, à 
semelhança dos ajustes feitos pelo grupo de LICK para os índices de metalicidade e que foram utilizados neste trabalho em 4.4.

Com o objetivo de iniciar o ajuste dessas funções para os índices de TiO apresentamos os resultados iniciais obtidos, ainda para um intervalo restrito de parâmetros atmosféricos, mas que deve ser expandido para permitir seu uso em aplicações mais amplas.

Os coeficientes dos ajustes obtidos podem ser vistos na tabela 18. Todos os ajustes estão na forma exponencial, ou seja, $W(\mathrm{TiO} 4)=e^{\left(57-0.15 \log g+1.04[\mathrm{Fe} / \mathrm{H}]-6.6 \ln T_{e f}\right)}($ para $\Delta \lambda \sim 8 \AA)$. Os intervalos de validade dessas funções são $3000 \mathrm{~K} \leq T_{\text {ef }} \leq 4500 \mathrm{~K}, 0 \leq \log g \leq 3$ e $-0.6 \leq[\mathrm{Fe} / \mathrm{H}] \leq$ 0. Para efeito de ilustração, na figura 30 é apresentada uma comparação entre os índices de TiO4 medidos nos espectros sintéticos e os reproduzidos pelo ajuste.

Tabela 18: Coeficientes das funções dos ajustes $W(T i O)=f\left(T_{e f}, \log g,[F e / H]\right)$.

\begin{tabular}{ccccccc}
\hline & \multicolumn{2}{c}{ TiO2 } & \multicolumn{2}{c}{ TiO3 } & \multicolumn{2}{c}{ TiO4 } \\
\hline Termo & $\Delta \lambda \sim 4 \AA$ & $\Delta \lambda \sim 8 \AA$ & $\Delta \lambda \sim 4 \AA$ & $\Delta \lambda \sim 8 \AA$ & $\Delta \lambda \sim 4 \AA$ & $\Delta \lambda \sim 8 \AA$ \\
\hline Constante & 75 & 75 & 81 & 46 & -40 & 57 \\
$\mathrm{~T}_{\mathrm{ef}}$ & 0.0012 & 0.0012 & - & 0.0012 & -0.0037 & - \\
$\log \mathrm{g}$ & -0.15 & -0.10 & -0.11 & -0.11 & -0.13 & -0.15 \\
{$[\mathrm{Fe} / \mathrm{H}]$} & 1.16 & 1.03 & 1.20 & 1.20 & 1.20 & 1.04 \\
$\ln \left(\mathrm{T}_{\mathrm{ef}}\right)$ & -9.3 & -9.4 & -9.7 & -0.7 & 6.9 & -6.6 \\
$\log$ g $\cdot[$ Fe/H] & -0.19 & - & - & - & - & - \\
\hline$\chi^{2}$ do ajuste & 0.90 & 0.90 & 0.90 & 0.90 & 0.95 & 0.94 \\
\hline
\end{tabular}

O ajuste desses índices para intervalores maiores de parâmetros atmosféricos e o ajuste de outros índices de TiO é parte das perspectivas deste trabalho de mestrado. 


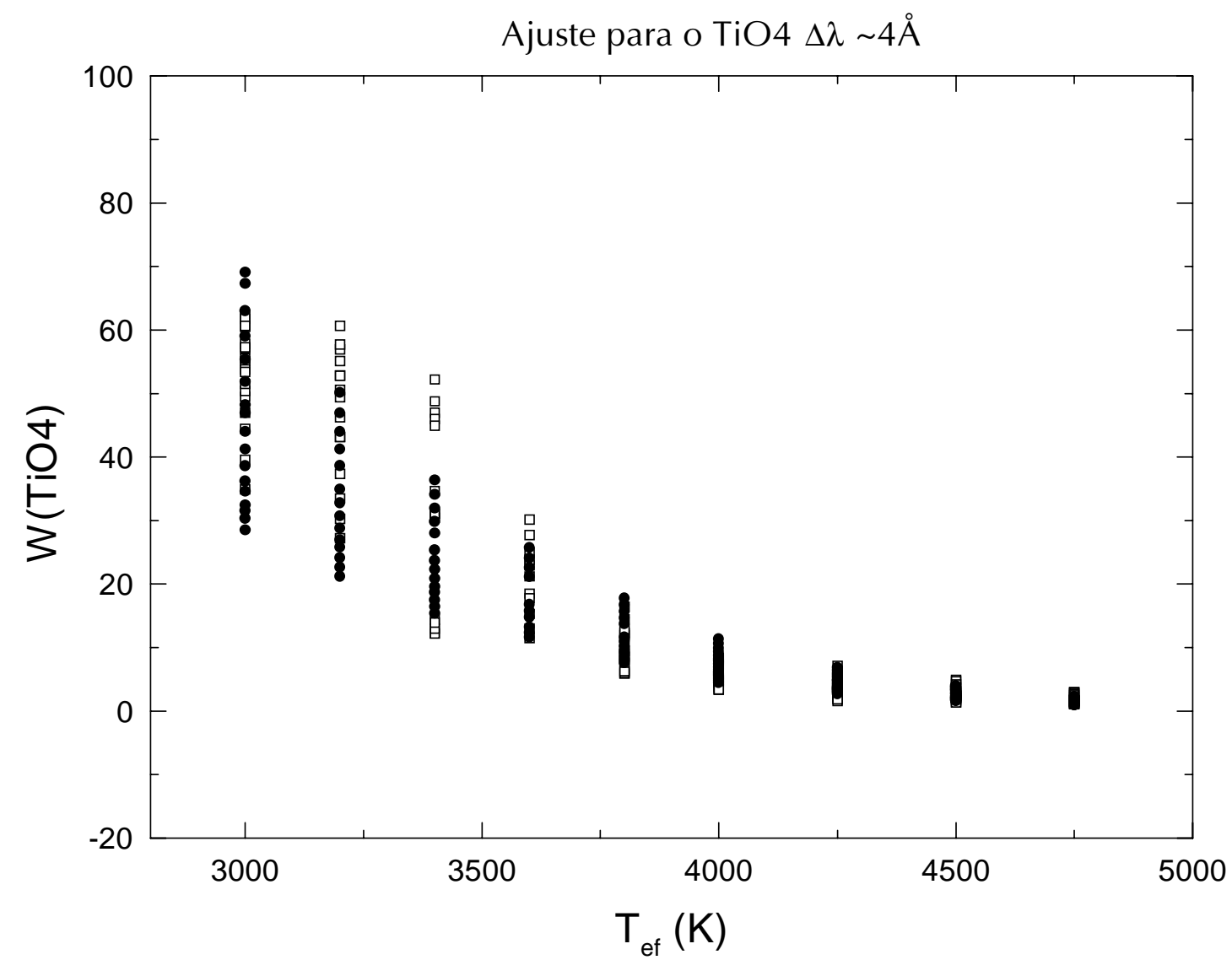

Figura 30: Índices de TiO4 medidos $(\Delta \lambda \sim 4 \AA)$ em função da temperatura. Os quadrados brancos indicam os índices medidos nos espectros sintéticos e os círculos pretos indicam o ajuste obtido. 


\section{Bibliografia}

Aaronson, M., Cohen, J.G., Mould, J., Malkan, M. 1978, ApJ, 223, 824

Allard, F., Hauschildt, P.H.: 1995, ApJ, 445, 433

Alvarez, R., Plez, B. 1998, A\&A 330, 1109

Armandroff, T.E. 1989, AJ 97, 375

Armandroff, T.E., Zinn, R. 1988, AJ 96, 92

Ashman, K., Zepf, S. 1998, em Globular Cluster Systems, Cambridge Astrophysics Series vol. 30, Cambridge University Press, Cambridge

Ashman, K., Bird, C., Zepf, S. 1994, AJ 108, 2348

Baade, W. 1944, ApJ 100, 167

Baade, W. 1951, Publ. Obs. Univ. Michigan 10, 7

Barbuy, B. 1982, Tese de Doutoramento, Université de Paris VII

Barbuy, B. 1994, ApJ 430, 218

Barbuy, B. 2000, em The Chemical Evolution of the Milky Way: Stars vs. Clusters, ed. F.Matteucci, Kluw1er Acad. Pub.

Barbuy B., Bica E., Ortolani S., 1998, A\&A 333, 117

Barbuy, B., Erdelyi-Mendes, M., Milone, A. 1992, A\&AS 93, 235

Barbuy, B., Freitas Pacheco, J.A., Idiart, T.: 1996, em New Light on Galaxy Evolution, IAU Symp. 171, Kluwer Acad. Pub., p. 340 
Barbuy, B., Perrin, M.-N., Cayrel, R., Katz, D., Van't Veer, C. 2000, A\&A, em preparação

Barbuy B., Renzini A., Ortolani S., Bica E., Guarnieri M.D., 1999, A\&A 341, 539

Baum, W.,A., Hiltner, W.A., Johnson, H.L., Sandage, A. 1959, ApJ 130, 749

Bessell, M., Castelli, F., Plez, B., 1998, A\&A 333, 231

Bica, E., Alloin, D. 1986, A\&A 162, 21

Bica, E., Alloin, D., Schmidt, A.A. 1990, A\&A 228, 23

Bica, E., Pastoriza, M. 1983, Astrophysics and Space Science 91, 99

Binney, J., Merrifield, M. 1998, em Galactic Astronomy, Princeton University Press, New Jersey.

Blaauw, A. 1965 em Galactic Structure (Stars and Stellar Systems, vol.5), ed. A. Blaauw, M. Schmidt, p. 435, Chicago: Univ. Chicago Press

Boulade, O., Rose, J., Vigroux, L. 1988, AJ 96, 1319

Bressan, A., Chiosi, C., Fagotto, F.: 1994, ApJS, 94, 63

Brown T., Ferguson H., Stanford S., Deharveng, J.-M., 1998, ApJ 504, 113

Brown, T., Bowers, C., Kimble, R., , Sweigart, A., Ferguson, H. 2000, ApJ 532, 308

Bruzual, G., Charlot, S. 1993, ApJ 405, 538

Bruzual, G. 1983, ApJ 273, 105

Bruzual, A. G., Barbuy, B., Ortolani, S., Bica, E., Cuisinier, F., Lejeune, T., Schiavon, R. P. 1997, AJ 114, 1531

Burstein, D., Faber, S.M., Gaskell, C.M., Krumm, N., 1984, ApJ 287, 586

Buzzoni, A., Gariboldi, G., Mantegazza, L. 1992, AJ 103, 1814

Buzzoni, A. 1988 em Towards Understanding Galaxies at Large Red-shifts, eds. R. G. Kron, A. Renzini, Dordrecht, Reidel, p. 61 
Cayrel R., Perrin M.-N., Barbuy B., Buser R., 1991, A\&A 247, 108

Caretta, E., Gratton, R.G. 1997, A\&AS 121, 95

Castilho, B. 1999, Tese de Doutoramento, Universidade de São Paulo

Cohen, J.G. 1978, ApJ 221, 788

Cohen, J. 1983, ApJ 270, 654

Cohen, J., Gratton, R. G., Behr, B., Carretta, E. 1999, ApJ 523, 739

Curcio, J.A., Drummeter, L.F., Knestrick, G.L. 1964, Applied Optics 3, 1401

Davidge, T.J. 1991, AJ 102, 896

Eggen, O.J., Lynden-Bell, D., Sandage, A. 1962, ApJ 136, 748

Faber, S.M., Friel, E.D., Burstein, D., Gaskell, C.M. 1985, ApJS 57, 711

Freedman, W. 1991, IAU Symp. 149

Friaça A.C.S., Terlevich R., 1998, MNRAS, 298, 399

Frogel, J. A. 1988, Ann. Rev. Astron. Astrophys. 26, 51

Frogel, J. A., Whitford, A. E. 1987, ApJ, 320, 199

Fuhr, J.R., Martin, G.A., Wiese, W.L., 1988, Atomic Transation Probabilities: Scandium through Manganese, Journal os Physical and Chemical Reference Data, vol. 17, suplemento no. 4

Gorgas, J., Faber, S.M., Burstein, D., Gonzalez, J.J., Courteau, S., Prosser, C.F 1993, ApJS 86, 153

Gray, D. 1992, The Observation and Analysis of Stellar Photospheres, Ca,bridge Astrophysics Series 20, Cambridge University Press

Greggio, L. 1996, em Interplay between Massive Star Formation, the ISM and Galaxy Evolution, ed. D. Kunth et al., Gyf sur Yvette: Edition frontieres, p. 89 
Grillmair C.J. et al. 1996, AJ 112, 1975

Guarnieri M.D., Ortolani S., Montegriffo P., Renzini A., Barbuy B., Bica E., Moneti A., 1998, A\&A, 33170

Guarnieri M.D., Renzini A., Ortolani S. 1997, ApJ 477, L21

Gulati, R.K., malagnini, M.L., Morossi, C. 1991, A\&A 247, 447

Gustafsson, B., Bell, R. A., Erikson, K., Nordlund, A. 1975, A\&A 42, 407

Hamuy M., Walker A.R., Suntzeff N.B., Gigoux P., Heathcote S.R., Phillips M.M., 1992, Publ. Astron. Soc. Pacific 104, 533

Hamuy M., Walker A.R., Suntzeff N.B., Gigoux P., Heathcote S.R., Phillips M.M., 1994, Publ. Astron. Soc. Pacific 106, 566

Hardy E., Couture J., Couture C., Joncas G. 1994, ApJ 107, 195

Harris, W. 1996, AJ 112, 1487

Hartwick, F. , 1975, P.A.S.P 87, 77

Idiart, T. 1995, Tese de Doutoramento, Universidade de São Paulo

Idiart, T. P., Pacheco, J. A. de F. 1995, AJ 109, 2218

Jacoby G.H., Hunter D.A., Christian C.A., 1994, ApJS 56, 25

Johnson, H.R., Mould, J.R., Bernat, A.P. 1982, AoJ, 258, 161

Keenam, P.C. 1966, ApJS 13, 333

Keenan, P.C., Keller, G., 1953, ApJ 117, 241

Kinman, T.D. 1959a, MNRAS 119, 499

Kinman, T.D. 1959b, MNRAS 119, 559

Kormendy, J., Bender, R. 1994, em Dwarf Galaxies, eds. G.Melyan, P. Prugniel, ESO Conf. 
Proc. No. 49, 161

Kurucz, R.L.: 1992, em The Stellar Populations of Galaxies, eds. B. Barbuy \& A. Renzini, Kluwer Acad. Pub., p. 225

Larson, R.B., 1975, Mon. Not. R. Astr. Soc. 173, 671

Larson, R.D. 1990, PASP 102, 709

Lee, Y.-W. 1992, AJ 104, 1780

Lockwood, G. W. 1972, ApJ 180, 845

Magris, G., Bruzual G. 1993, ApJ 417, 102

Martin, G.A., Fuhr, J.R., Wiese, W.L., 1988, Atomic Transation Probabilities: Scandium through Manganese, Journal os Physical and Chemical Reference Data, vol. 17, suplemento no. 3

Matteucci, F., Brocatto 1990, ApJ 365, 539

Matteucci, F., Romano, D., Molaro, P. 1999, A\&A 341, 458

Mayal, N.U., 1946, ApJ 104, 290

McLachlan, G. J., Basford, K. 1988, Statistics: Textbooks and Monographs, Dekker, New York

McWilliam, A. \& Rich, R.M. 1994, ApJS 91, 749

Milone, A., Barbuy, B. 1994, A\&AS 108, 449

Milone, A., Barbuy, B., Schiavon, R. P. 2000, AJ no prelo

Minniti, D. 1995, A\&AS 113, 299

Minniti, D., Olszewski, E.W., Liebert, J., White, S.D.M., Hill, J.M., Irwin, M.J. 1995, Mon. Not. R. Astron. Soc. 277, 1293

Morgan, W.W. 1953, Publ. Astron. Soc. Pac. 68, 509

Morgan, W.W. 1959, AJ 64, 432 
Mould, J.R. 1978, ApJ 220, 580

Mould. J.R, McElroy, D. 1978, ApJ 220, 580

Nieto, J.-L., Prugniel, P. 1987, A\&A 186, 30

O'Connell, R.W. 1980, ApJ 236, 430

Origlia, L., Ferraro, F.R., Fusi Pecci, F., Oliva, E. 1997, A\&A 321, 859

Ortolani, S., Barbuy, B., Bica, E. 1990 , A\&A 236, 362

Ortolani, S., Bica, E., Barbuy, B. 1992, A\&AS 92, 441

Ortolani, S., Renzini, A., Gilmozzi, R., Marconi, G., Barbuy, B., Bica, E., Rich, M. 1995, Nature 377, 701

Peletier, R. 1989, Tese de Doutorado, Rijksuniv. Groningen

Pfenniger, P., Friedli, D. 1991, A\&A 252, 75

Pilachowski, C. A. 1984, ApJ 281, 614

Plez, B., Brett, J.M., Nordlund, A. 1992, A\&A, 256, 551

Plez, B. 1997, comunicação privada

Raha, N., Sellwood, J.A., James, R. A., Kahn, F. D. 1991, Nature 352, 411

Renzini, A. (1999) astro-ph/9902108

Renzini, A. 1986, em Stellar Populations, eds. C. A. Norman, A. Renzini, M.Tosi, Cambridge, p.213

Renzini, A. 1993, em Galactic Bulges, eds. H. Dejonghe \& H.J.Habing, IAU Symp. 143, Kluwer, Dordrecht, 1993

Renzini, A. \& Greggio, L. 1990, em Bulges of Galaxies, eds. J.B.Jarvis \& D.M. Terndrup, Conf. \& Workshop Ser. 35, ESO, Garching 
Renzini, A., Pecci, F.F. 1988, Ann. Rev. Astron. Astrophys. 26, 199

Renzini, A. 1998, AJ 115, 2459

Rich, R.M.1988, AJ 95, 828

Rich, R.M. 1998, em The Central Regions of the Galaxy and Galaxies, ed. Y. Sofue IAU, p.11

Rich, R.M., McWilliam, A. 2000, astro-ph/0005113

Rich, R., Ortolani, S., Bica, E., Barbuy, B. 1998, AJ 116, 1295

Rose, J.A. 1994, AJ 107, 206

Rose, J.A., Shibing, D. 1999, AJ 117, 2213

Rutledge 1997, PASP 109, 883

Sandage, A. 1986, Ann. Rev. Astron. Astrophys. 24, 42

Sandage, A., Binggeli, B. 1984, AJ 89, 919

Schiavon, R.P. 1998, Tese de doutoramento, IAG-USP

Schiavon, R., Barbuy, B. 1999, ApJ 510, 934

Schiavon, R., Barbuy, B. 2000, em preparação

Schiavon, R., Barbuy, B., Bruzual, A., 2000, ApJ 532, 453

Searle, L., Zinn, R. 1978, ApJ 225, 357

Sharpless, 1956, ApJ 124, 342

Spinrad, H., Taylor, B.J. 1969, ApJ 157, 1279

Spinrad, H., Taylor, B.J. 1971, ApJS 22, 445

Spite, M. 1967, Ann. Astrophys 30, 211

Tantalo, R., Chiosi, C., Bressan, A. 1998, A\&A 333, 823 
Terndrup, D.M. 1988, AJ 96, 884

Tripicco, M.J., Bell, R.A. 1990, AJ 99, 691

van den Bergh, S. 1993, ApJ 411, 178

van den Bergh, S. \& Younger, F., 1979, AJ 84, 1305

Webbink, R.F. 1985, em Dynamics of Star Clusters; IAU Symposium, Princeton, Dordrecht

Whitford, 1978, ApJ 226, 777

Wiese, W.L.,Martin, G.A., Fuhr, J.R. 1969, Atomic Transation Probabilities: Sodium through Calcium, NSRDS-NBS 22

Worthey, G., Faber, S.M., González, J., Burstein, D., 1994, ApJS 94, 687

Ziegler, B.L., Bender, R. 1998, A\&A 330, 819

Zinn, R. 1980, ApJS 42, 19

Zinn, R. 1985, ApJ 293, 424

Zinn, R. 1993, em Globular Cluster-Galaxy Connection, ASP Conference Series 48, eds. G. H. Smith, J. P. Brodie, San Francisco, p. 38

Zinn, R., West 1984, ApJS 55, 45 